\title{
Feasibility and optimum design study of a low speed wind turbine rotor system for underground communication power
}

John E. Harman

West Virginia University

Follow this and additional works at: https://researchrepository.wvu.edu/etd

\section{Recommended Citation}

Harman, John E., "Feasibility and optimum design study of a low speed wind turbine rotor system for underground communication power" (2008). Graduate Theses, Dissertations, and Problem Reports. 4377. https://researchrepository.wvu.edu/etd/4377

This Thesis is protected by copyright and/or related rights. It has been brought to you by the The Research Repository @ WVU with permission from the rights-holder(s). You are free to use this Thesis in any way that is permitted by the copyright and related rights legislation that applies to your use. For other uses you must obtain permission from the rights-holder(s) directly, unless additional rights are indicated by a Creative Commons license in the record and/ or on the work itself. This Thesis has been accepted for inclusion in WVU Graduate Theses, Dissertations, and Problem Reports collection by an authorized administrator of The Research Repository @ WVU. For more information, please contact researchrepository@mail.wvu.edu. 


\title{
FEASIBILITY AND OPTIMUM DESIGN STUDY OF A LOW SPEED WIND TURBINE ROTOR SYSTEM FOR UNDERGROUND COMMUNICATION POWER
}

\author{
by \\ John E. Harman \\ Thesis submitted to \\ the College of Engineering and Mineral Resources \\ at West Virginia University \\ in partial fulfillment of the requirements \\ for the degree of \\ Master of Science \\ in \\ Aerospace Engineering
}

Approved by

James Smith, Ph.D, Committee Chairperson

Kenneth Means, Ph.D.

Roy Nutter, Jr., Ph.D.

Department of Mechanical and Aerospace Engineering

Morgantown, West Virginia

2008

Keywords: Low, speed, wind, turbine,diffuser,shroud 


\section{A B S T R A C T}

\section{FEASIBILITY AND OPTIMUM DESIGN STUDY OF A LOW SPEED WIND TURBINE ROTOR SYSTEM FOR USE IN UNDERGROUND COMMUNICATION POWER}

\section{by John Harman}

A need has been recognized to have battery charging capabilities in underground mines, independent of outside AC power sources. In the event of emergency, the radios located throughout underground mines stay charged for periods insufficient to ensure the safety of trapped mineworkers. Air is always being distributed to supply oxygen and to dilute explosive gases throughout all sections of the mine. An idea to charge the batteries using the energy stored in the moving air was recently proposed. The feasibility of using a small wind turbine to charge the batteries in this airlflow will be addressed by this thesis. If the proposal is feasible, a numerical model will be constructed to design an optimal rotor system for the device.

The use of a small wind turbine to aid in emergency mine communication was found to be feasible and a numerical model utilizing Blade Element Momentum theory has been developed to produce optimal solutions to the battery charging problem. Several rotor configurations have been found to produce the amount of power required to charge the batteries (4 Watts). Due to the structural concerns in an underground mine, a wind turbine should be shielded for the protection of workers. A diffuser shroud can provide this structure and also increase the power output of the system for a given size rotor. A simple diffuser shroud is evaluated and included in the model. Results from the model include the physical parameters needed to efficiently design a wind turbine system for use in this application. 


\section{A C K NOW LE D G M E N T S}

I would to thank, first and foremost, my research advisor, Dr. James Smith, for overseeing this project and for his encouragement and enthusiasm toward my academic career. I would like to thank also, the members of the examining committee for devoting their precious time, abilities and advice toward my research. I would also like to thank Henry Graham and Gerald Angle for providing assistance and guidance throughout my research.

Lastly, I would like to thank my family for supporting all my efforts no matter the consequence. They are always a source of strength and confidence in any endeavor I have ever encountered. 


\section{TABLE OF CONTENTS}

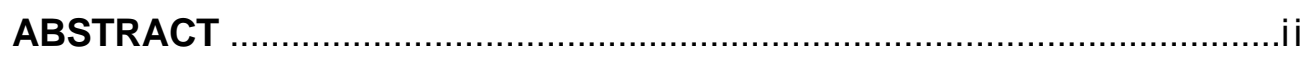

LIST OF FIGURES …...................................................................

LIST OF TABLES .......................................................................... vii

LIST OF SYMBOLS / NOMENCLATURE ............................................... viii

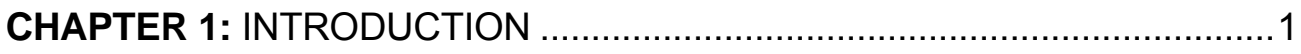

CHAPTER 2: LITERATURE REVIEW ............................................... 4

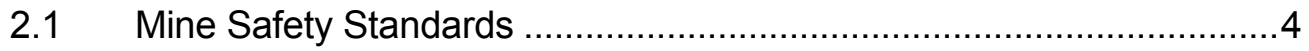

2.2 Small Scale Wind Power Research.................................................... 7

2.2.1 Waterpumping Windmills .................................................................................

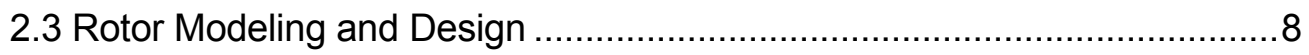

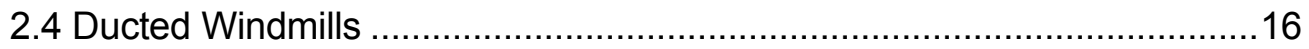

CHAPTER 3: OPTIMUM DESIGN PROCEDURE .....................................23

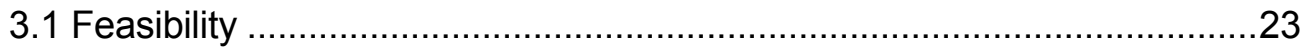

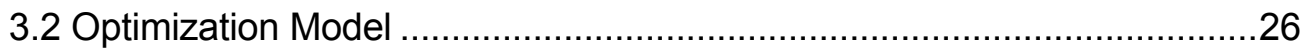

3.3 Addition of the Diffuser Shroud to the Optimization Model ......................32

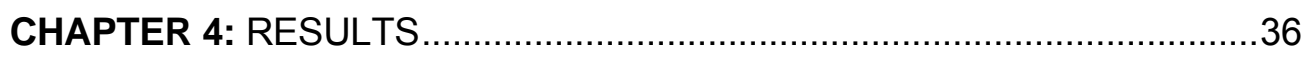

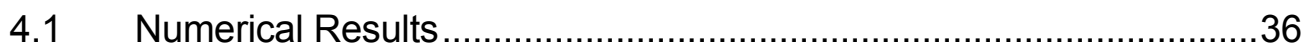

4.2 Comparison of Results to Other Experiments/Theory ......................53

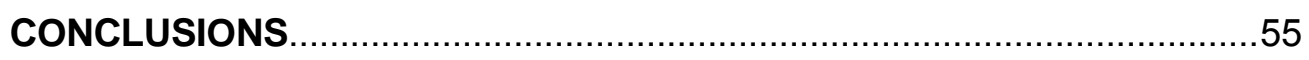

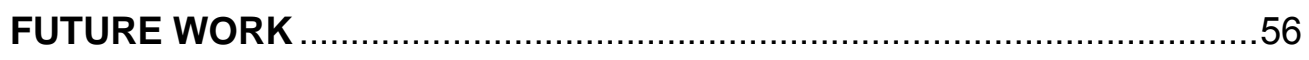

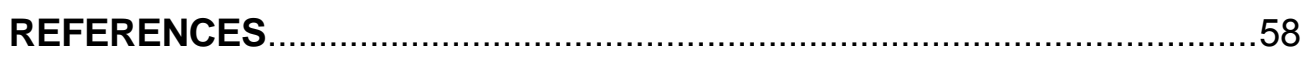

APPENDIX A:CURVED PLATE CHARACTERISTICS .............................60

APPENDIX B:ADDITIONAL FIGURES AND DATA ..............................61

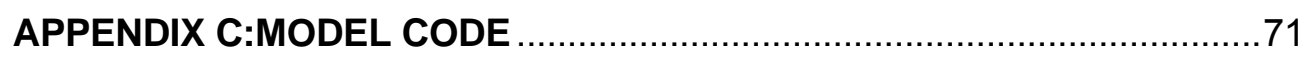




\section{LIST OF FIGURES}

Figure 1 High solidity, multi-blade rotor [6].

Figure 2 Analytical methods comparison with CWD 2470 experiment for Power Coefficient and Tip Speed Ratio[7]

Figure 3 BEM analysis Maximum Cp versus tip speed ratio for various blade numbers/solidities for SG6043 airfoil [7].

Figure 4 Maximum $\mathrm{Cp}$ vs Solidity for non-twisted constant chord blades (shows optimum pitch angle as well) [7]

Figure 5 Tip speed ratio at maximum power coefficient versus solidity (pitch angles from $0-20$ degrees) [7] 13

Figure 6 Power coefficient versus tip speed ratio for a 12 bladed rotor with a solidity of 0.25 [7] .... 14

Figure 7 Power coefficient versus Tip Speed ratio calculated for three pitch angle settings compared

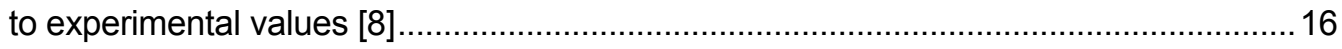

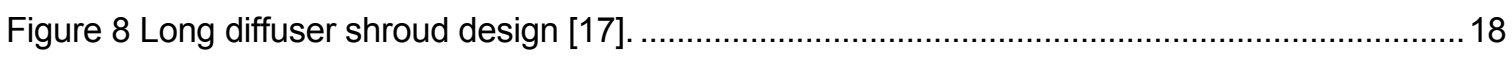

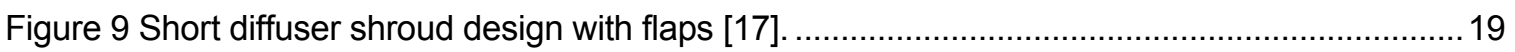

Figure 10 Shorter annular wing diffuser cross-section [17] ....................................................... 19

Figure 11 Typical Duct setup and nomenclature. [19]

Figure 12 Power curves for varying rotor diameters and performance coefficients..........................24

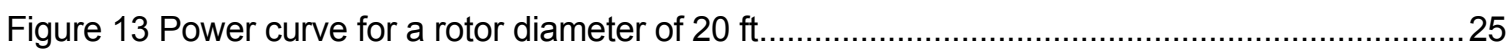

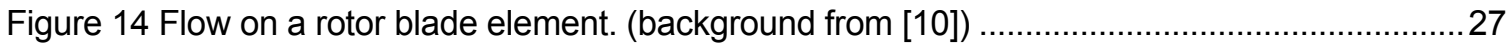

Figure 15 Velocity and pressure relations at each stage of the diffuser[20]. ..................................33

Figure 16 Effect of blade \# and chord length on $\mathrm{C}_{\mathrm{p}}$ at an inflow angle of 22 degrees. ......................37

Figure 17 Effect of blade \# and chord length on $C_{p}$ at an inflow angle of 26 degrees. ..................... 37

Figure 18 Effect of blade \# and chord length on $\mathrm{C}_{\mathrm{p}}$ at an inflow angle of 29 degrees. ...................... 38

Figure 19 Effect of blade \# and chord length on $C_{p}$ at an inflow angle of 33 degrees. ......................38

Figure 20 Effect of blade \# and chord length on $C_{p}$ at an inflow angle of 37 degrees. ...................... 39

Figure 21 Surface plot showing effects of blade \# and chord length on power coefficient at 25

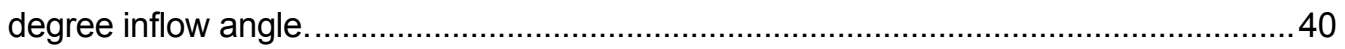

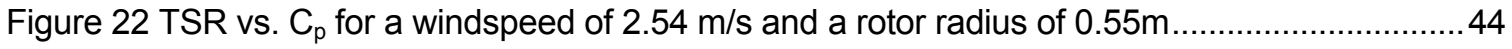

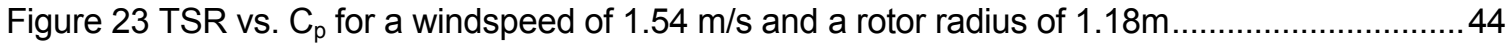

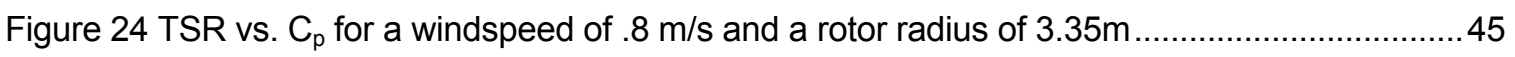

Figure 25 Optimum twist angle over the blade......................................................................... 47

Figure 26 Varying DNA for a windspeed of $1.54 \mathrm{~m} / \mathrm{s}$ and a diffuser exit ratio of $0.57 \mathrm{~m}$.................51

Figure 27 Curvature of blade used in calculations[8] ................................................................. 60

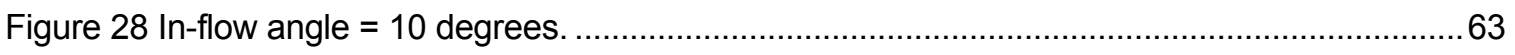

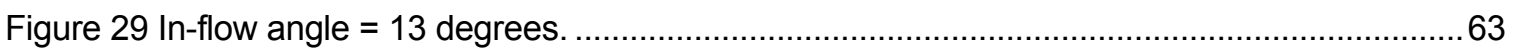

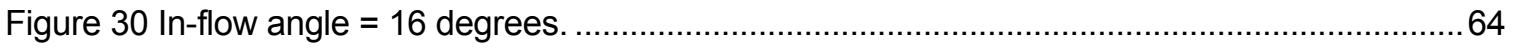




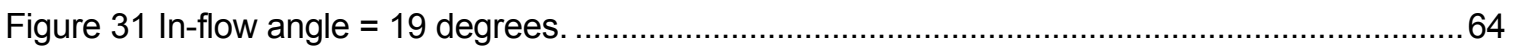

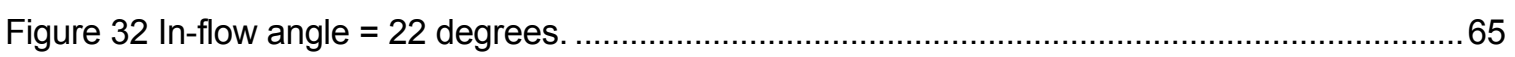

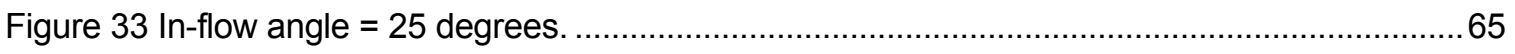

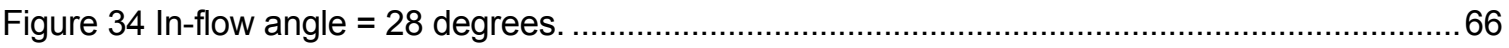

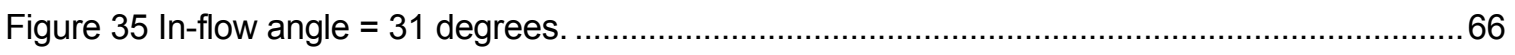

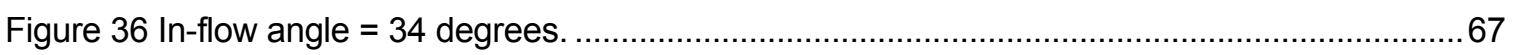

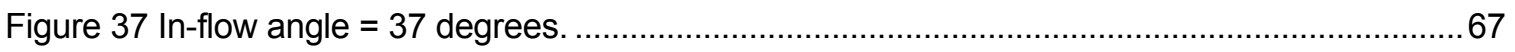

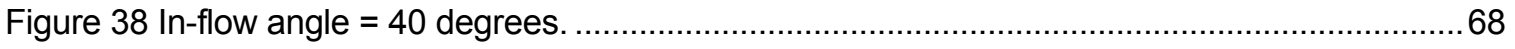

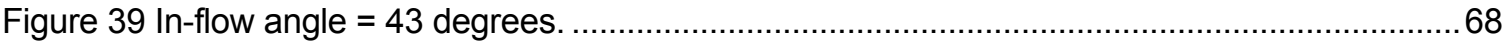

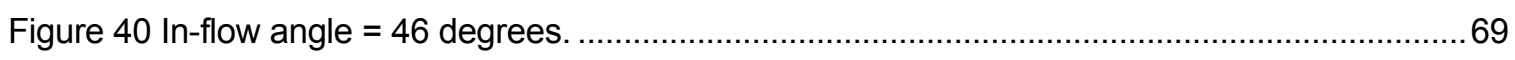

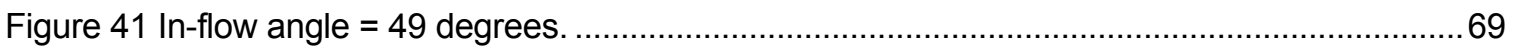

Figure 42 Photo of rotor blades within a diffuser shroud, manufactured by the French company,

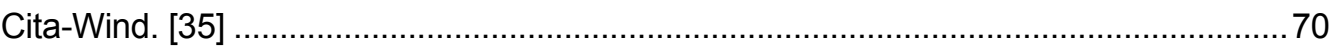




\section{LIST OF TABLES}

Table 1 Physical characteristics of the rotors tested in Rijs and Smulders.

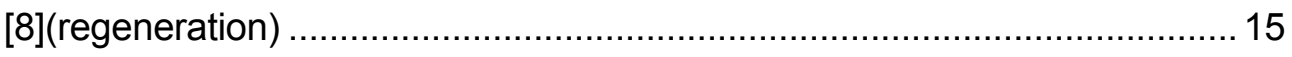

Table 2 Optimum Design Parameter for rotor radius of $0.5 \mathrm{~m}$ at a wind velocity of 2.54

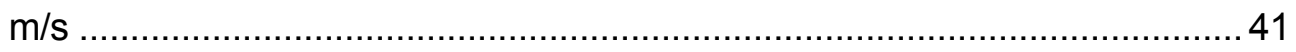

Table 3 Fixed pitch optimum setups showing how small the rotor can be at each end of the windspeed range. ............................................................................. 42

Table 4 Ideal twist optimums for a windspeed of $2.54 \mathrm{~m} / \mathrm{s}$ and a rotor radius of $0.535 \mathrm{~m} . .46$

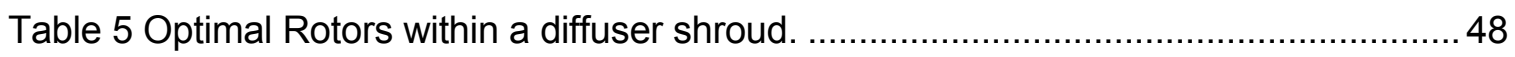

Table 6 Optimal Rotors within a diffuser shroud (constant DNA mid-range velocity)......... 49

Table 7 Optimal Rotors within a diffuser shroud (Fairly large DNA) ................................50

Table 8 Optimal Rotors within a diffuser shroud (low end of velocity range).....................52

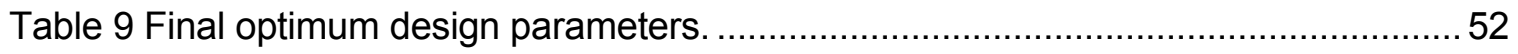

Table 10 Comparison of unshrouded BEM (theoretical and experimental) results from

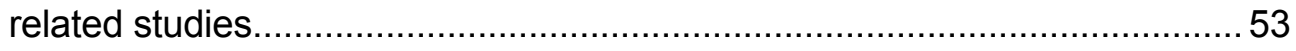

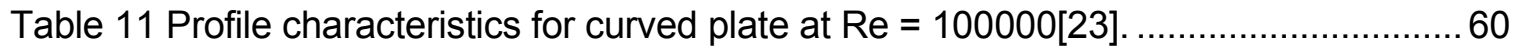

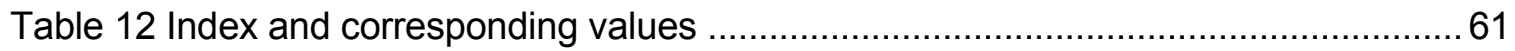




\section{LIST OF SYMBOLS / NOMENCLATURE}

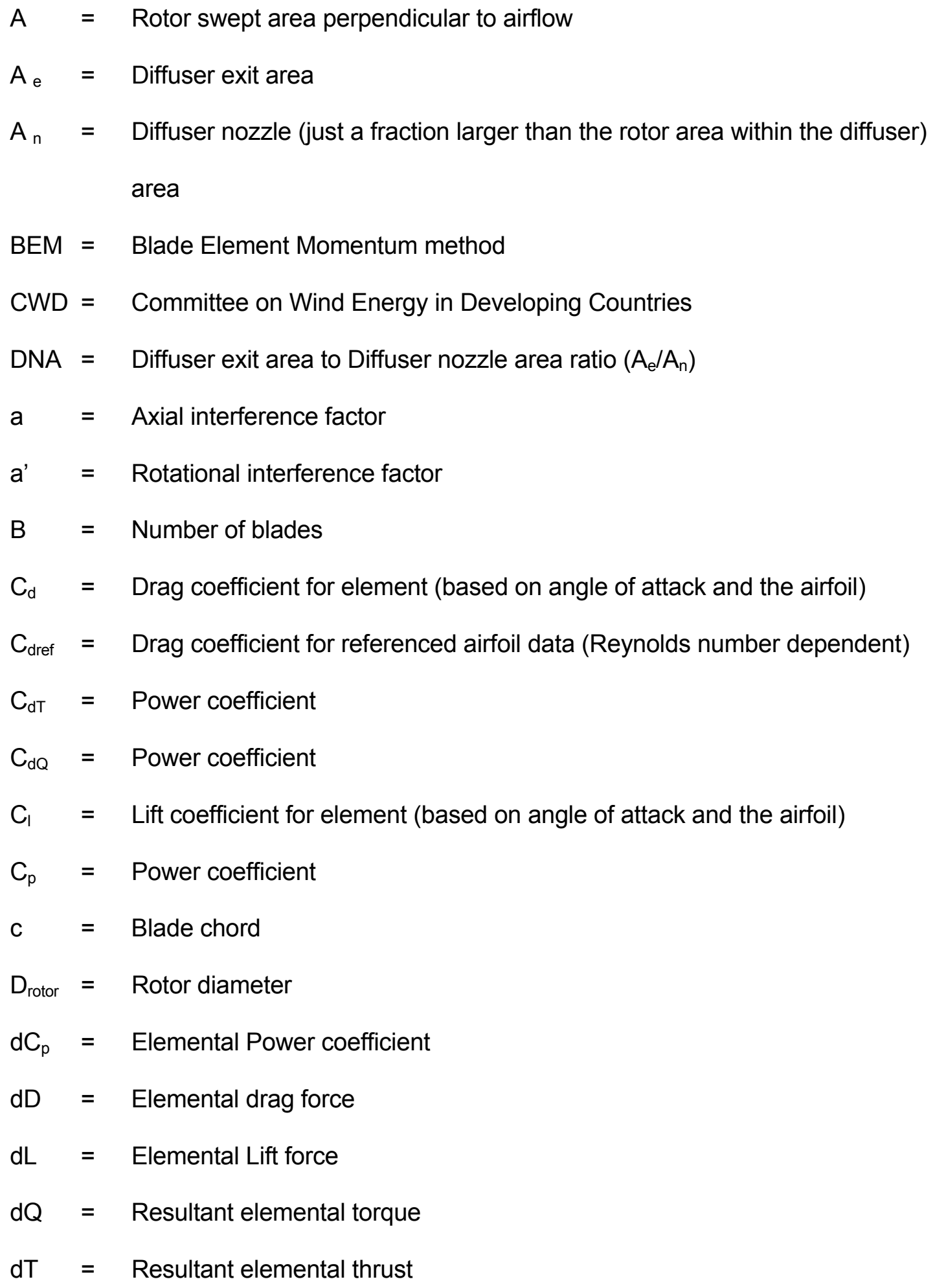




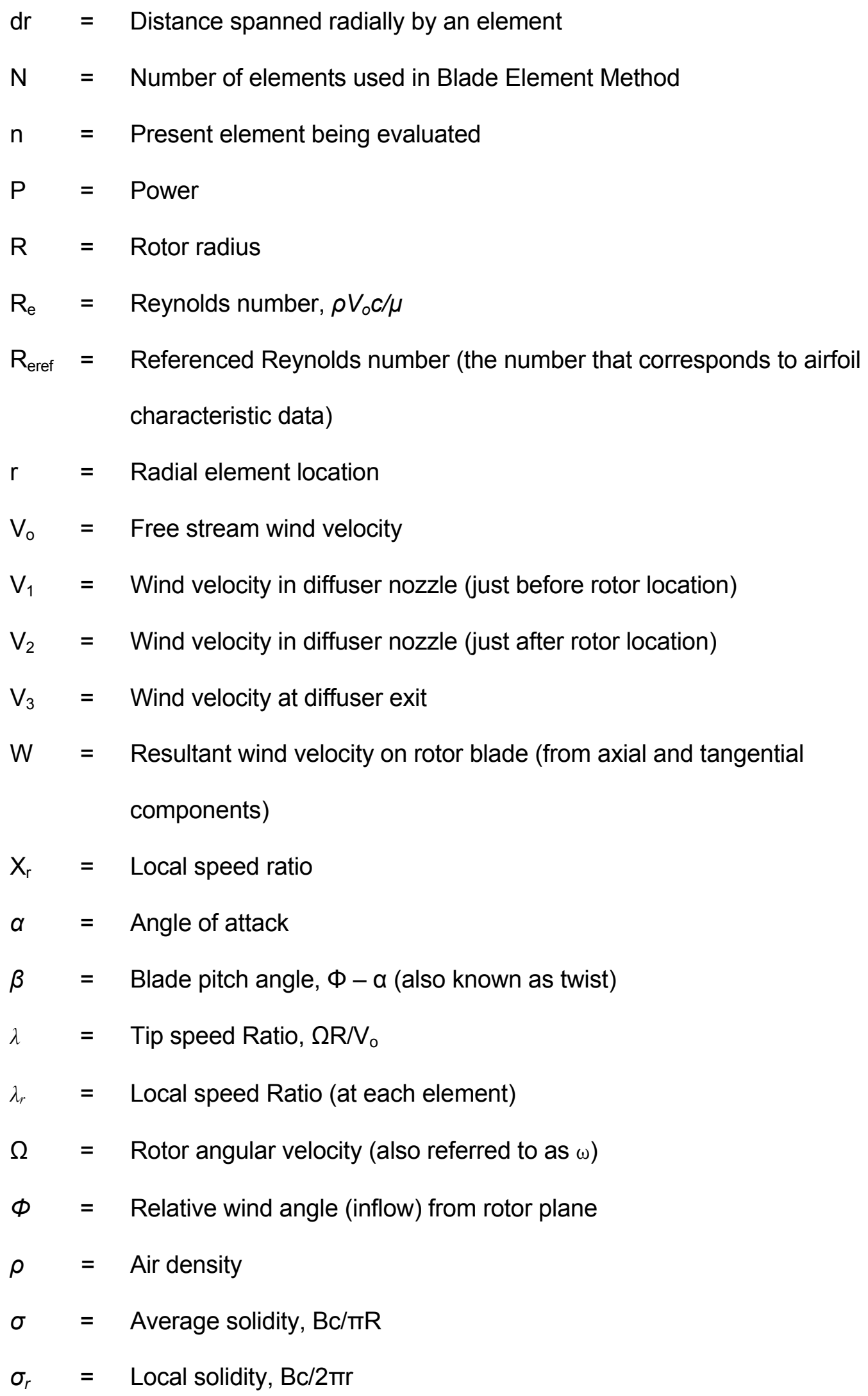




\section{CHAPTER 1: INTRODUCTION}

Underground mine safety has become an increasingly important issue in the past few decades. After the most recent mine disasters, a need was recognized for an increased capacity to charge the emergency radio batteries that are scattered throughout underground mines. In an emergency situation, explosion or otherwise, the high voltage power that runs throughout a mine is cut off to avoid added explosion and fire hazards for any workers that may still be present. For example, in this type of situation, it is often not known how the ventilation system may have been affected during the emergency. This means that methane could build up in some parts of the mine and this combined with high voltage power is a very dangerous combination.

Therefore, the Mine Safety and Health Administration (MSHA) requires that in certain situations the power be cut off from the mine. Due to this, any communication from within the mine must be powered by some other means. There are battery powered radios placed in certain locations throughout every underground mine. These batteries last for short periods of time (12-14 hours) after the main power has been cut off in the case of an emergency. In some of these situations, miners could be trapped for much longer than 12 hours before a rescue crew can enter the area. Underground mining safety equipment and procedures are designed to sustain human life for much longer than this short span. However, if communication is lost after this amount of time, rescue crews may be searching blind for trapped miners. It is for this reason, that an upgrade in the battery charging capabilities in underground mines is desired. This thesis will address the battery problem by proposing a wind turbine system to be powered by the ventilation airflow produced in every underground mine. 
All underground mines have ventilation systems. The mines must sustain enough oxygen for miners to breath. They must also evacuate harmful and explosive gases that could build up in the mine. The first objective is to confirm that this proposal is feasible and that the amount of power needed to charge the batteries can be obtained from the airflow within the mine by this type of system. The second objective is to design a rotor, for the turbine system, that will meet the power requirements as efficiently as possible. The objectives will be approached by initially designing a computer model that will output an optimal rotor design based on several input conditions specified by the user.

Several factors need to be considered when designing a wind turbine rotor. The design process can become very complicated. Aerodynamic performance, power ratings, weight, blade deflections, clearances, material, loading, mounting, starting and overspeed control are just some of the design parameters that must be considered [1]. Due to some of the design requirements of this project, many of these design concerns will have little importance. Weight and material are not a big concern due to the size constraints of the problem. Since the windspeed in the mine will never exceed $10 \mathrm{mph}$, overspeed, loading and blade deflections are also not a large concern. Based on these simplifications, this study's main concern will be the aerodynamic performance, clearance and power output of the turbine rotor.

Clearance and power are straightforward issues. Clearance will depend on the size of the ventilation air escape-ways. Power required is dependent upon the amount of continuous power required to charge the radio batteries. Power output itself is dependent on the aerodynamic performance of the wind turbine rotor.

Aerodynamic performance is a more complicated parameter. It can involve complex blade analysis, lift and drag, pitch, twist, number of blades, blade shape, interference factors, wake rotation and tip speed ratios among many other parameters. 
Tip speed ratio is defined as the speed of the blade tip of the turbine rotor to the wind speed. Again due to the lower speeds, some of the more complex aerodynamics become less influential to this study.

The focus of the rotor design will encompass the number of blades, blade shape and pitch, rotor size, interference factors and tip speed ratios. These factors all influence the power and torque output of the rotor shaft. Due to the rugged environment that the wind turbines will be placed in, some sort of housing will have to be considered to protect the miners from the rotor. This will have an affect on the aerodynamics of the rotor. A shroud that maximizes the airflow through the rotor should be used in order to maximize its power output. This is another consideration that will affect the analysis of the final rotor design. 


\section{CHAPTER 2: LITERATURE REVIEW}

This chapter provides background information and previous research performed on topics related to this project. Any previous research performed in fields pertaining to this project will also be presented in this chapter. To understand the scope of this research, there must first be an understanding of the current technology and the standards that exist in both mine safety and in the realm of wind power.

\subsection{Mine Safety Standards}

Underground mines can be very dangerous work places. Many factors make underground mining one of the most dangerous jobs in the world, today. Confined quarters, lack of natural light, cave-in possibilities and explosion/fire hazards all contribute to the danger in underground mining. Heavy machinery driven in the dark is hazardous enough. Add to that high voltage power lines, deafening noise levels and the possibility of flammable gas build up, and the environment becomes potentially deadly. In recent years death tolls have been reduced by impressive numbers. From 1940 to 1968 explosions and fires accounted for the deaths of 491 miners. In 1969 the Federal Coal Mine Health and Safety Act was passed by the Mine Health and Safety Administration (MSHA). Since the passage of the safety act, only 178 explosion and fire related deaths have occurred. MSHA sees this as a significant, successful reduction of deaths, but realizes that this number is still unacceptable. A large part of this reduction in death toll is due to the implementation of effective ventilation standards.[2]

The ventilation standards set guidelines on how much methane content is allowed in underground mines, establish air flow quantities that must reach the working faces of mines along with many other related issues. These guidelines provide clean air to workers 
as well as minimize the explosion hazard that may exist from flammable gas build up. These guidelines, however, cannot prevent accidents from happening and emergency situations still occur in underground mines.

In the event of an emergency, several safety precautions are taken in an attempt to save the lives of any workers who may be in the affected area. One of these precautions is the cutoff of high voltage power. If a cave-in, fire, explosion or other hazard is encountered the power that runs through the mine is shut off.

During an incident, there is usually limited information as to what has happened and no way to know what has been affected in other parts of the mine. If this is indeed the case and any of the high voltage cables have been damaged then a recipe for further damage is present. Thus, the high voltage power to the mine is normally shut down. This protects the miners, but it also hinders communications with the outside world. The power that gets shut off is also the source of the power for the telephones stationed throughout the mine. There are battery operated radios stationed throughout the mine as well. These radios now serve as the only link between trapped miners and rescuers. These batteries will last from $12-14$ hours once the main power has been cut off from the mine. This is best case scenario however, and in the event of an emergency when everyone is trying to contact the outside world, the batteries will last for even shorter time periods.

This creates a major problem. Most disasters can cause problems that last for much longer times then $12-14$ hours. Sometimes rescue teams can't enter the mine within this amount of time if the status of the mine and the air inside isn't known. If situations (collapse, explosion, etc.) in the mine change, after this communication window is closed, then the rescue team would have no way of knowing where trapped miners are located and if they are even alive. This puts the rescuers in even more danger than they would normally encounter. 
MSHA has developed requirements on the ventilation quantities in each different type of mine. The following excerpts are from the MSHA Federal regulations document and state the standards for ventilation quantities in underground mines.

“(a)(1) In bituminous and lignite mines the quantity of air shall be at least 3,000 cubic feet per minute reaching each working face where coal is being cut, mined, drilled for blasting, or loaded. When a greater quantity is necessary to dilute, render harmless, and carry away flammable, explosive, noxious, and harmful gases, dusts, smoke, and fumes, this quantity shall be specified in the approved ventilation plan. A minimum air quantity may be required to be specified in the approved ventilation plan for other working places or working faces.

(b) In bituminous and lignite mines, the quantity of air reaching the last open crosscut of each set of entries or rooms on each working section and the quantity of air reaching the intake end of a pillar line shall be at least 9,000 cubic feet per minute unless a greater quantity is required to be specified in the approved ventilation plan. This minimum also applies to sections which are not operating but are capable of producing coal by simply energizing the equipment on the section.

(c) In longwall and shortwall mining systems--

(1) The quantity of air shall be at least 30,000 cubic feet per minute reaching the working face of each longwall, unless the operator demonstrates that a lesser air quantity will maintain continual compliance with applicable methane and respirable dust standards. This lesser quantity shall be specified in the approved ventilation plan. A quantity greater than 30,000 cubic feet per minute may be required to be specified in the approved ventilation plan.

[3]"

These requirements are given in volumetric flow rates, so the actual wind speed will depend on the size of the mine entry. The requirements provide an indication of how much airflow is available in underground mines. However, they are still somewhat vague regarding velocities, and since there is such a wide range of flow rates specified (3000 $30000 \mathrm{cfm}$ ) with no exact entry size standard, a smaller range will have to be decided upon once the design process begins. 


\subsection{Small Scale Wind Power Research}

Modern wind turbines have become very technologically advanced. They are very large, usually have 2 or 3 blades and are designed for wind speeds much higher than the scope of this project. For this reason, a lot of the research data taken in the modern wind energy field isn't useful to the small scale, low speed application that is being proposed. However, some of the basic aerodynamic design considerations used to develop this technology are useful and will be considered for this study.

Some previous research has been done on small scale, low speed wind power. Most of the applications for this type of research deal with generating power to charge batteries or with pumping water for agricultural purposes. Both of these types of applications take advantage of wind speeds that are still faster than the airspeeds found in most mines. Both also deal with rotor sizes that are larger scales then would be found in most mine entryways. Nevertheless, the research done on these applications is helpful for this project.

\subsubsection{Waterpumping Windmills}

Windmills were used to pump water from wells for numerous water applications. The wind energy converters provided water for livestock, crops and even to supply the needs of steam locomotives in the 1800's. In general, these types of windmills use the same type of rotor design. The rotors have multiple blades and are driven by aerodynamic drag. The blades are simple flat surfaces and usually have uniform pitch angles [4]. The rotors have high solidity ratios. Solidity ratio is the percentage of the total rotor area (disc) that is occupied by the rotor blades. Due to the high solidity, the rotors have large starting torque, low tip speed ratios and they encounter low Reynolds numbers (less than $1 \times 10^{5}$ ) $[5,30]$. This will be discussed further in the rotor design section of this paper. 
Figure 1 shows an 18 blade wind pump rotor with tailfin. The tailfin is used to furl the windmill out of high wind speeds so it doesn't fly apart. Most of the American pumping windmill rotors designed for low wind speed look similar to this one.

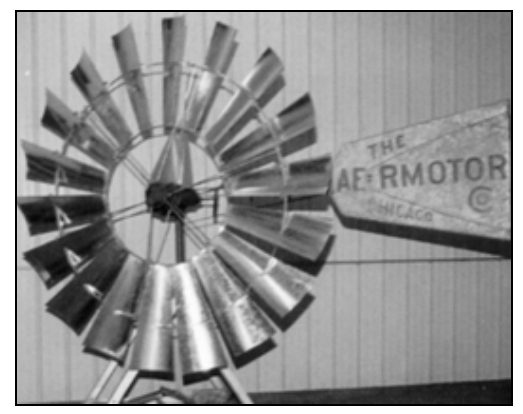

Figure 1 High solidity, multi-blade rotor [6].

These types of rotors vary in size from about 6 feet in diameter to around 20 feet in diameter. The most widely used material for the wind pumping rotor was steel. This type of windmill operates at tip speed ratios (TSR) from 0 to 2 , which is much lower than the large modern wind turbines which operate at tip speed ratios of 4 to 8 [7].

\subsection{Rotor Modeling and Design}

There are several ways to analytically model wind turbine rotor behavior and characteristics. The most proven and popular include (from simplest to more complex): actuator disc theory, Glauert annulus momentum vortex theory (blade element theory), prescribed-wake vortex theory (which can be applied in several ways) and free wake vortex theory. Actuator disc theory is a one dimensional model that relates the turbine to a disc through which the static pressure decreases. The process involves several simplifying solutions including that there is no rotation of flow caused by the disc. Glauert strip theory involves analyzing each radial section of the rotor blade independently with 2D airfoil data and equations based on continuity and momentum conservation. Glauert's theory has been modified over the years to improve accuracy and applicability. Prescribed wake momentum theory analyzes vortices behind each section of the rotor blade. 2-D 
airfoil data is used in this theory as well and the simplest approach assumes a rigid helical wake behind the rotor. Free-wake vortex theory attempts to iteratively model the true path of the trailing vortices. It is the most complicated of the methods. Blade Element Momentum theory (BEM) is a combination of strip theory and Momentum theory. It has become a very accurate analytical tool in the rotor design field. It is beyond the scope of this paper to describe in detail the procedure involved in each of these modeling methods. A detailed discussion with modeling equations for each theory can be found in Eggleston [1] and Glauert [21,31].

Several studies have been done that utilize an analytical method to theoretically model the behavior of wind turbine rotors. The studies use some of the theories mentioned above to analyze and optimize wind turbine rotors and compare their results to valid experimental results.

A study on the implications of solidity and blade number on rotor performance of horizontal axis wind turbines was done at Clarkson University by M. Duquette and K. Visser [7]. The study varies blade numbers $(3,6$, and 12$)$, blade pitch angles and solidity ratios using several modeling methods to optimize a rotor design for a lower speed $(8 \mathrm{~m} / \mathrm{s})$ and smaller scale wind turbine ( 1 meter radius). The study compares several theoretical methods against data from corresponding experiments. The comparisons include Blade Element-Momentum Method (BEM) with Prandtl tip/hub loss, Blade Element Method with finite wing correction, Expanding Wake Method and a Rigid Wake Method. The airfoil used for all blade sections in this study was an SG6043. Figure 2 shows the relationship between Power Coefficient and Tip Speed Ratio for each of the numerical methods, in their study, as well as the experimental results. The experimental data in this case comes from a CWD 2540 rotor study found in Rijs and Smulders [8]. The characteristics of this rotor can be found in Table 1 in the discussion of the Rijs and Smulders study[8]. 


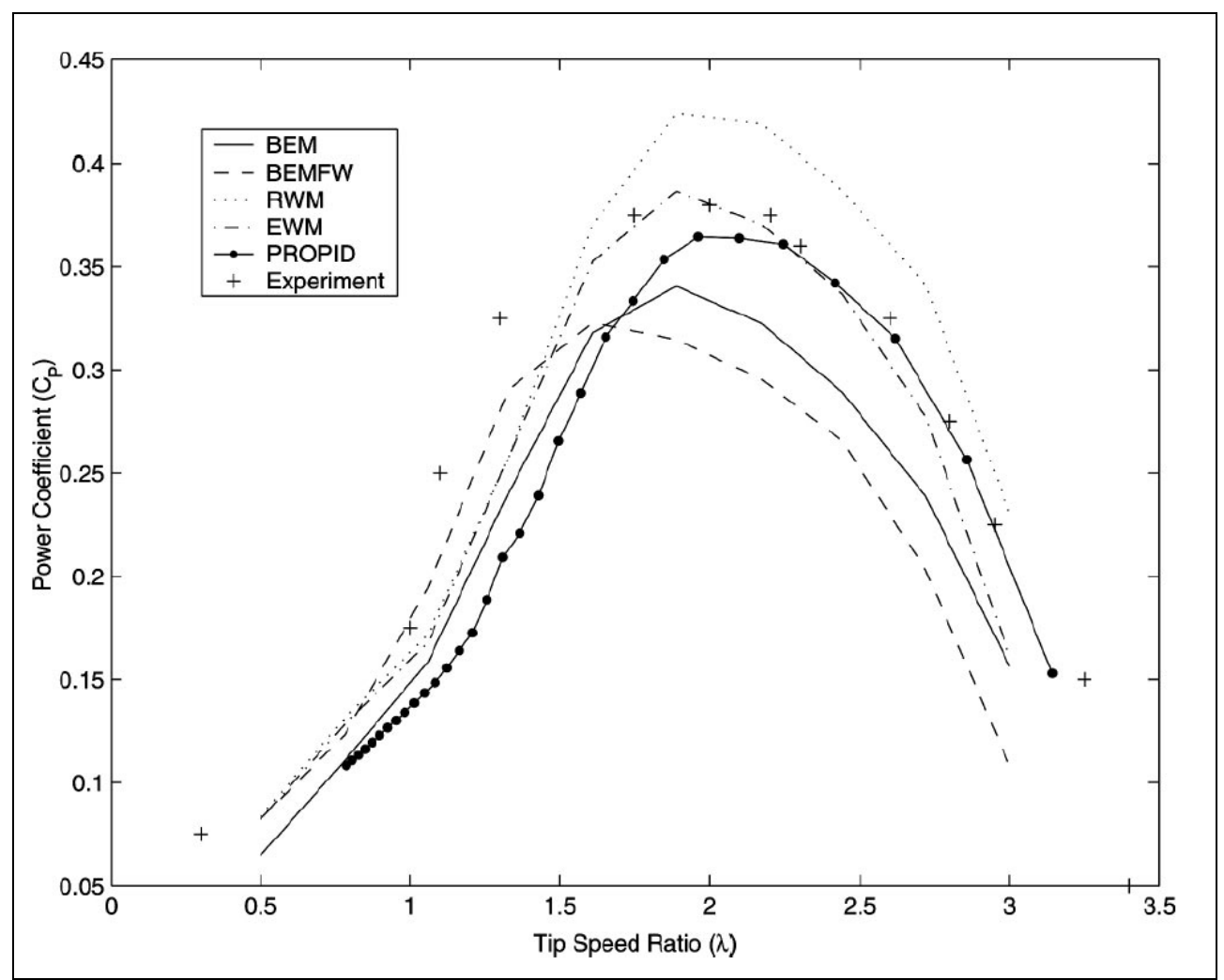

Figure 2 Analytical methods comparison with CWD 2470 experiment for Power Coefficient and Tip Speed Ratio[7]

The graph from [7] above shows that the Expanding Wake Method most closely matches the experimental data. It and the other methods, with the exception of the Rigid Wake Method, slightly under calculated the power coefficient.

Figure 3 shows the same $C_{p}$ versus $X$ relationship for varying blade numbers and solidities based on Blade Element Method. The same SG6043 airfoil was analyzed. The plot shows the optimum solidity for the corresponding tip speed ratio. Interestingly, the 12 bladed rotor demonstrated the highest power coefficient. The plot shows an optimum solidity at 0.14 for the 12 bladed rotor at a tip speed ratio of about 3.6. 


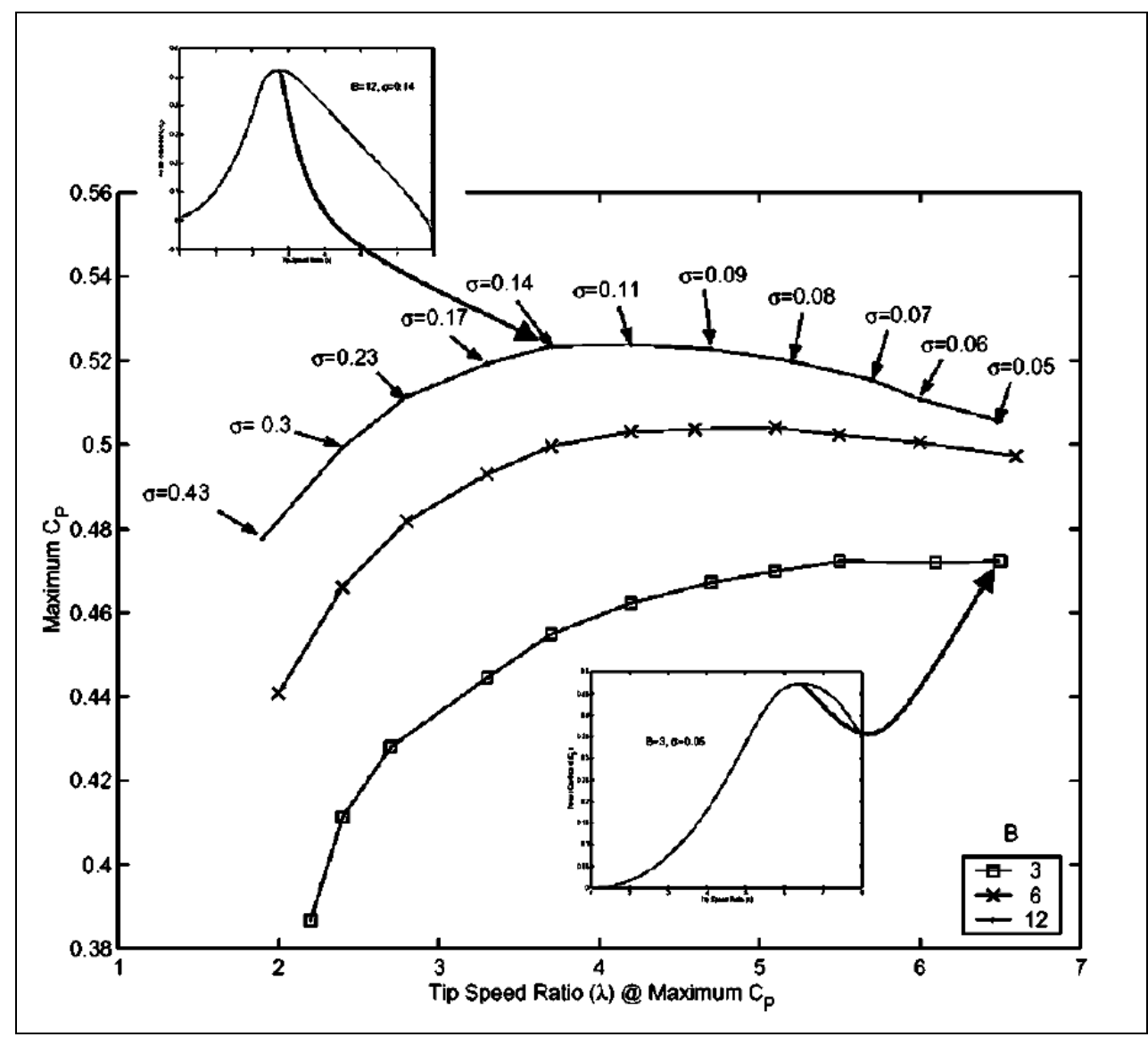

Figure 3 BEM analysis Maximum Cp versus tip speed ratio for various blade numbers/solidities for SG6043 airfoil [7].

Figure 4 displays data pertaining to untwisted, constant chord bladed rotors. The plot provides insight about the power coefficient for varying solidities, pitch and blade numbers. 


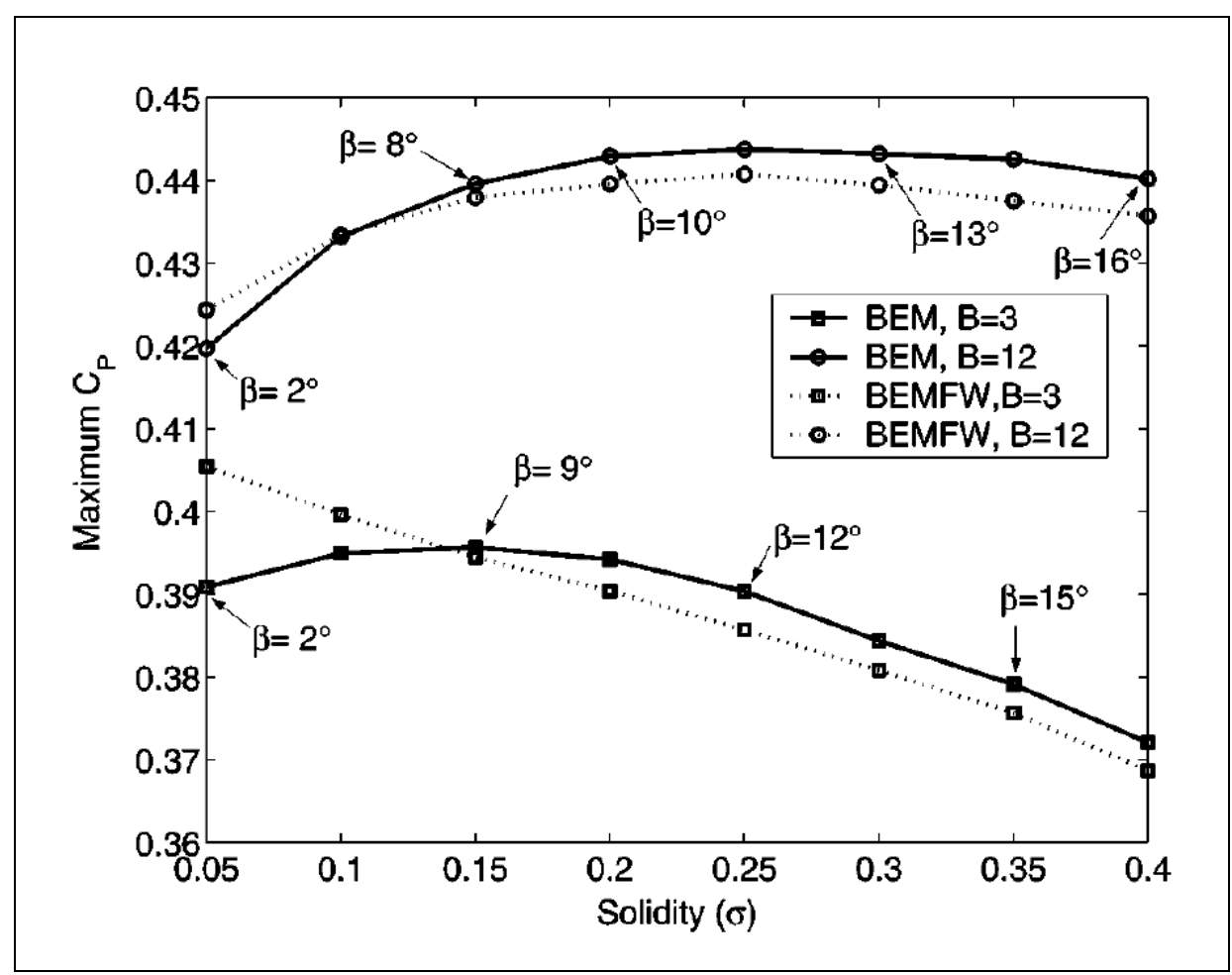

Figure 4 Maximum Cp vs Solidity for non-twisted constant chord blades (shows optimum pitch angle as well) [7]

Both BEM models showed similar results in Figure 4 for the 12 bladed rotor. The optimal rotor setup with constant chord, non-twisted blade seemed to have pitch angle values between 10 and 13 degrees and solidity values between 0.2 and 0.3 .

Figure 5 compares solidity to tip speed ratios at maximum power coefficient for the same setups as in Figure 4. For the optimal solidity range $(0.2-0.3)$ it can be seen that the tip speed ratio will be somewhere between 2.5 and 3.5. The pitch angle values for the data in this graph were varied from 0 to 20 degrees (more detailed descriptions of pitch angle and other aerodynamic terms can be found in Section 3.2). 


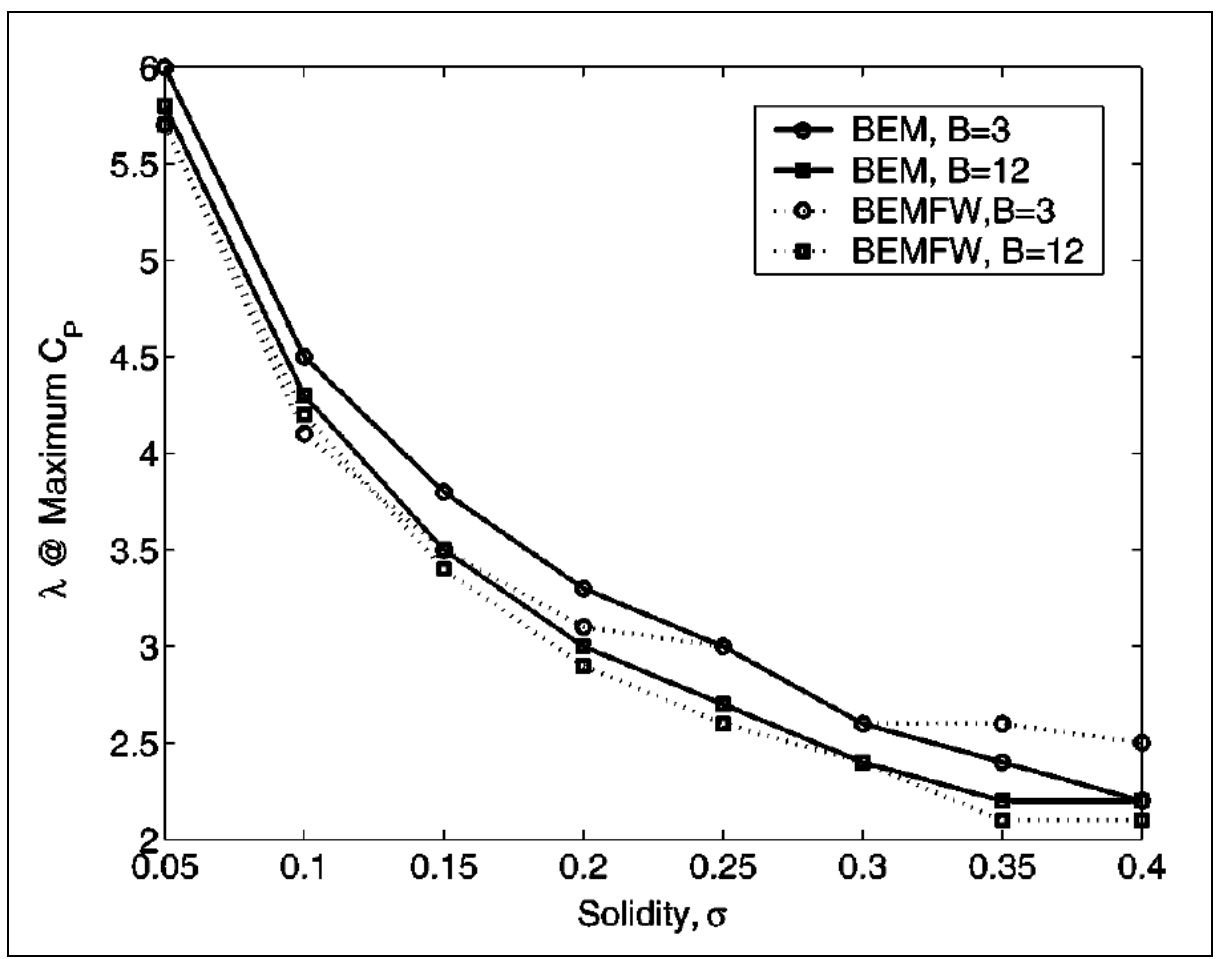

Figure 5 Tip speed ratio at maximum power coefficient versus solidity (pitch angles from $0-20$ degrees) [7]

Figures 4 and 5 used data from only BEM analysis. Duquette and Visser then compared both a rigid and a free wake method to these BEM results. They compared several different solidities but included below is a plot of the results for a solidity ratio of 0.25 which is in the optimal range found previously. Figure 6 displays the comparison and agrees with BEM results that put the optimum tip speed ratio between 2.5 and 3.5. 


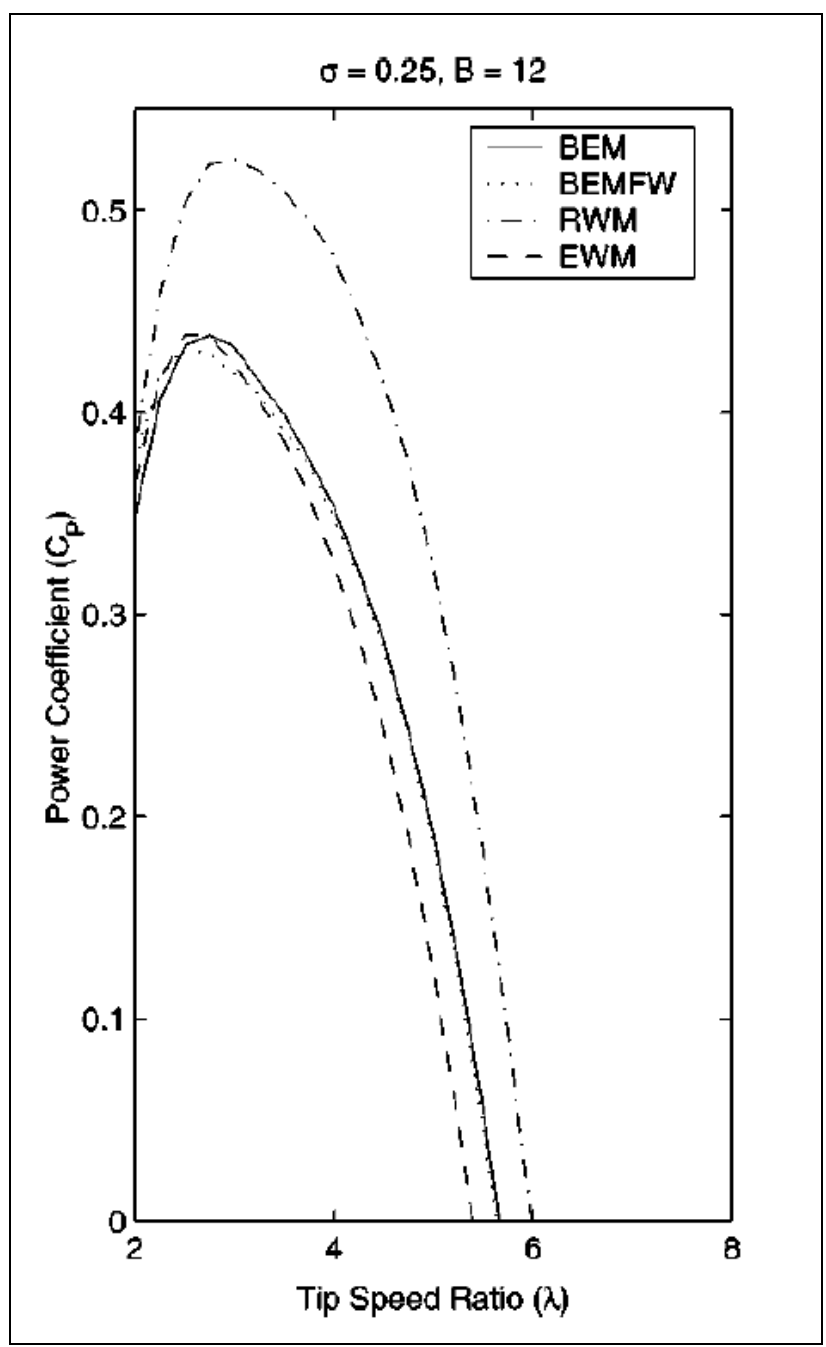

Figure 6 Power coefficient versus tip speed ratio for a 12 bladed rotor with a solidity of 0.25 [7]

The BEM analysis from Duquette and Visser's study[7] produces an optimal tip speed ratio approximately equal to 3 . This scenario corresponds to a rotor coefficient of about 0.42 for the rotor studied.

In 1988, Rijs and Smulders [8] attempted to design a computer program that would be accurate for rotor systems that operate at both slow and fast speeds. Previous programs proved to be accurate for just faster moving rotors. The program utilized strip theory (Blade Element Theory) combined with momentum theory to perform the mathematical calculations required for aerodynamic analysis. Rather than using a 
traditional iterative method, (which can involve convergence problems [9]) Rijs and Smulders solved the Blade Element equations analytically using a method from Jones [10] and Curvers [11]. Rijs and Smulders did theoretical calculations on four different slow moving rotors at a Reynolds number of $1 \times 10^{5}$. Table 1 displays the characteristics of these four rotors.

Table 1 Physical characteristics of the rotors tested in Rijs and Smulders. [8](regeneration)

\begin{tabular}{|c|c|c|c|c|c|c|c|c|}
\hline & \multicolumn{2}{|c|}{ Cwd 2000} & \multicolumn{2}{|c|}{ CWD 5000} & \multicolumn{2}{|c|}{ CWD 2740} & \multicolumn{2}{|c|}{ 'Dempster 14' } \\
\hline $\begin{array}{l}\text { Blade } \\
\text { Number }\end{array}$ & \multicolumn{2}{|c|}{6} & \multicolumn{2}{|c|}{8} & \multicolumn{2}{|c|}{6} & \multicolumn{2}{|c|}{18} \\
\hline Blade Root & \multicolumn{2}{|c|}{0.39} & \multicolumn{2}{|c|}{0.67} & \multicolumn{2}{|c|}{0.37} & \multicolumn{2}{|c|}{0.99} \\
\hline Radius (rotor) & \multicolumn{2}{|c|}{1} & \multicolumn{2}{|c|}{2.5} & \multicolumn{2}{|c|}{1.37} & \multicolumn{2}{|c|}{2.13} \\
\hline$\lambda$ design & \multicolumn{2}{|c|}{1.7} & \multicolumn{2}{|c|}{1.8} & \multicolumn{2}{|c|}{2} & \multicolumn{2}{|c|}{1} \\
\hline $\begin{array}{l}\text { Blade curv. } \\
(\%)\end{array}$ & \multicolumn{2}{|c|}{10} & \multicolumn{2}{|c|}{10} & \multicolumn{2}{|c|}{10} & \multicolumn{2}{|c|}{5 to 12} \\
\hline $\begin{array}{l}\text { Tube pos. } \\
(\%)\end{array}$ & \multicolumn{2}{|c|}{50} & \multicolumn{2}{|c|}{25} & \multicolumn{2}{|c|}{33} & \multicolumn{2}{|c|}{-} \\
\hline geometry & C & $\beta$ & $\mathrm{C}$ & $\beta$ & $\mathrm{C}$ & $\beta$ & C & $\beta$ \\
\hline root & 0.29 & 33.9 & 0.45 & 38.5 & 0.33 & 28.4 & 0.19 & 45 \\
\hline tip & 0.29 & 12.8 & 0.45 & 14.1 & 0.33 & 17.3 & 0.49 & 29.2 \\
\hline
\end{tabular}

The rotors in Table 1 were tested experimentally in three separate studies; [12], [13], and [14]. The experimental results from these studies were compared to the theoretical results of Rijs and Smulders. Figure 7 displays results from part of their study. It shows the comparison of the theoretical method with experimental measurements from Beurskens and Hageman [14]. 


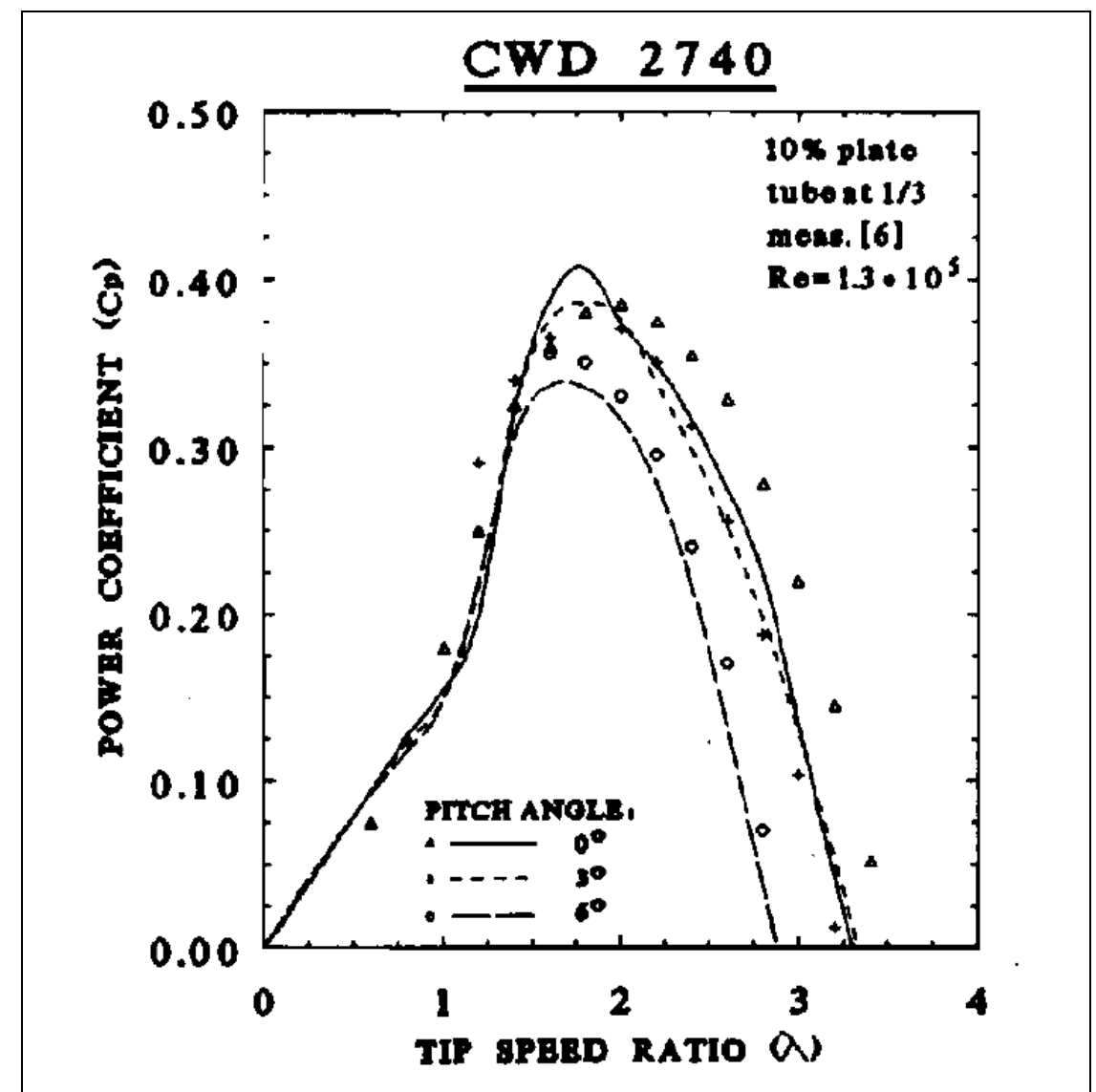

Figure 7 Power coefficient versus Tip Speed ratio calculated for three pitch angle settings compared to experimental values [8]

The calculated results match very closely with the results of the corresponding experiment.

Results from the other rotors in this study also correspond closely with their corresponding experiments. Rijs and Smulders successfully created a model that accurately performs aerodynamic calculations on both fast and slow moving rotors. The results found in the collaboration of these studies will provide useful data for comparison to results of the design study that is contained in this thesis.

\subsection{Ducted Windmills}

There are a number of ways to augment the power output of wind turbines. The most effective 'encasement type' method uses an annular airfoil that surrounds the rotor 
and diffuses the wind after it passes the rotor plane. Several studies have been performed on the subject of using diffuser shrouds to augment the flow through a windmill rotor. Theoretically, a duct can provide significant power increases when implemented properly[15,16,26,27,28,29]. A correctly designed duct can provide faster windspeeds through the rotor as well as decrease tip losses encountered with unshrouded wind turbines $[15,16,26,27,28,29]$. The maximum coefficient of power achievable by a wind turbine is $16 / 25$ (approximately $59.3 \%$ ) [16]. This means that only $59.3 \%$ of the power available in a streamtube (column) of wind can be extracted by a wind turbine. This value is known as the Betz limit.

Due to the decreased tip losses around the rotor, a diffuser shroud can increase the coefficient of power of a wind turbine rotor. It is more beneficial to think of the diffuser shroud as a power augmenter rather than something to boost the power coefficient of the rotor. A diffuser shroud can simply be an annular wing that sucks more air, by means of lift, through the center of the ring [17]. The diffuser will simply increase the amount of power available (potential energy) by increasing the velocity that the rotor will encounter. The swept area also increases with the addition of a duct because it now must include not only the rotor but the diffuser as well. Since power is directly linked to the swept area, the incoming wind velocity and also the power coefficient, a diffuser shroud can significantly increase the power output of a wind turbine. The air velocity inside a diffuser will be greatest at the nozzle (narrowest part of the diffuser - see Figures 10\&11). This is also where the rotor should be placed, so that it will encounter the maximum airflow (see Appendix $B$ for a picture of a wind turbine inside a diffuser).

Some of the discussed studies provide details into how a diffuser shroud will affect the flow through a turbine and the power out of the turbine. Igra [17] reports that the augmentation capacity of a diffuser shroud is a result of the shroud's ability to support sub- 
atmospheric pressure in the region of the turbine. Igra states several requirements for obtaining maximum augmentation from a shroud:

a) The exit pressure of the shroud should be as low as possible (well below zero);

b) the diffuser exit area to turbine area ratio $\left(A_{e} / A_{t}\right)$ for a given diffuser efficiency should be as large as possible; and the

c) diffuser efficiency should be as large as possible for a given diffuser area ratio.

Igra's research outlines the development from a long, very efficient, but bulky diffuser shroud to a shorter more compact shroud that still produces significant augmentation. First annular flaps were used to accelerate and direct some of the air outside into the diffuser wake. Then the shroud was made out of an airfoil that will produce suction to pull more air into the turbine section. The research displays models and results for each type of shroud. Figures 8, 9 and 10 show Igra's original long diffuser design, flapped design and annular airfoil design, respectively.

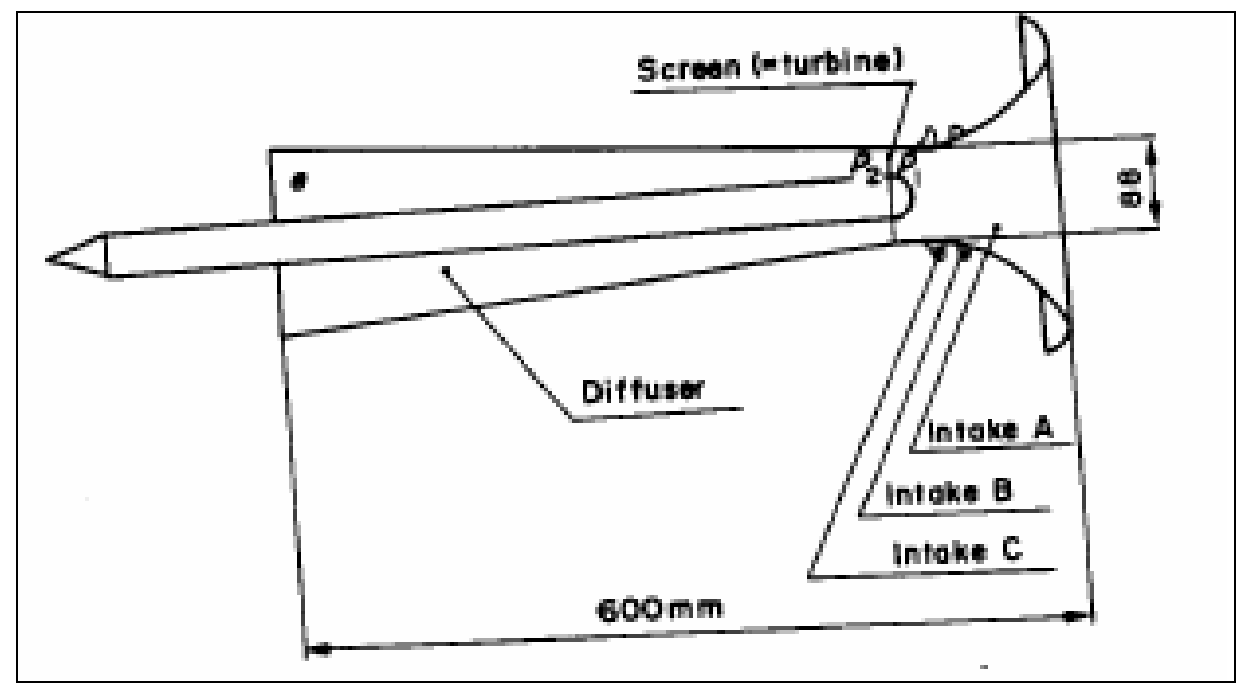

Figure 8 Long diffuser shroud design [17]. 


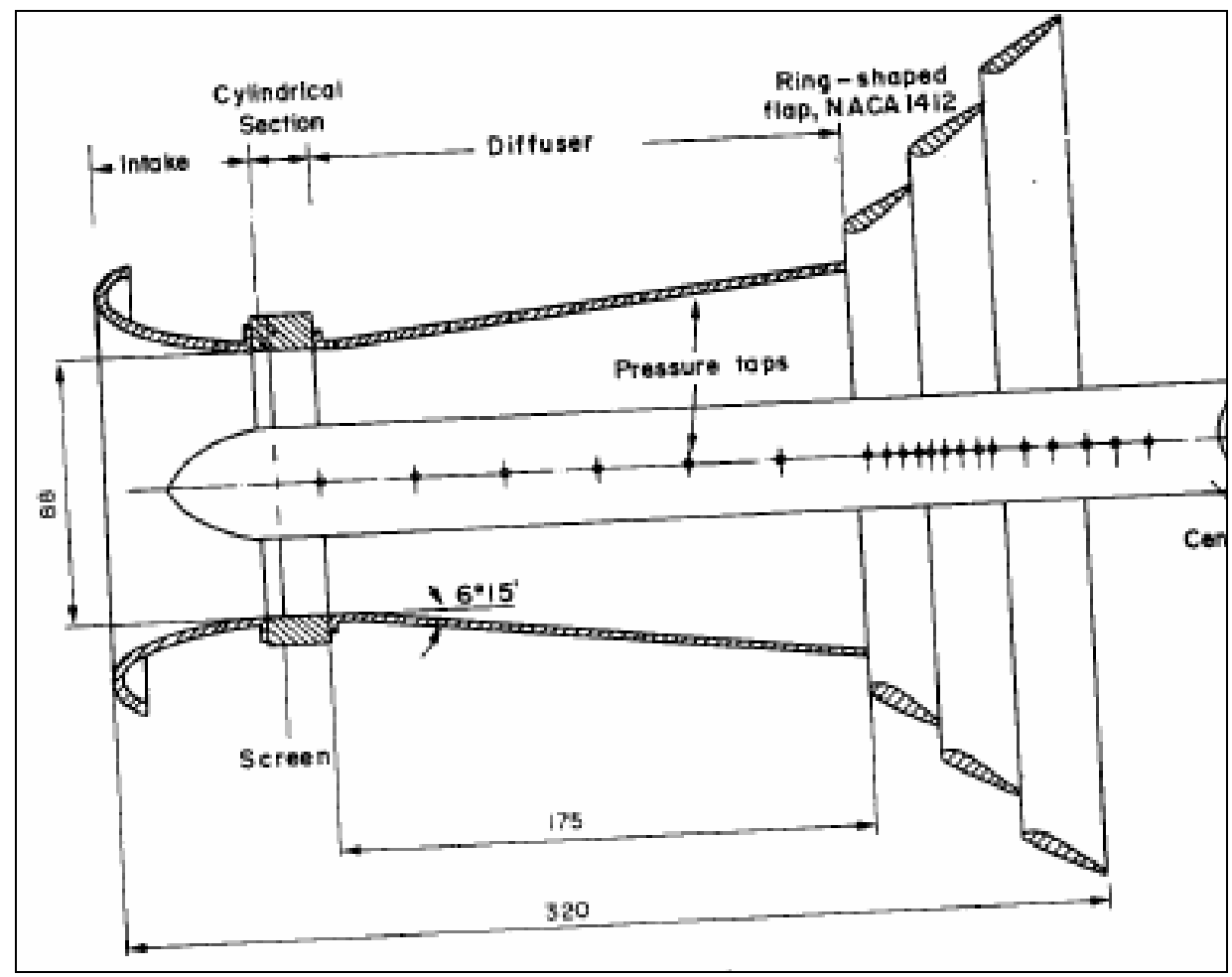

Figure 9 Short diffuser shroud design with flaps [17].

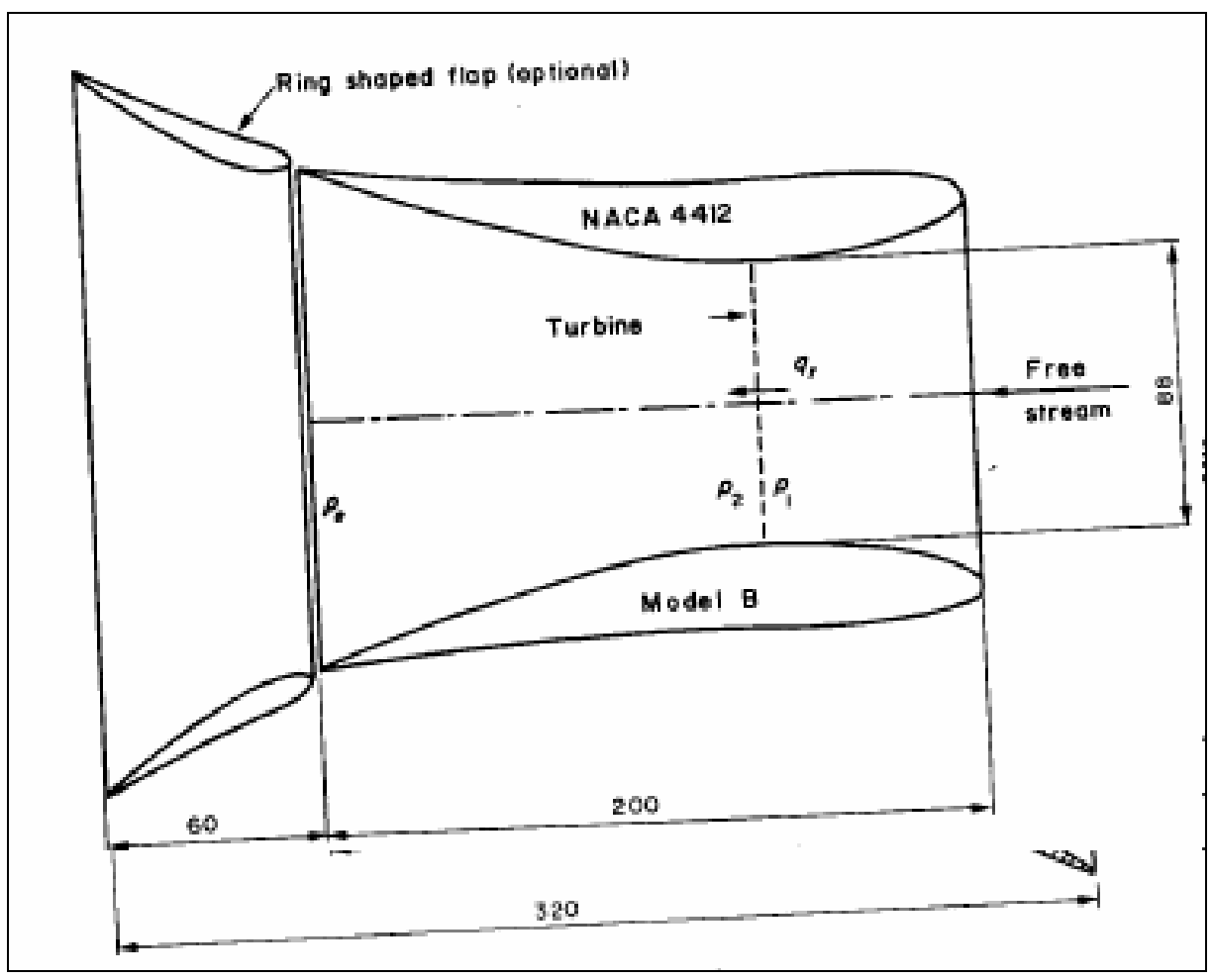

Figure 10 Shorter annular wing diffuser cross-section [17]. 
Each of these progressive designs performed better than the previous. The flap in the third design caused an increase of $52 \%$ in augmentation in relation to an annular wing without the flap. Igra then began experimenting by radially stretching the rear section of the shroud to vary the exit diameters. This variation indicated that the augmentation increased as the exit diameter increased. The shroud designs were also tested at different yaw angles into the wind. Results showed that the unflapped shrouds (that are made from annular wings) produce slightly better augmentation at yaw angles between 15 and 23 degrees. This is not surprising due to the nature of the airfoil used for the shroud. The flaps change the behavior of the augmentation factor at non-zero yaw angles. The flapped models performed best at 0 yaw (wind parallel to shroud axis). Igra was able to drastically reduce the length of the proposed shroud and still keep significant augmentation factors. Igra's results were verified by Foreman, Gilbert and Omen [18].

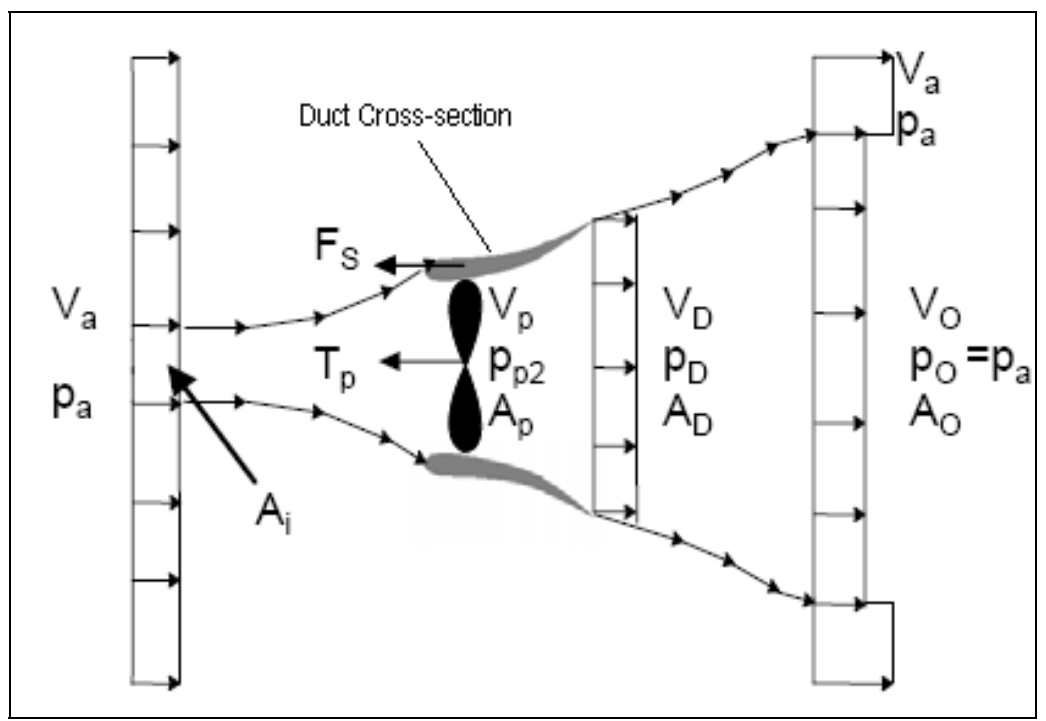

Figure 11 Typical Duct setup and nomenclature. [19]

Werle and Presz [19] outline a simple theoretical procedure to introduce the effects of a diffuser shroud into a model previously geared toward unshrouded turbines. Figure 11 shows a cross-section of the duct arrangement. The approach relates a shroud coefficient $\left(C_{s}\right)$ to the area of the diffuser at the rotor $\left(A_{p}\right)$ and the capture area $\left(A_{i}\right)$. The coefficient 
$\left(C_{s}\right)$ is a parameter in the development of the shroud force $\left(F_{s}\right)$. The following excerpt from the study describes the shroud force and its coefficient.

"for the inviscid, incompressible shrouded flow depicted in Figure 1, any axial pressure change due to the energy addition or extraction by a prop causes the flow streamlines to expand or contract laterally, giving rise to a velocity component normal to the shroud. Because of this, the Kutta-Joukowski theorem requires an axial force, $F_{S}$, to occur on the shroud as a result of the interaction between this induced velocity component normal to shroud axis and the shroud's ring vortex vector associated with the shroud/duct's aerodynamic circulation. The critical aspect of this classical theoretical model is that it relates the axial force on the shroud solely and directly to the energy addition or extraction at the prop location. From this classical theoretical foundation plus dimensional analysis considerations, the current formulation takes the shroud force, FS, to be proportional to the force induced by the pressure change across the prop, Ap(pp2-pp1), through a newly defined axial force coefficient, $C_{S}$ " [19]

Werle and Presz [19] go on to develop a power equation that includes the shroud coefficient. This could be very useful in an optimization model because the only parameters that needed to define $\mathrm{C}_{\mathrm{s}}$ are the inlet area and the area of the diffuser at the rotor. So, essentially a modification of the unshrouded power equation to include this parameter would effect the power output of the turbine. However, the validity of this approach is questionable due to the fact that the exit area of the diffuser is not clearly used in the development of the parameter. If this approach were to be implemented, further research into its results would need to be performed.

Van Bussel[20] revisits diffuser theories for empty diffusers, diffusers containing wind turbines and unshrouded wind turbines. Using momentum theory, a relationship is developed that can be used to calculate the velocity in the nozzle of the diffuser, which is where the turbine will be placed. The relationship is based on the freestream wind velocity, the axial induction factor of the turbine rotor, the diffuser exit to nozzle area ratio and the backpressure velocity ratio. This means that the augmented airflow can be 
calculated and used in the calculation of power output for the wind turbine rotor in a diffuser.

Each of the studies mentioned in this literature review deal with some aspect related to the design study at hand. Some of the theories used and developed will prove helpful in the solution of this problem. Any information used in the following design process will be explained in full detail and cited accordingly.

From the literature review performed, no studies or designs have been produced for a shrouded wind turbine for use in the low-speed wind conditions specified. The following sections will explain the procedures used in developing an optimum design for the solution of the mine radio, battery charging problem. 


\section{CHAPTER 3: OPTIMUM DESIGN PROCEDURE}

This chapter outlines in detail the steps taken to address the wind turbine rotor design problem. First, a feasibility study will be developed. Once the feasibility of such a device is verified, an optimum design must be found. Due to the range of conditions, an optimization model must be built to predict how a rotor will behave under the specified

circumstances. A shroud must also be designed for the application. Once an optimum design or designs has been found, the results should be compared to any similar studies and experiments that have been performed. Each of the steps will be covered in the following sections.

\subsection{Feasibility}

Since there is such a wide range of different conditions, no one apparent windspeed can selected. A wind velocity range from $50-500 \mathrm{ft} / \mathrm{min}$ will be used for the design range, which fits the MSHA requirements. This range will cover the conditions found in most underground mines. As a standard, unless otherwise specified, the generalized mine entry will have dimensions of $8 \mathrm{ft}$ tall by $20 \mathrm{ft}$ wide. The power required to charge the radio batteries is approximately 2 watts. Based on generator and electrical losses and a safety factor, the power out of the wind turbine rotor must be about 4 watts. Power out of an unshrouded wind turbine rotor is related to the swept area of the rotor, windspeed, density and the coefficient of performance of the rotor. Eq. 1 displays the power out of a turbine rotor,

$$
P=C_{p} \frac{\rho}{2} V_{o}^{3} A
$$

Density will be taken at standard sea level conditions, $1.225 \mathrm{~kg} / \mathrm{m}^{3}$. For an ideal rotor which has the maximum possible coefficient of power of 0.593 , at a windspeed of 350 
$\mathrm{ft} / \mathrm{min}(1.778 \mathrm{~m} / \mathrm{s})$, a rotor diameter of about $5.15 \mathrm{ft}$ is required to produce 4 Watts of power. This windspeed, chosen for this calculation, is in the middle of the velocity range. Realistically, rotors with Cp's as high as this do not currently exist. The figures below display a first order look at the relationship between the windspeed, power and rotor size.

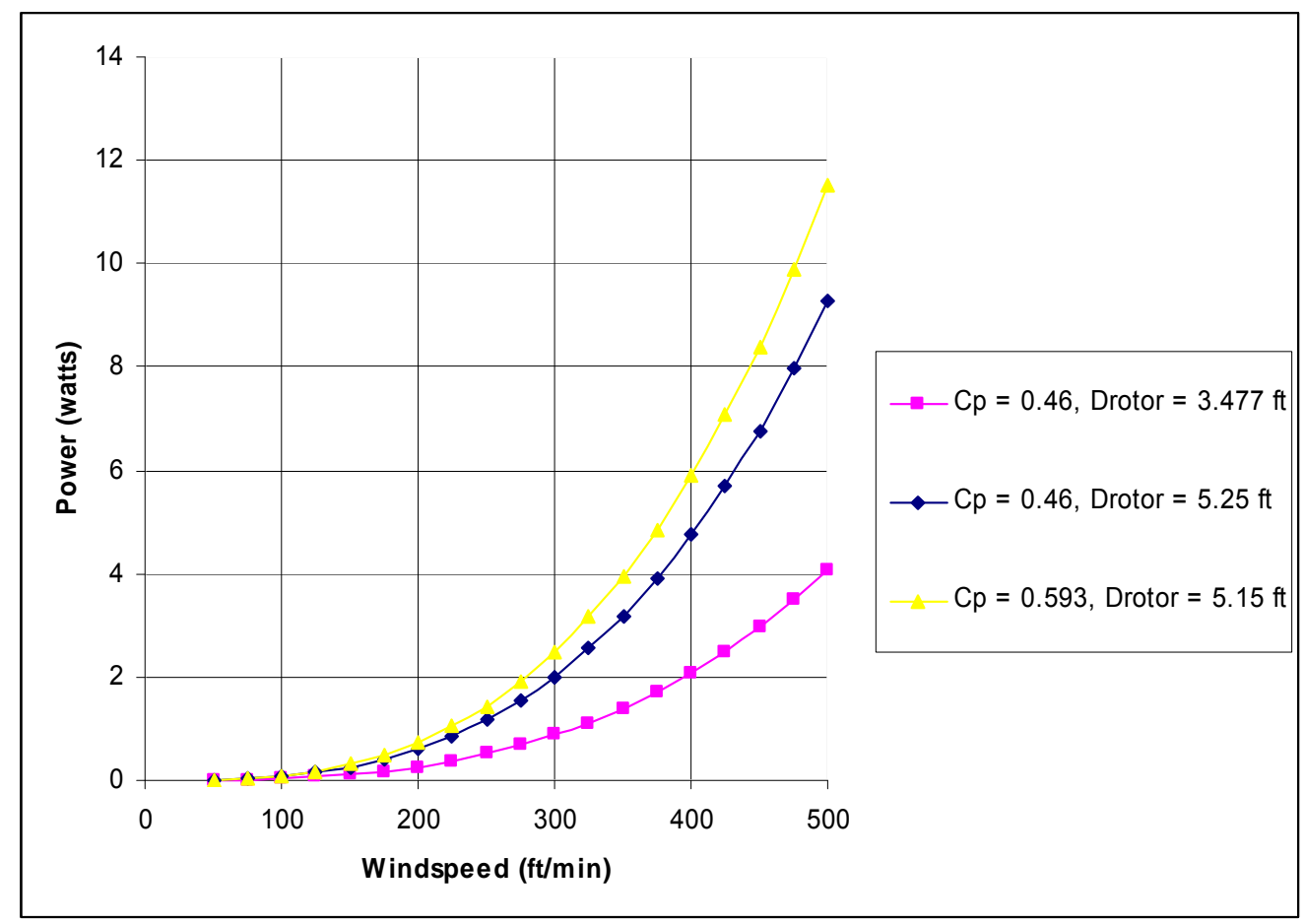

Figure 12 Power curves for varying rotor diameters and performance coefficients.

From Figure 12 it can be seen that for a realistic rotor $\left(C_{p}=0.46\right)$ at the high end of the velocity range a rotor diameter of about $3.5 \mathrm{ft}$ is needed to produce 4 watts. Also, it can be seen that a rotor diameter of $5.25 \mathrm{ft}$ will produce 4 watts at about $375 \mathrm{ft} / \mathrm{min}$. For an $8 \mathrm{ft}$ by $20 \mathrm{ft}$ mine entry way, a $5 \mathrm{ft}$ diameter rotor is feasible. The rotor will fit in the contained area. It can also be seen from the plot that the low end of the velocity range is not productive at all. Even for rotors of much larger size, the low end of the windspeed range will still not produce power sufficient enough to charge the radio batteries. Figure 13 emphasizes the fact that an unshrouded rotor cannot supply the required power for the application in the lower one third of the windspeed range. 


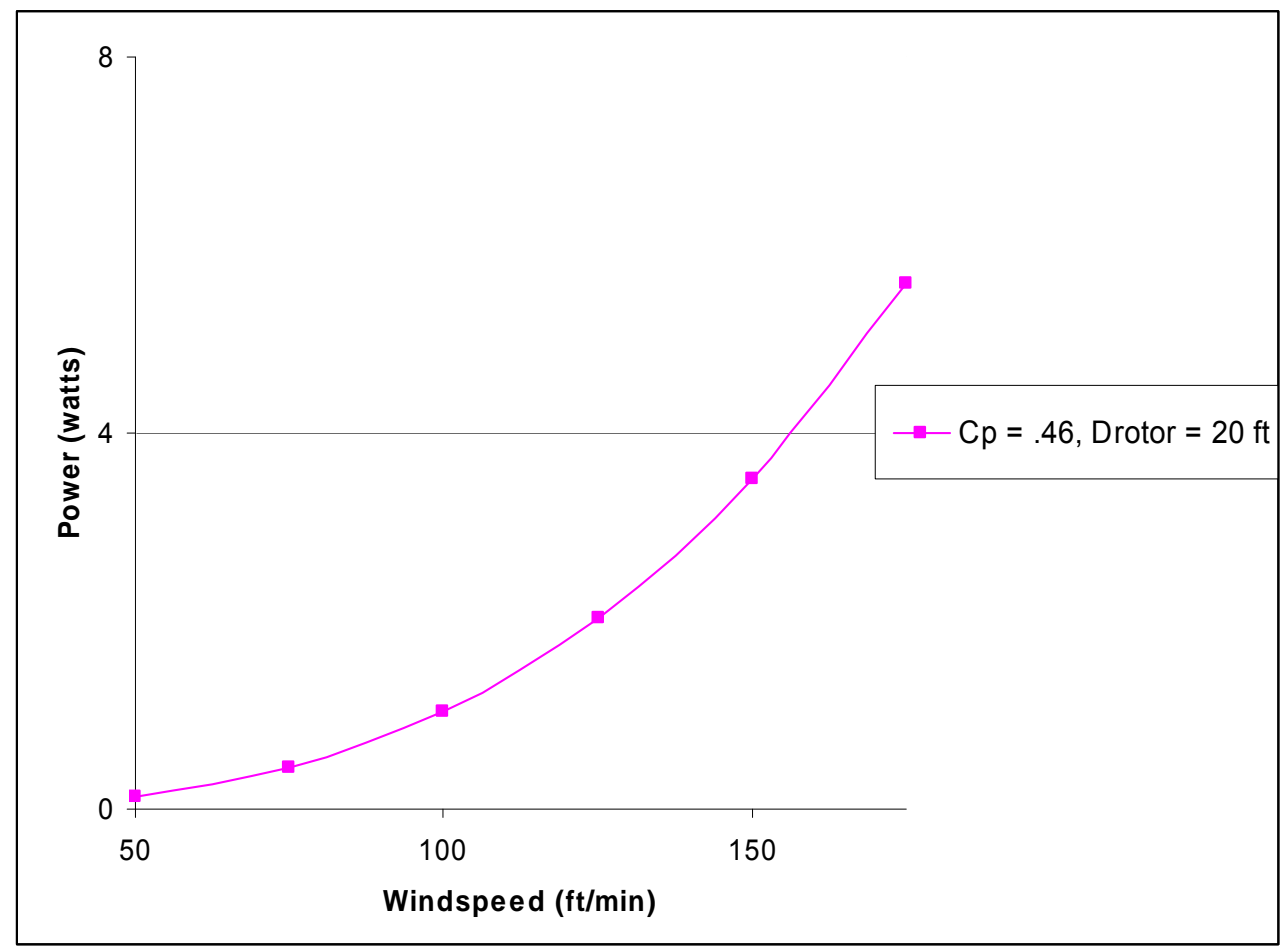

Figure 13 Power curve for a rotor diameter of $20 \mathrm{ft}$

Figure 13 displays the power results for a rotor much larger than the rotors previously discussed. The data is only reported to show that at the low end of the air velocity range (less than $150 \mathrm{ft} / \mathrm{min}$ ), it is impossible (with a traditional unshrouded turbine as large as the mine entry) to produce the power required. This means that if air speeds in a particular mine were at the low end of the range, a wind turbine system is not a feasible solution to charge the radio batteries (unless future electrical technology enables the batteries to be charged with less power).

However, since the power out is directly related to the cube of the windspeed, as the air speed in the mine increases, so does the feasibility of such a solution. And as stated, the upper end of the wind range should provide ample speed to build a sufficiently small but efficient wind turbine. With the added power augmentation of a diffuser shroud (not included in Figure's 12 or 13), a wind turbine should be able to meet the needs presented by the issue. 


\subsection{Optimization Model}

The first order study shows that this idea can work on a portion of the wind conditions in the study. A numerical model was developed to quickly and easily output the geometry and design parameters of an optimum wind turbine rotor based upon inputs related to the mine (mainly size and airspeed). Matlab was used as a calculation/design tool. The computer codes for the model can be seen in Appendix C. Blade element momentum theory was utilized in the model. It was chosen due to its proven performance qualities in previous relevant research $[8,10,22,30,32]$. The method and procedure used in developing the numerical model are discussed in detail in the following section. Due to the complex nature of rotor blade aerodynamics, it was decided that the first model would simply deal with an unshrouded (thus unaugmented turbine). The diffuser shroud will be added in as an augmenter at a later stage in the research/design process.

Blade element momentum theory is a combination of general momentum theory and simple strip theory. Strip theory utilizes the concept of a blade element or "strip". Each rotor blade is split into span-wise segments. Each element covers a small radial distance on the blade, $d r$. Figure 14 displays the forces and angles associated with a 2-D cross-section of an element of a common rotor blade. 


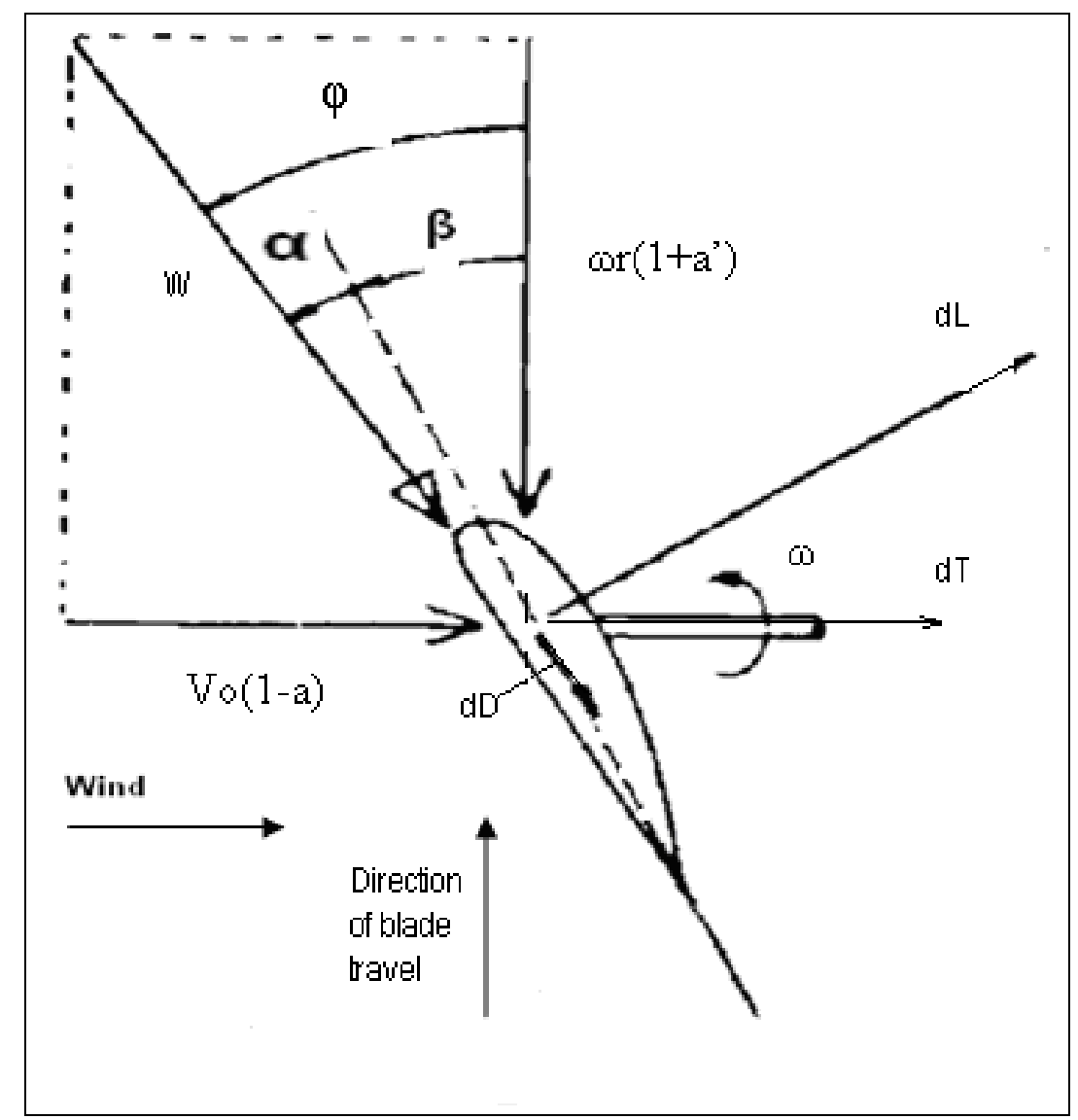

Figure 14 Flow on the cross section of a rotor blade element. (background from [10])

The forces on each strip can vary and each contributes to the total force on the rotor blades. As air flows through the turbine, the rotor interrupts the normal flow stream. Blade element momentum methods calculate axial and tangential interference factors that are used in defining this interaction. In Figure 14 these factors are seen as $a$ (axial) and $a^{\prime}$ (tangential). These interference factors are very influential in the calculations of the aerodynamics of the rotor. The angle between the plane of blade travel (rotation) and the resultant wind velocity is $\phi$. The angle of attack, $\alpha$, is the difference between the relative in-flow angle, $\phi$,of the wind and the blade twist (pitch) angle, $\beta$. If the airfoil that is to be used for the blades is known, then the lift coefficient $C_{l}$ and the drag coefficient $C_{d}$ can be found from given airfoil data. This airfoil data comes from testing at a specified Reynolds number. $C_{\mid}$is found to stay fairly constant for different Reynolds numbers. However, $C_{d}$ 
changes if the Reynolds number changes. Eq. 2 shows how to update $C_{d}$ with changing Reynolds number. $C_{d}$ will have to be updated for each case where chord length changes since Reynolds number is dependent on chord length.

$$
C_{d}=C_{d r e f} \frac{\operatorname{Re}_{r e f}}{\operatorname{Re}}
$$

The resultant thrust, $d T$, and the resultant torque, $d Q,($ not shown in Figure 14 but acting equal and opposite to the tangential resultant velocity term) are defined by Eq. 3 and Eq. 4 respectively below:

$$
\begin{array}{ll}
d T=C_{d T} q B c d r & \text { and } \\
d Q=C_{d Q} q B c r d r & \text { Eq. } 3
\end{array}
$$

where $q$ is the dynamic pressure, $B$ is the number of blades, $c$ is the chord length of the element and $d r$ is the radial distance covered by the element. The coefficients for these resultant forces $C_{d T}$ and $C_{d Q}$ can be calculated using Eq.'s 5 and 6:

$$
\begin{array}{ll}
C_{d T}=C_{l}(\alpha) \cos \phi+C_{d}(\alpha) \sin \phi & \text { and } \\
C_{d Q}=C_{l}(\alpha) \sin \phi-C_{d}(\alpha) \cos \phi . &
\end{array}
$$

Momentum theory then looks at a columnar annulus of air that effects the same element discussed above. New relationships can then be developed for the elemental thrust and torque that involve the axial and tangential interference factors. These equations are displayed below as:

$$
\begin{array}{ll}
d T=4 \pi \rho V_{o}^{2} a(1-a) F d r & \text { and } \\
d Q=4 \pi \rho r^{3} V_{o}^{2} a^{\prime}(1-a) F d r .
\end{array}
$$


The $F$ term in the above equations is called the Prandtl tip/hub loss factor. This factor accounts for losses from airflow effects at the hub and tips of the rotor blades. The tip and the hub both have separate but similar functions. However, hub losses are often neglected in describing rotors with small hubs [22]. The Prandtl tip loss factor is defined in Eq. 9 as,

$$
F=\frac{2}{\pi} a \cos \left(\exp \left(\frac{B(r-R)}{2 r \sin \phi}\right)\right)
$$

It should be noted that when the diffuser shroud is added, the tip losses will become very small and can be neglected or $(F=1)[15,16]$. Since the design constraints require the turbine being designed to be protected by a shroud, the tip losses will not be included in the design calculations. By equating Eq's 7 and 9 and Eq's 3 and 4, the interference factors can now be solved as;

$$
\begin{gathered}
a=\frac{1}{\frac{4 F \sin ^{2} \phi}{\sigma_{r} C_{d T}}+1} \quad \text { and } \\
a^{\prime}=\frac{1}{\frac{4 F \sin \phi \cos \phi}{\sigma_{r} C_{d Q}}-1}
\end{gathered}
$$

where $\sigma_{r}$ is the local solidity of the rotor blade for a particular element. Eq. 12 defines the local solidity. The $r$ variable in Eq. 9 and 12 is the defining radius of the element or the radius from the center of the rotor to the center of the element and

$$
\sigma_{r}=\frac{B c}{2 \pi r}
$$

In most research applications an iterative solution procedure is used. Initial values for $a$ and $a^{\prime}$ are guessed, $\phi$ is calculated based on these values, $\alpha$ is also calculated, then the 
interference factors $a$ and $a^{\prime}$ are updated until there is convergence. This convergence scheme is used to estimate performance of a selected blade setup. Rather than use this convergence method and have to guess and check numerous times, a method noted by Jones [10] and Curvers [11] and discussed in Rijs and Smulders [8] will be used. The referenced method will produce a number of data curves that will display the performance of different rotor setups over the varying range of constraints. This will allow the designer to select the optimal setup for use in specific conditions. This method uses the same equations but, rather than initially guessing the interference factors, the flow angle $\phi$ is assumed and used as the starting point for calculations. From this point, the torque and thrust coefficients are calculated from Eq.'s 4 and 5 . The local solidity at each element is determined by Eq. 11. Eq.'s 9 and 10 are then used to calculate the interference factors. These interference factors are then used to calculate an elemental speed ratio, $\lambda_{r}$, defined as,

$$
\lambda_{r}=\frac{(1-a)}{\left(1+a^{\prime}\right) / \tan \phi}
$$

Once the local speed is known, the elemental power coefficient can be calculated as,

$$
d C_{P}=4 \lambda_{r}^{2}(1-a) a^{\prime}
$$

This term can then be integrated over the entire blade to determine the coefficient of power of the entire rotor. A very close approximation can be obtained by taking the mean of the local $C_{p}$ 's found from Eq. 14. However, for this to be accurate each elemental annulus must have the same area. Eq. 15 shows how to calculate element divisions so that the annular areas will be equal to one another. $n$ is the number of the element for which the division is being calculated and $N$ is the total number of elements in the blade or, 


$$
d r=R \sqrt{\frac{n}{N}}
$$

From this, the defining radius of each element is taken halfway between the element division for each particular element. Once the power coefficient is found by taking the mean of the local power coefficients, the power output of the rotor is easily obtained by using Eq. 1.

This calculation method was implemented using MATLAB. Each inflow angle will produce a different power output (separate solution) for a specified rotor size, chord and blade number. The calculation process is iterated to solve each inflow angle for a varying number of blades and varying chord lengths. The size of the rotor is also varied to determine the smallest possible design configuration that will produce the required output. Results from running these calculations (for a single inflow angle) will give design configurations for constant pitch, constant chord rotor blades. The results then simply have to be searched for the designs that produce the largest power outputs. In this case, a certain inflow angle (combined with blade number and chord length) will provide an optimum design. It is not certain which blade number or chord length will produce the best design but this study makes it possible to analyze the underlying implications of these variables combined with the varying inflow angles.

Each element has a different optimum inflow angle based on the flow properties through the rotor. This means that in order to achieve a true optimum rotor design the rotor blades will have to have a twist (pitch) distribution based on these optimum inflow angles. In order to determine the optimum twist distribution, the iteration results can be searched numerically to find the inflow angles that provide the highest local (elemental) power coefficient. These values are saved within the model and can then be plotted against the blade station number to show the optimum twist (pitch) distribution. The same 
process can be used to determine the optimum chord (taper) distribution. These configurations, since they have a higher overall power coefficient, will produce more power than the constant pitch configurations found by just a single inflow angle. There will be an optimum configuration for each blade number simulated.

The inflow angles will be specified based upon which angle provides the best coefficient of performance. This means that the only other variable that must be selected is the chord length. The model will return the number of blades and the chord length for each optimum case. These values determine the solidity of the rotor. In theory, there should be an optimum rotor solidity and tip speed ratio for each blade number analyzed $[7,22]$.

The model will display a large number of the most efficient designs. This is not only to provide results for comparison but to allow the designer to pick from a number of options (if they exist) in order to allow for simplicity in future manufacturing and testing. Figures and tables displaying the results from the model (without a diffuser shroud) can be found in the first section of Results.

\subsection{Addition of the Diffuser Shroud to the Optimization Model}

Now that a working model for an unshrouded turbine has been developed, the next stage of the design must be implemented. As stated earlier, some sort of protective "outer shell" must surround the wind turbine as a safety precaution in the mine. Due to this requirement, it is in the designer's best interest to design the covering to augment the power output of the wind turbine. The simplest, most productive design is that of a diffuser shroud built of an annular airfoil that increases the airflow (with respect to the freestream) through the rotor of the turbine. The dimensions of the best diffuser design are not known. In order to select an optimum shroud, the effects the shroud will have on the airflow must be analyzed. 
In this case, any complex airflow behavior will not be studied in detail. Instead, a simple method, using the diffuser area ratios as the defining element, will be implanted. The method will simply determine the induced velocity caused by the diffuser. From this increased velocity and the new swept area defined by the diffuser, the power out of the system can be determined. This will provide a means to determine a reasonably efficient diffuser shroud. The equations below outline the procedure for determining the velocity entering the rotor and the procedure for including the diffuser shroud in the design model. Figure 15 shows the pressure and velocity relations used to set up Van Bussel's [20] research. These relations as well as the theory developed by Van Bussel will be used to model the diffuser shroud.

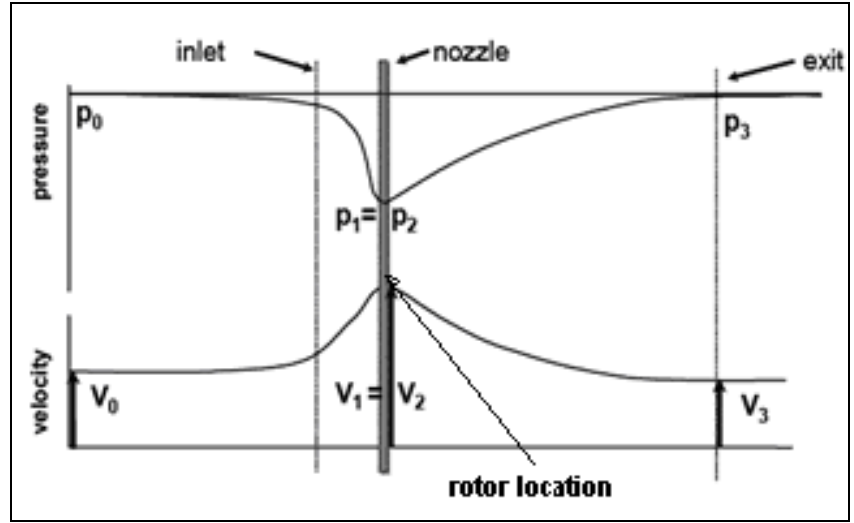

Figure 15 Velocity and pressure relations at each stage of the diffuser[20].

From this theory, it is assumed that the same conditions apply after the diffuser exit that apply after an ordinary wind turbine rotor[20,24]. From this, the relationship between exit velocity and freestream velocity is shown in Eq. 16 as

$$
V_{3}=(1-a) V_{o} .
$$

If extra back pressure is present at the exit of the diffuser then the exit velocity changes and can be calculated using Eq. 17. $\gamma$ is introduced as the backpressure velocity ratio in

$$
V_{3}=\gamma(1-a) V_{o} \text {. }
$$


Based on the continuity equation, the velocity at the nozzle of the diffuser (narrowest point - where the rotor will be located) can be determined from the diffuser exit area ratio $A_{e}$ and the freestream wind velocity. Eq. 18 displays this relationship as

$$
V_{1}=A_{e} V_{3}
$$

Using this relationship a useful correlation can be developed between the freestream velocity and the nozzle velocity inside the diffuser (just in front of the rotor). The equation is shown below,

$$
V_{1}=A_{e} \gamma(1-a) V_{o}
$$

For simplicity, the back pressure velocity ratio will be assumed to be unity (no extra back pressure)[20]. Now, the augmented velocity, that largely influences how much power the shroud will add to the system, can be easily calculated using the geometry of the diffuser and the freestream wind velocity. From Igra [17], it is known that as the diffuser exit area increases, the augmentation of the shroud will increase (until the ratio is so steep that the airflow stalls). Several simulations will be performed to see which diffuser shroud (area ratios) should be selected for the design. So, a design with a shroud just large enough to achieve the desired power should be selected. Anything larger and space constraints in the mine entry will be compromised. This new velocity, $V_{1}$, can now be used in the calculation of the final power drawn from the wind turbine rotor. It should be noted that the area used in the power calculation is still the swept area of the rotor itself. Eq. 20 shows the power output of a wind turbine rotor augmented by a diffuser shroud as

$$
P=C_{p} \frac{\rho}{2} V_{1}^{3} A
$$

It should also be noted that the coefficient of power will change slightly due to the decreased tip losses involved with the diffuser shroud. The tip losses will be neglected in the model to account for this change $[15,16]$. 
These changes will be implemented in the optimization model. The results will be analyzed to determine how much difference the diffuser shroud makes, as well as the shape of the overall final design. Important comparisons and data can be found in the Results section. 


\section{CHAPTER 4: RESULTS}

\subsection{Numerical Results}

The first part of this section presents the results generated by the optimization model for an unshrouded wind turbine design. Within the model (Appendix $C$ ), the user specifies the freestream wind velocity and the radius of the rotor based on the conditions and space available in the mine entryway. Only the cases needed to show trends in the data will be shown in this document. Once the velocity and radius are defined the model will generate solutions for a range of inflow values (about 10 degrees to 50 degrees) over each blade element. Each inflow value, along with a blade number and a chord length will produce different interference factors, speed ratios and solidities, which in turn generates different power coefficients. Certain combinations of these variables will produce more power than the other solutions. The results shown below display the data and trends used to find these optimums. The first results are for a windspeed of $2.54 \mathrm{~m} / \mathrm{s}(500 \mathrm{ft} / \mathrm{min})$. This is the very high end of the velocity range specified. The first rotor radius analyzed is $0.5 \mathrm{~m}$.

Figures 13 - 17 display the relationships between blade number, chord length and rotor coefficient of power. Each figure is for a different inflow angle; therefore, the effects of varying this angle can be seen by comparing each of the plots. There is a different plot for every inflow angle solved, but to save time only a few of the most significant ones have been displayed here. The rest can be found in Appendix B. 


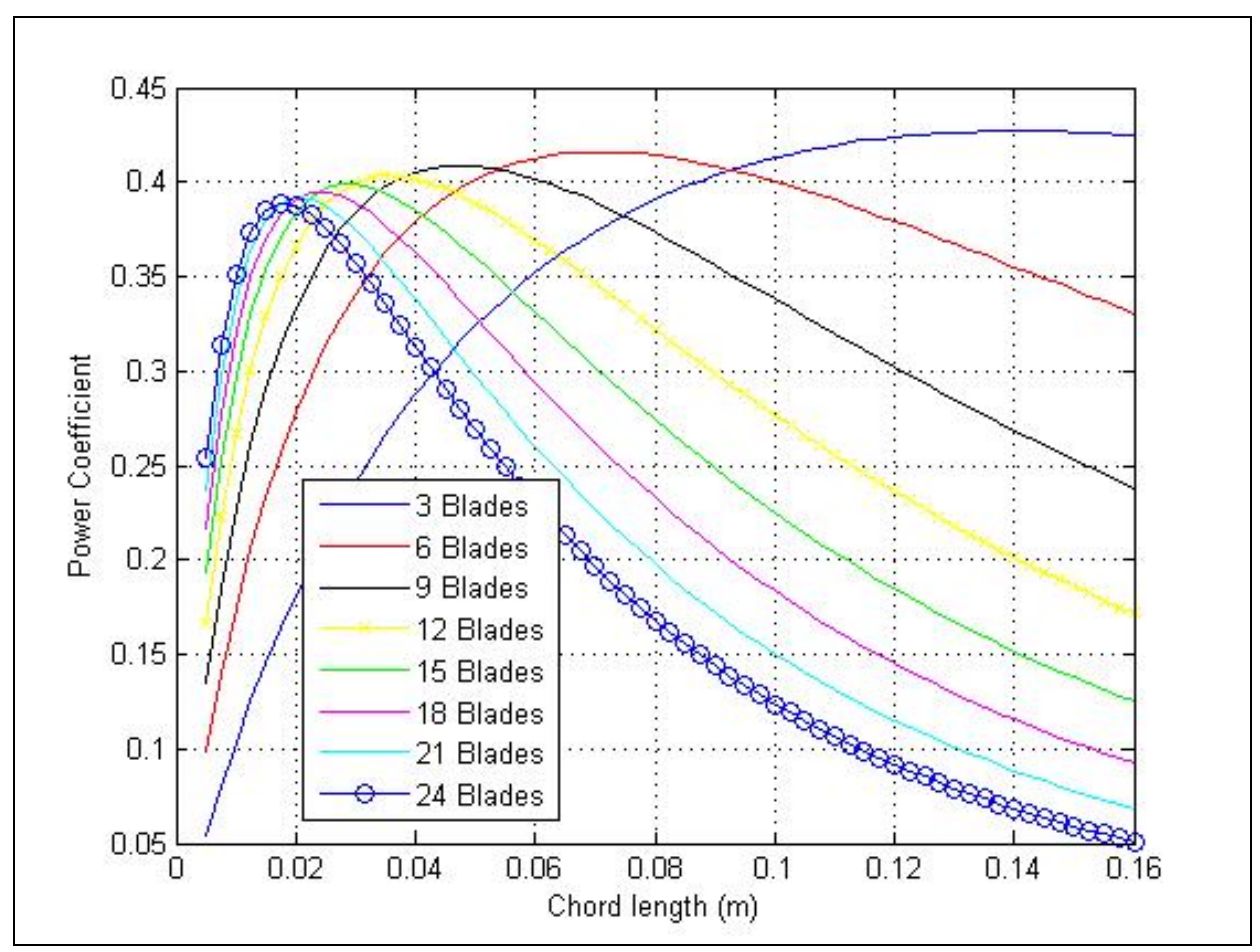

Figure 16 Effect of blade \# and chord length on $\mathrm{C}_{\mathrm{p}}$ at an inflow angle of 22 degrees.

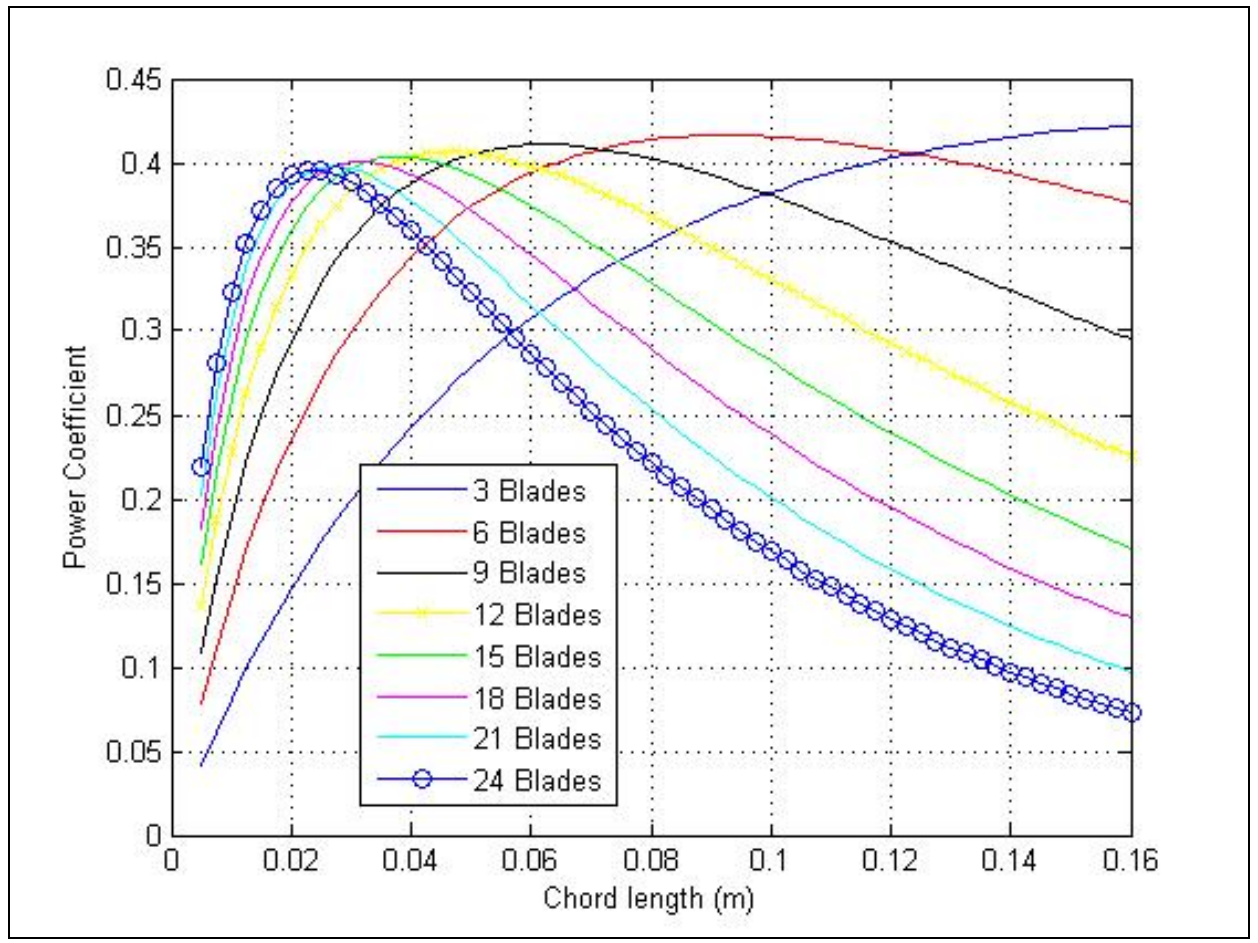

Figure 17 Effect of blade \# and chord length on $C_{p}$ at an inflow angle of 26 degrees. 


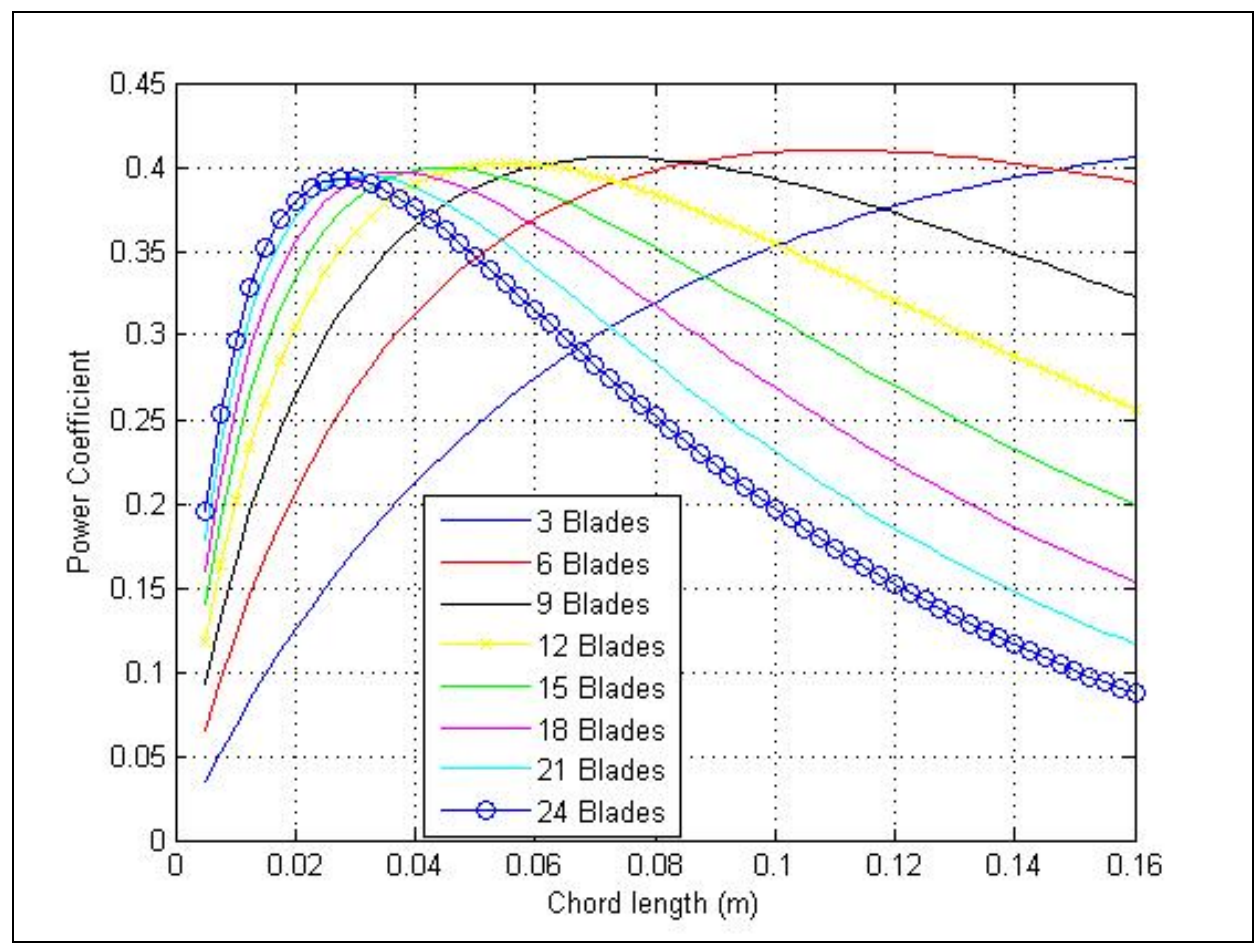

Figure 18 Effect of blade \# and chord length on $C_{p}$ at an inflow angle of 29 degrees.

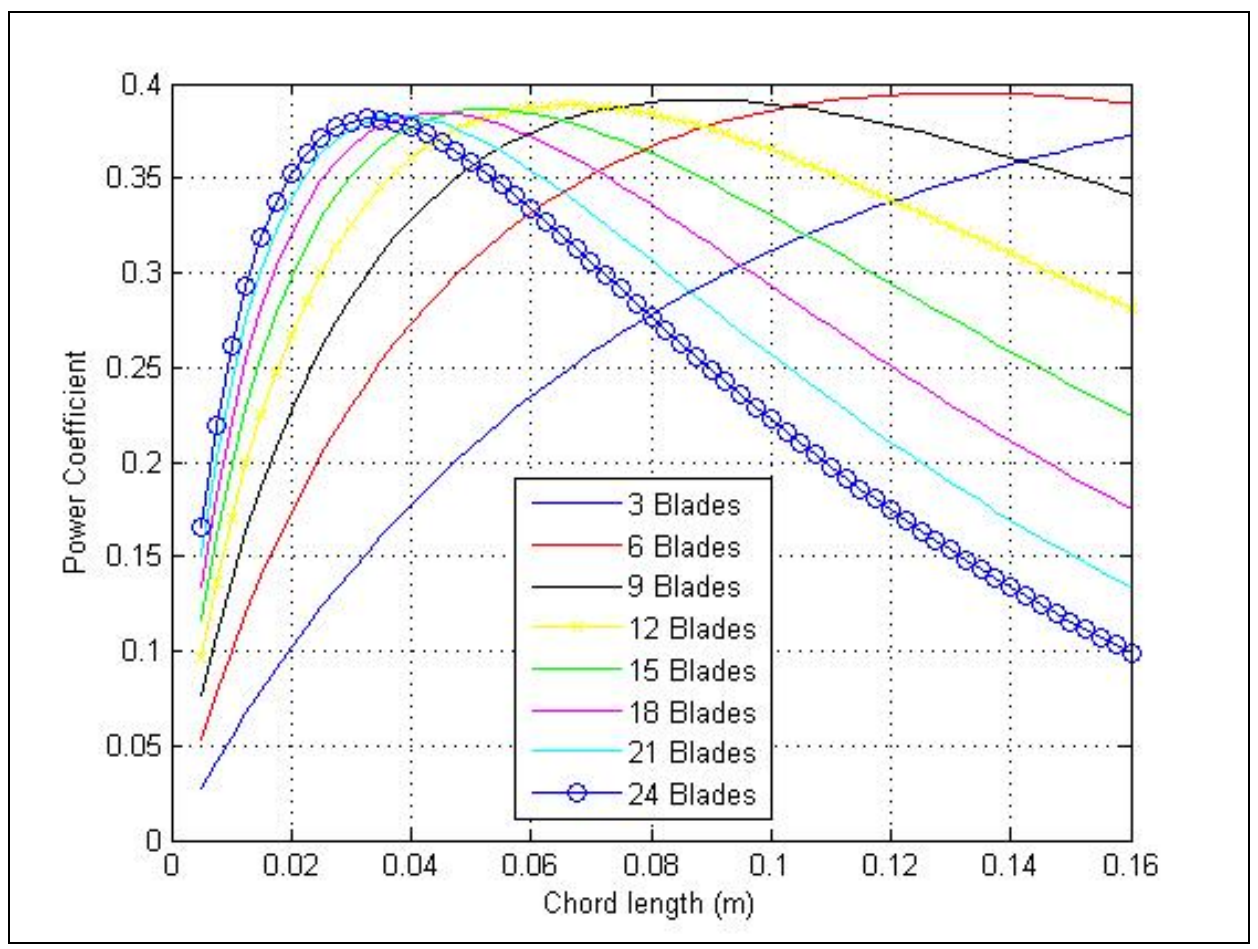

Figure 19 Effect of blade \# and chord length on $C_{p}$ at an inflow angle of 33 degrees. 


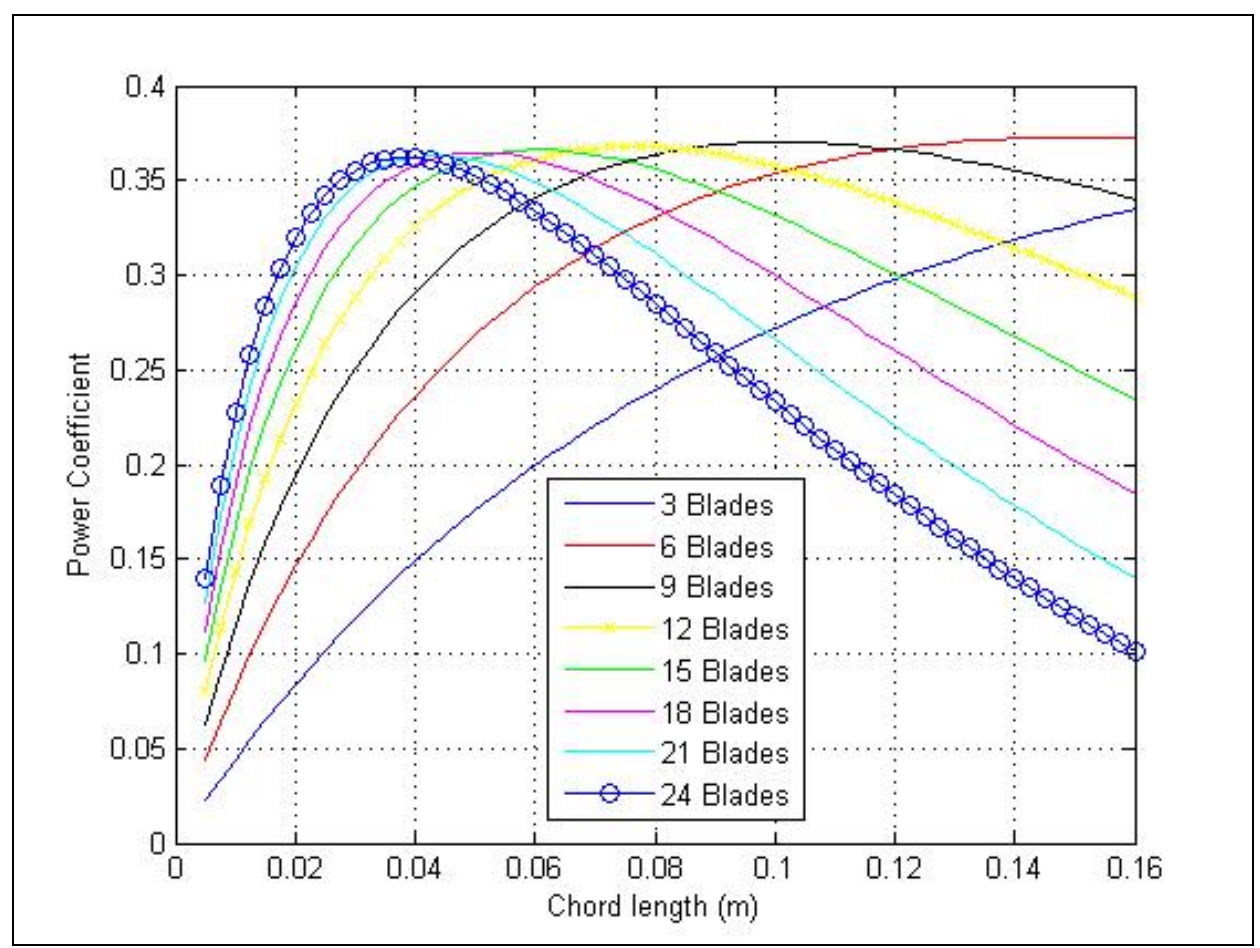

Figure 20 Effect of blade \# and chord length on $C_{p}$ at an inflow angle of 37 degrees.

As illustrated by the graphs, the lower blade numbered setups (3-9) have optimum power coefficients at larger chord length values, while the higher blade numbers (>9) have optimums at lower chord lengths. This means that there is an optimum solidity range that should produce more efficient results. Coefficients of power as high as 0.42 can be reached using blade setups of 6 or 3 blades at a 26 degree inflow angle. At the optimum solidity peaks, varying the blade number only affects the coefficient of power by a few hundredths. It can be observed that as the inflow angle increases (analogous to increasing pitch), the higher blade number rotors perform more efficiently. The efficiency of the rotors in these cases is still lower than the efficiencies seen by the 3 and 6 blade rotors, but only by minimal amounts. When the inflow angle becomes greater than 29 degrees the power coefficients of all the rotor configurations begin to decrease.

The implications displayed in Figures $13-17$ will not change with regards to windspeed. For this reason, these relationships will not be displayed for the other 
windspeeds analyzed. Figure 18 indicates the same relationships in a 3D surface plot that shows a definite "optimum ridge" for one of the highest performance inflow angles, 25 degrees. The dark red color in the plot gives the optimum solidity setups for this inflow angle.

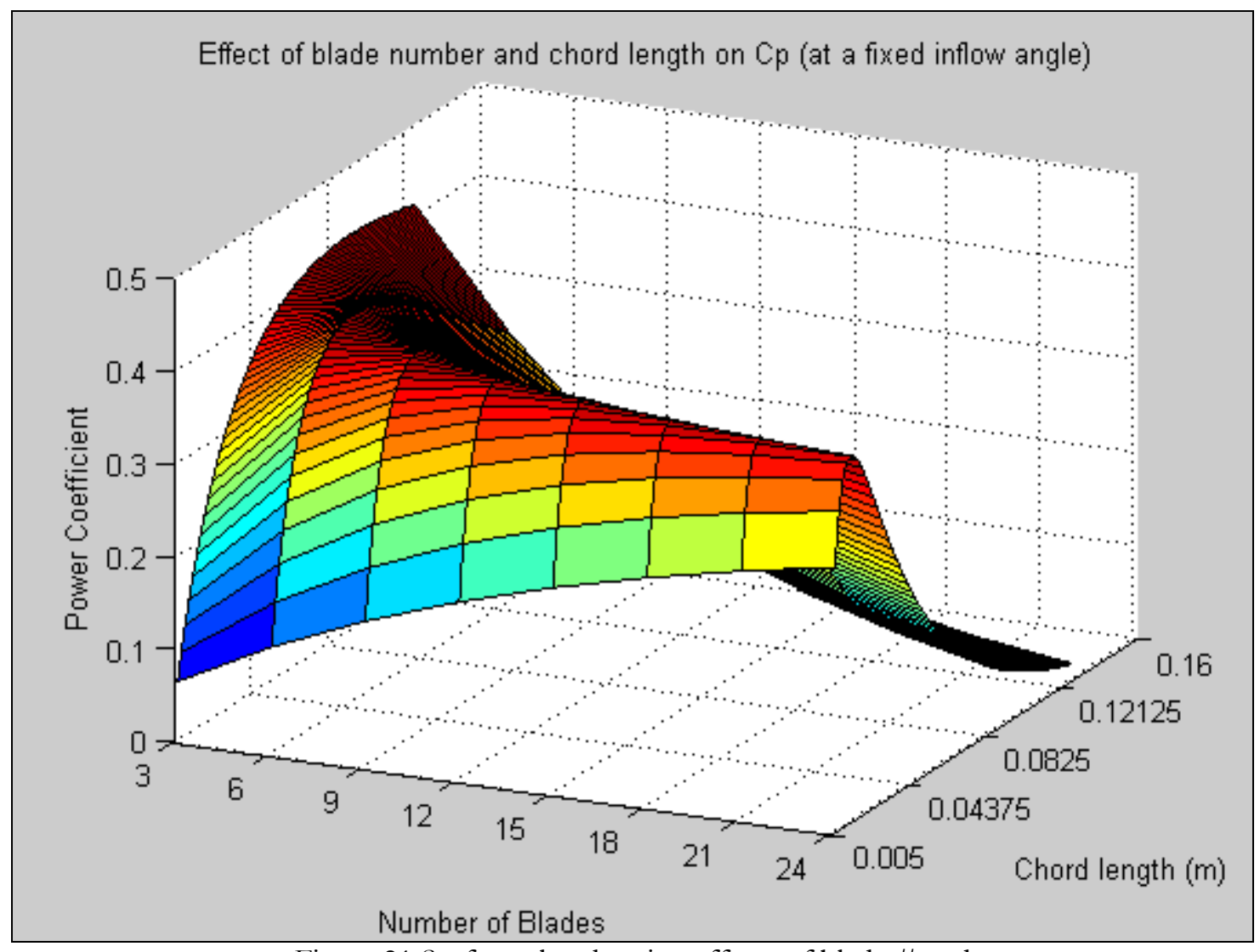

Figure 21 Surface plot showing effects of blade \# and chord length on power coefficient at 25 degree inflow angle.

For these results, an angle of attack of 6 degrees was used. For a curved plate, this angle of attack corresponds to $C_{\mid}$and $C_{d}$ reference values of 1.315 and .057 respectively. These values come from a Reynolds number of 100000 , where $C_{d}$ is updated for every case to correspond to the correct Reynolds number. A diagram showing the blade curvature for this type of blade can be seen in Appendix A. 
The table below shows the characteristics of each of the optimum rotor setups found by the model and its power output for the case discussed above. These cases all have constant pitch blades.

Table 2 Optimum Design Parameter for rotor radius of $0.5 \mathrm{~m}$ at a wind velocity of $2.54 \mathrm{~m} / \mathrm{s}$

\begin{tabular}{|c|c|c|c|c|c|}
\hline $\begin{array}{c}\text { Blade } \\
\text { number }\end{array}$ & Solidity & $\begin{array}{c}\text { Chord } \\
(\mathrm{m})\end{array}$ & $\begin{array}{c}\text { Pitch } \\
(\mathrm{deg})\end{array}$ & $\begin{array}{c}\text { TSR } \\
\text { (watts) }\end{array}$ \\
\hline 3 & 0.291 & 0.1525 & 17 & 1.73 & 3.37 \\
\hline 6 & 0.315 & 0.0825 & 18 & 1.64 & 3.29 \\
\hline 9 & 0.329 & 0.0575 & 18.5 & 1.60 & 3.24 \\
\hline 12 & 0.344 & 0.045 & 19 & 1.56 & 3.21 \\
\hline 15 & 0.334 & 0.035 & 19 & 1.57 & 3.18 \\
\hline 18 & 0.344 & 0.03 & 19.5 & 1.54 & 3.16 \\
\hline 21 & 0.368 & 0.0275 & 20 & 1.49 & 3.14 \\
\hline 24 & 0.382 & 0.025 & 20.5 & 1.45 & 3.12 \\
\hline
\end{tabular}

The optimum solidity range (for this size rotor in this windspeed) is around $29-38 \%$ depending on the number of blades in the rotor. The optimum pitch is between $17-20$ degrees. Tip Speed Ratio optimums all look very similar $(1.45-1.75)$ in the cases studied.

It is now known which constant pitched designs will provide the best rotor power coefficients for this application. It must now be determined the smallest size rotor that can be used to achieve the required power to charge the radio batteries. For the case discussed in the above graphs $\left(R=0.5, V_{0}=2.54 \mathrm{~m} / \mathrm{s}\right)$ the power output for a 6 bladed turbine with a chord length of $0.0825 \mathrm{~m}$, and a constant pitch angle of 18 degrees (this is an optimum solidity setup taken from the model) is approximately $3.29 \mathrm{~W}$. This means that to achieve the required power output $(4 \mathrm{~W})$, with an unshrouded design, the rotor will have to be slightly larger than this. The following table displays rotor sizes required to achieve the needed power for several different windspeeds with an unshrouded, constant pitch rotor setup. 
Table 3 Fixed pitch optimum setups showing how small the rotor can be at each end of the windspeed range.

\begin{tabular}{|c|c|c|c|c|c|}
\hline \multicolumn{6}{|c|}{$V_{0}=2.54 \mathrm{~m} / \mathrm{s} R=0.55 \mathrm{~m}$} \\
\hline $\begin{array}{c}\text { Blade } \\
\text { number }\end{array}$ & Solidity & $\begin{array}{l}\text { Chord } \\
\text { (m) }\end{array}$ & $\begin{array}{l}\text { Pitch } \\
\text { (deg) }\end{array}$ & TSR & $\begin{array}{l}\text { Power } \\
\text { (watts) }\end{array}$ \\
\hline 3 & 0.278 & 0.16 & 16.5 & 1.777 & 4.09 \\
\hline 6 & 0.313 & 0.09 & 18 & 1.647 & 4.00 \\
\hline 9 & 0.326 & 0.0625 & 18.5 & 1.606 & 3.94 \\
\hline 12 & 0.330 & 0.0475 & 19 & 1.578 & 3.90 \\
\hline 15 & 0.347 & 0.04 & 19.5 & 1.534 & 3.86 \\
\hline 18 & 0.365 & 0.035 & 20 & 1.492 & 3.83 \\
\hline 21 & 0.365 & 0.03 & 20 & 1.492 & 3.81 \\
\hline 24 & 0.347 & 0.025 & 19.5 & 1.534 & 3.79 \\
\hline \multicolumn{6}{|c|}{$V_{0}=1.54 \mathrm{~m} / \mathrm{s} \quad \mathrm{R}=1.18 \mathrm{~m}$ (large) } \\
\hline $\begin{array}{c}\text { Blade } \\
\text { number }\end{array}$ & Solidity & $\begin{array}{c}\text { Chord } \\
\text { (m) }\end{array}$ & $\begin{array}{l}\text { Pitch } \\
\text { (deg) }\end{array}$ & TSR & $\begin{array}{l}\text { Power } \\
\text { (watts) }\end{array}$ \\
\hline 3 & 0.129 & 0.16 & 10.5 & 2.627 & 4.00 \\
\hline 6 & 0.259 & 0.16 & 16 & 1.838 & 4.13 \\
\hline 9 & 0.316 & 0.13 & 18 & 1.643 & 4.08 \\
\hline 12 & 0.324 & 0.1 & 18.5 & 1.608 & 4.04 \\
\hline 15 & 0.334 & 0.0825 & 19 & 1.572 & 4.00 \\
\hline 18 & 0.340 & 0.07 & 19 & 1.565 & 3.97 \\
\hline 21 & 0.354 & 0.0625 & 19.5 & 1.525 & 3.95 \\
\hline 24 & 0.356 & 0.055 & 19.5 & 1.523 & 3.93 \\
\hline \multicolumn{6}{|c|}{$V_{0}=.8 \mathrm{~m} / \mathrm{s} \quad \mathrm{R}=3.35 \mathrm{~m}$ (too large - unfeasible) } \\
\hline $\begin{array}{c}\text { Blade } \\
\text { number }\end{array}$ & Solidity & $\begin{array}{l}\text { Chord } \\
\text { (m) }\end{array}$ & $\begin{array}{l}\text { Pitch } \\
\text { (deg) }\end{array}$ & TSR & $\begin{array}{l}\text { Power } \\
\text { (watts) }\end{array}$ \\
\hline 3 & 0.046 & 0.16 & 5.5 & 4.107 & 3.62 \\
\hline 6 & 0.091 & 0.16 & 9 & 3.013 & 4.16 \\
\hline 9 & 0.137 & 0.16 & 11.5 & 2.497 & 4.38 \\
\hline 12 & 0.182 & 0.16 & 13.5 & 2.175 & 4.48 \\
\hline 15 & 0.228 & 0.16 & 15.5 & 1.929 & 4.53 \\
\hline 18 & 0.274 & 0.16 & 17 & 1.759 & 4.54 \\
\hline 21 & 0.319 & 0.16 & 18.5 & 1.615 & 4.53 \\
\hline 24 & 0.336 & 0.1475 & 19 & 1.569 & 4.51 \\
\hline
\end{tabular}

Table 3 displays optimum unshrouded rotor configurations for three different scenarios. In each case, the rotor size has been adjusted by trial and error to match the smallest size that will produce approximately 4 watts (at one or more of the setups). At the high end of the windspeed range, a rotor with radius $0.55 \mathrm{~m}$ provides the required 4 watts. At this windspeed, a 3 bladed rotor performs most efficiently. In the middle of the flow range $(1.54 \mathrm{~m} / \mathrm{s})$, the rotor must increase in size to achieve the same amount of power. A 
6 bladed rotor with a radius of $1.18 \mathrm{~m}$ provides the needed 4 watts at this windspeed. This rotor is on the verge of being too large to fit in the mine safely and efficiently. As can be imagined, when the airspeed drops even lower to $0.8 \mathrm{~m} / \mathrm{s}$ the rotor must be very large ( $3.35 \mathrm{~m}$ in radius) to achieve 4 watts. A rotor of this magnitude is not feasible as a solution for the application. It can be seen that the multibladed rotor configurations perform better at the low end of the velocity range. The rotors with less blades perform more efficiently at higher windspeeds. One issue with low blade number configurations is that to reach the optimum solidity the chord length must increase. With small wind turbines this could cause problems at the rotor hub. This issue will be addressed later in the design process if it proves troublesome once the diffuser shroud is added. Other important design parameters such as solidity, tip speed ratio (TSR) and pitch angle can be seen in Table 3 as well. TSR is a very common parameter used to analyze wind turbine rotor performance. The following three plots (Figures $22-24$ ) display relationships between TSR and $C_{p}$ at the three different wind speeds and rotor sizes that are discussed above. 


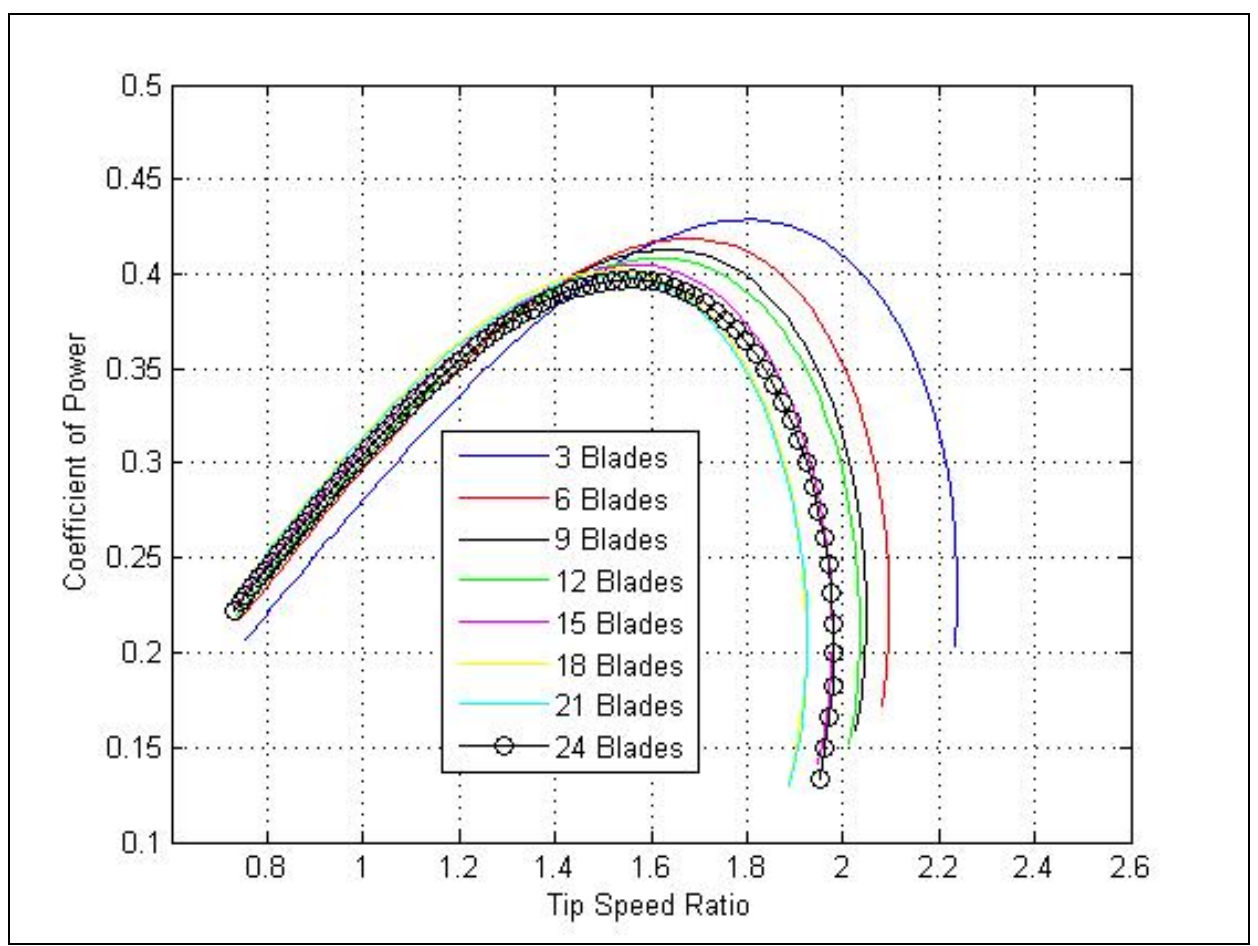

Figure 22 TSR vs. $C_{p}$ for a windspeed of $2.54 \mathrm{~m} / \mathrm{s}$ and a rotor radius of $0.55 \mathrm{~m}$

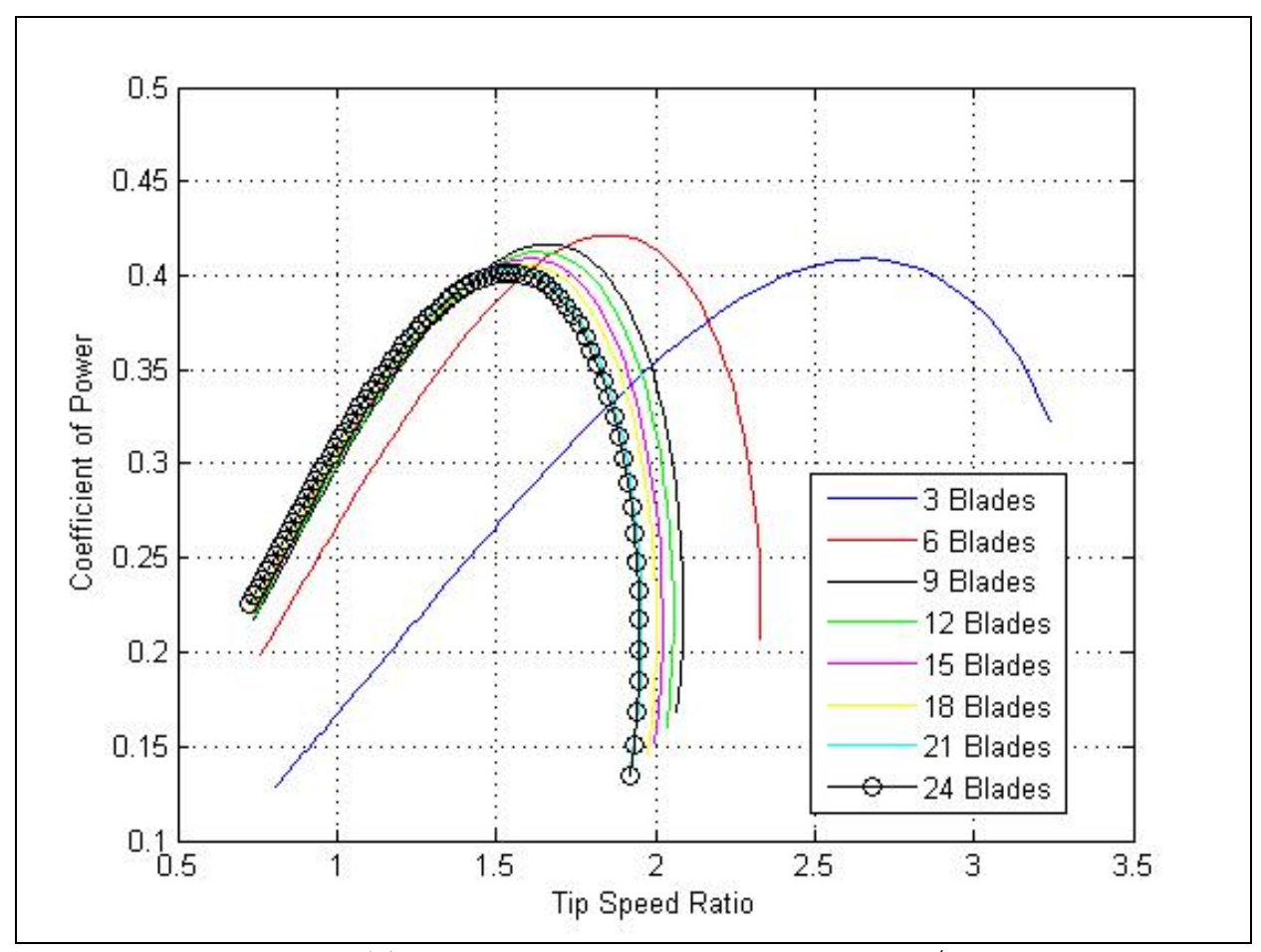

Figure 23 TSR vs. $C_{p}$ for a windspeed of $1.54 \mathrm{~m} / \mathrm{s}$ and a rotor radius of $1.18 \mathrm{~m}$ 


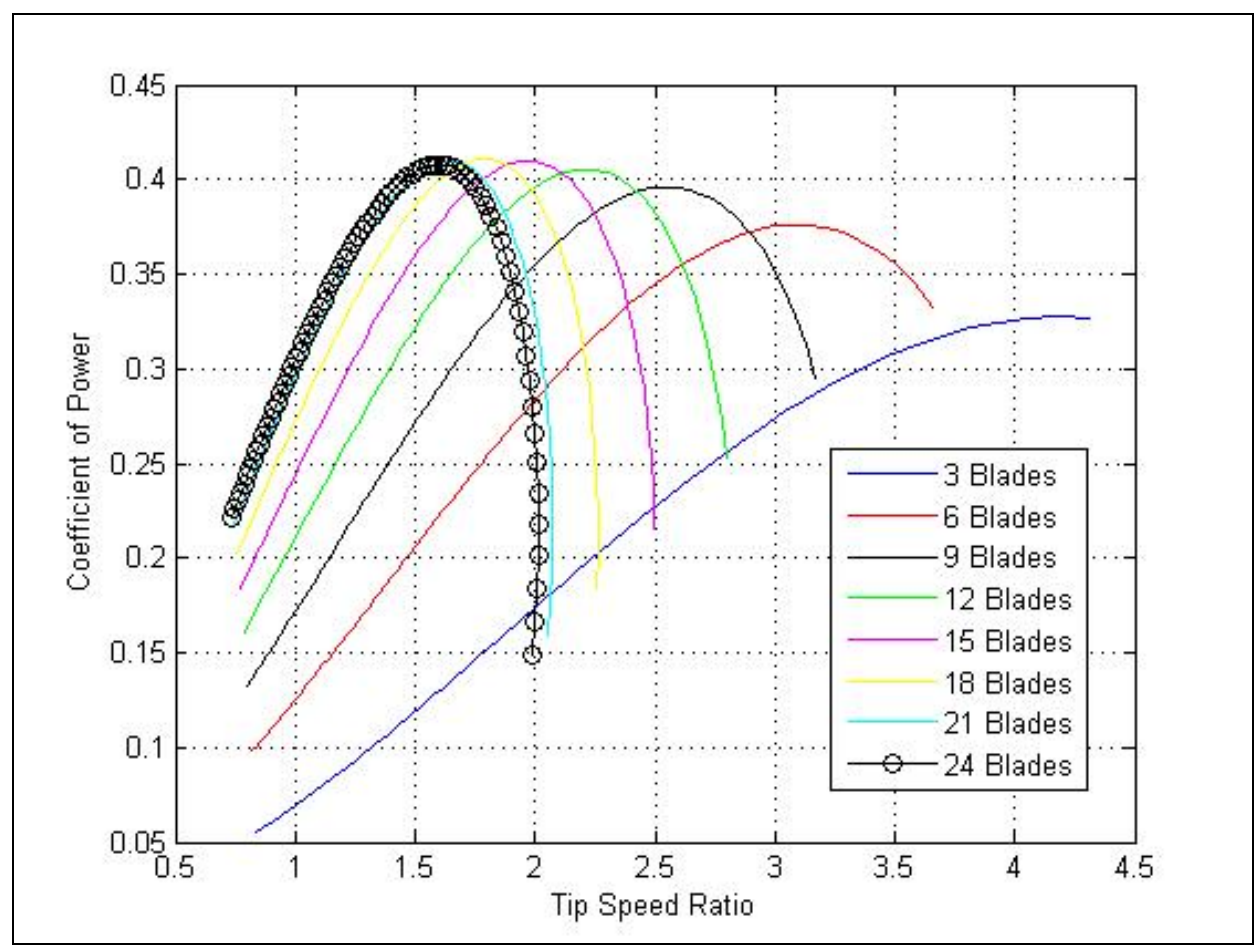

Figure 24 TSR vs. $\mathrm{C}_{\mathrm{p}}$ for a windspeed of $.8 \mathrm{~m} / \mathrm{s}$ and $\mathrm{a}$ rotor radius of $3.35 \mathrm{~m}$

It must be noted that the data on each of these curves is generated from varying the inflow angle (each a completely different rotor setup at one wind speed). This means that the data curves found in these three graphs cannot be compared to Figures 6 and 7 (from relevant research), which are generated for only one rotor configuration at varying tip speed ratios. The optimum cases in both studies can be compared, but the entire data curve cannot. Figures 22, 23 and 24 are meant only to provide insight into the data found in Table 3. From these three plots it can be seen that the optimum configurations with higher blade numbers can perform at lower tip speed ratios than that of the lower blade number setups. The peaks correspond to the optimum scenario (inflow angle and solidity) for that particular blade number. As stated earlier, these optimum scenarios are the cases displayed in Table 3.

All the above data is for constant pitched rotor blade designs. There exists an optimum pitch angle for each element that provides a $\max C_{p}$. If the blade is twisted to 
match each of these optimums then the blade will be more efficient. This type of distribution in normal wind turbine rotor blades is called ideal twist. The optimization model determines the optimum twist distribution for the rotors analyzed. Indeed, the power output of these configurations is higher than that of the constant pitched designs discussed earlier. Table 4 displays the optimum rotor configurations for a twisted blade at the high end of the airspeed range.

Table 4 Ideal twist optimums for a windspeed of 2.54 $\mathrm{m} / \mathrm{s}$ and a rotor radius of $0.535 \mathrm{~m}$

\begin{tabular}{|c|c|c|}
\hline \multicolumn{3}{|c|}{$\begin{array}{l}\text { Ideal twist optimum configurations }(\mathrm{R}=0.535, \mathrm{Vo}= \\
2.535)\end{array}$} \\
\hline Blade number & chord length (m) & Power (watts) \\
\hline 3 & 0.12 & 4.06 \\
\hline 6 & 0.0775 & 3.97 \\
\hline 9 & 0.055 & 3.90 \\
\hline 12 & 0.0425 & 3.85 \\
\hline 15 & 0.035 & 3.82 \\
\hline 18 & 0.03 & 3.79 \\
\hline 21 & 0.025 & 3.76 \\
\hline 24 & 0.0225 & 3.74 \\
\hline
\end{tabular}

With this type of setup, the size of the rotor required to provide 4 watts of power can be decreased slightly to around $0.535 \mathrm{~m}$. However, this reduction is not significant enough to provide feasible results at the lower end of the air velocity range. Figure 25 displays the optimum pitch over the blade for a 3 bladed rotor. This "ideal twist' plot is very similar for each of the blade number setups so only one figure needs to be shown. From Figure 25, the pitch at the blade root will be approximately 32 degrees and will twist gradually to about 11 degrees at the tip. 


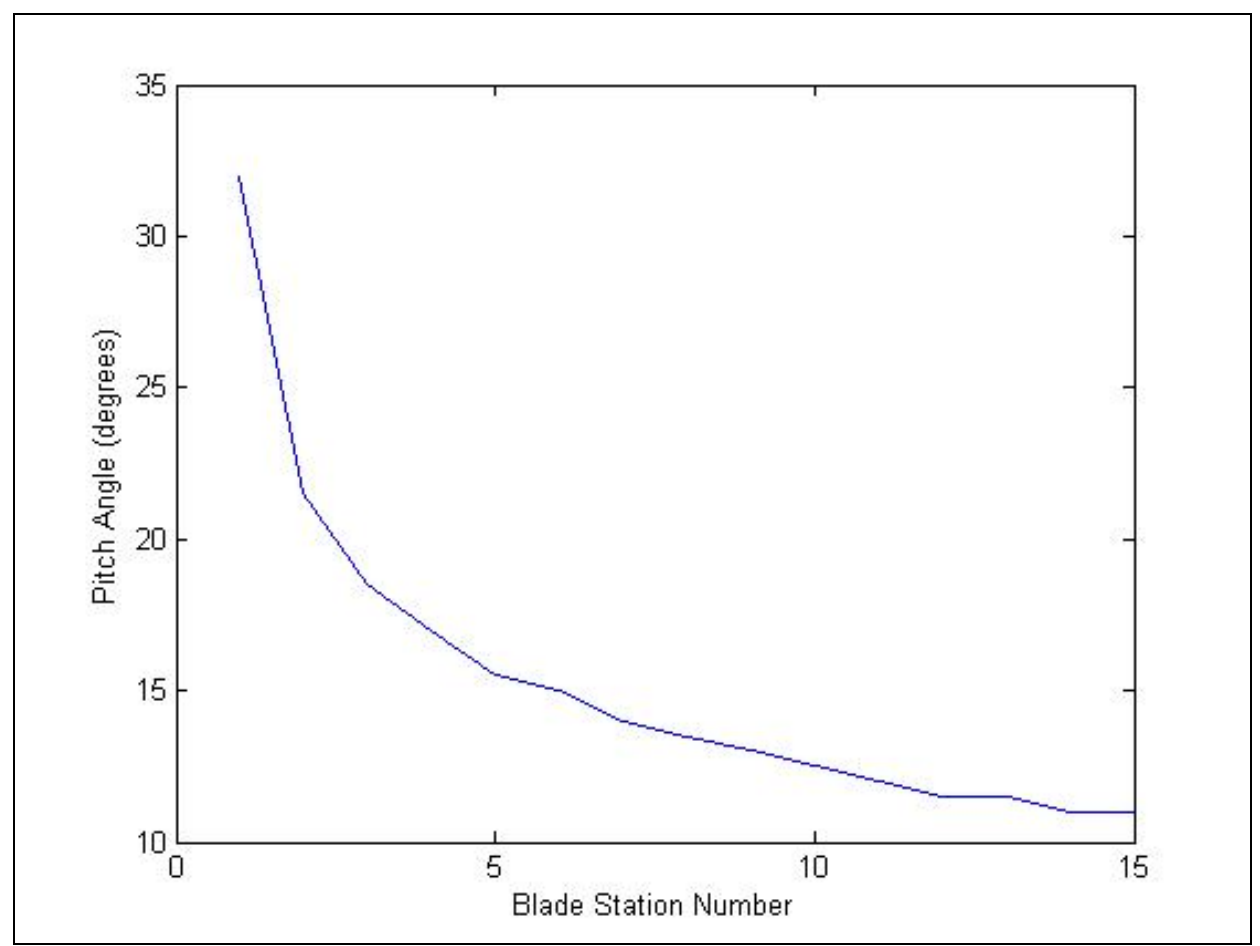

Figure 25 Optimum twist angle over the blade.

The size of the rotor required will decrease due to augmented airflow produced by the diffuser shroud. The diffuser assumed in the design is an annular wing with a profile similar to that shown in Figure 8. To be reasonable, no diffuser area ratios greater than 3 will be considered. Above this level the diffusion area ratio is very aggressive and will make the device too large for the application.

Now the results for a rotor setup including a diffuser shroud will be displayed and discussed. The following tables present the power output and physical parameters of some of the optimal rotor configurations for several different scenarios. For simplicity in the model, the rotors all have constant pitch and constant chord. No ideal twist rotors were analyzed in this section.

Table 5 displays the output from optimum setups found at a rotor radius of $0.38 \mathrm{~m}$ in the mid-range of the windspeed. The diffuser exit-area-to-nozzle-area ratio (DNA) is large in this example. However, none of the rotors can supply the amount of power required. 
Table 5 Optimal Rotors within a diffuser shroud.

\begin{tabular}{|c|c|c|c|c|c|c|c|}
\hline \multicolumn{10}{|c|}{ Vo $1.54 \mathrm{R}=0.38 \mathrm{~m}$} & $\begin{array}{c}\text { Diff. exit } \\
\text { Blade } \\
\text { number }\end{array}$ & Solidity & $\begin{array}{c}\text { Chord } \\
(\mathrm{m})\end{array}$ & $\begin{array}{c}\text { Pitch } \\
(\mathrm{deg})\end{array}$ & TSR & $\begin{array}{c}\text { Power } \\
\text { (watts) }\end{array}$ & $\begin{array}{c}\text { exit } \\
\text { radius(m) }\end{array}$ & $\begin{array}{c}\text { area } \\
\text { nozzle } \\
\text { area ratio }\end{array}$ \\
\hline 3 & 0.182 & 0.0725 & 24.5 & 1.49 & 2.18 & 0.5700 & 2.238 \\
\hline 6 & 0.201 & 0.04 & 26 & 1.40 & 2.13 & & \\
\hline 9 & 0.207 & 0.0275 & 26.5 & 1.37 & 2.09 & & \\
\hline 12 & 0.201 & 0.02 & 26.5 & 1.37 & 2.07 & & \\
\hline 15 & 0.220 & 0.0175 & 27.5 & 1.31 & 2.05 & & \\
\hline 18 & 0.226 & 0.015 & 28 & 1.29 & 2.03 & & \\
\hline 21 & 0.220 & 0.0125 & 27.5 & 1.31 & 2.02 & & \\
\hline 24 & 0.201 & 0.01 & 26.5 & 1.37 & 2.00 & & \\
\hline
\end{tabular}

In the next three cases, shown in Table 6, the DNA is kept constant, while both the rotor areas and the diffuser exit area are increased until the power required is reached. It is seen that a rotor of radius $0.515 \mathrm{~m}$ with a diffuser exit radius equaling about $0.77 \mathrm{~m}$ can produce the required power. This is an improvement from the unshrouded rotor by about $35 \%$ in overall size to produce the same amount of power at this windspeed. The optimal solidity and other parameters are also seen in the tables. 
Table 6 Optimal Rotors within a diffuser shroud (constant DNA mid-range velocity)

\begin{tabular}{|c|c|c|c|c|c|c|c|}
\hline \multicolumn{8}{|c|}{$\mathrm{Vo}=1.54 \mathrm{R}=0.4 \mathrm{~m}$} \\
\hline $\begin{array}{l}\text { Blade } \\
\text { number }\end{array}$ & Solidity & $\begin{array}{c}\text { Chord } \\
\text { (m) }\end{array}$ & $\begin{array}{l}\text { Pitch } \\
\text { (deg) }\end{array}$ & TSR & $\begin{array}{l}\text { Power } \\
\text { (watts) }\end{array}$ & $\begin{array}{l}\text { Diffuser } \\
\text { exit } \\
\text { radius }(m)\end{array}$ & $\begin{array}{c}\text { Diff. exit } \\
\text { area to } \\
\text { nozzle } \\
\text { area ratio }\end{array}$ \\
\hline 3 & 0.185 & 0.0775 & 24.5 & 1.48 & 2.42 & 0.5999 & 2.238 \\
\hline 6 & 0.191 & 0.04 & 25.5 & 1.43 & 2.36 & & \\
\hline 9 & 0.197 & 0.0275 & 26 & 1.40 & 2.32 & & \\
\hline 12 & 0.215 & 0.0225 & 27 & 1.34 & 2.30 & & \\
\hline 15 & 0.209 & 0.0175 & 27 & 1.34 & 2.27 & & \\
\hline 18 & 0.215 & 0.015 & 27.5 & 1.32 & 2.26 & & \\
\hline 21 & 0.209 & 0.0125 & 27 & 1.34 & 2.24 & & \\
\hline 24 & 0.239 & 0.0125 & 29 & 1.24 & 2.23 & & \\
\hline \multicolumn{8}{|c|}{$V_{o}=1.54 R=0.45 m$} \\
\hline $\begin{array}{c}\text { Blade } \\
\text { number }\end{array}$ & Solidity & $\begin{array}{c}\text { Chord } \\
(\mathrm{m})\end{array}$ & $\begin{array}{l}\text { Pitch } \\
\text { (deg) }\end{array}$ & TSR & $\begin{array}{l}\text { Power } \\
\text { (watts) }\end{array}$ & $\begin{array}{l}\text { Diffuser } \\
\text { exit } \\
\text { radius(m) }\end{array}$ & $\begin{array}{c}\text { Diff. exit } \\
\text { area to } \\
\text { nozzle } \\
\text { area ratio }\end{array}$ \\
\hline 3 & 0.180 & 0.085 & 24.5 & 1.49 & 3.07 & 0.6747 & 2.238 \\
\hline 6 & 0.191 & 0.045 & 25.5 & 1.43 & 3.00 & & \\
\hline 9 & 0.207 & 0.0325 & 26.5 & 1.37 & 2.95 & & \\
\hline 12 & 0.212 & 0.025 & 27 & 1.34 & 2.92 & & \\
\hline 15 & 0.212 & 0.02 & 27 & 1.34 & 2.89 & & \\
\hline 18 & 0.223 & 0.0175 & 27.5 & 1.31 & 2.87 & & \\
\hline 21 & 0.223 & 0.015 & 28 & 1.29 & 2.85 & & \\
\hline 24 & 0.212 & 0.0125 & 27.5 & 1.32 & 2.83 & & \\
\hline \multicolumn{8}{|c|}{$\mathrm{Vo}=1.54 \mathrm{R}=0.515 \mathrm{~m}$} \\
\hline $\begin{array}{c}\text { Blade } \\
\text { number }\end{array}$ & Solidity & $\begin{array}{c}\text { Chord } \\
(\mathrm{m})\end{array}$ & $\begin{array}{l}\text { Pitch } \\
\text { (deg) }\end{array}$ & TSR & $\begin{array}{l}\text { Power } \\
\text { (watts) }\end{array}$ & $\begin{array}{l}\text { Diffuser } \\
\text { exit } \\
\text { radius(m) }\end{array}$ & $\begin{array}{c}\text { Diff. exit } \\
\text { area to } \\
\text { nozzle } \\
\text { area ratio }\end{array}$ \\
\hline 3 & 0.176 & 0.095 & 24 & 1.52 & 4.04 & 0.7719 & 2.238 \\
\hline 6 & 0.195 & 0.0525 & 25.5 & 1.43 & 3.95 & & \\
\hline 9 & 0.195 & 0.035 & 25.5 & 1.43 & 3.89 & & \\
\hline 12 & 0.204 & 0.0275 & 26.5 & 1.37 & 3.84 & & \\
\hline 15 & 0.209 & 0.0225 & 27 & 1.34 & 3.81 & & \\
\hline 18 & 0.223 & 0.02 & 27.5 & 1.31 & 3.78 & & \\
\hline 21 & 0.227 & 0.0175 & 28 & 1.29 & 3.75 & & \\
\hline 24 & 0.223 & 0.015 & 28 & 1.29 & 3.73 & & \\
\hline
\end{tabular}

The lower blade number rotors again perform more efficiently than the higher blade numbers and the optimal solidities are all around $20 \%$. If the DNA is now increased to 3 , the rotor and the diffuser can decrease in size. 
Table 7 Optimal Rotors within a diffuser shroud (Fairly large DNA)

\begin{tabular}{|c|c|c|c|c|c|c|c|}
\hline \multicolumn{8}{|c|}{$\mathrm{Vo}=1.54 \mathrm{R}=0.34 \mathrm{~m}$} \\
\hline $\begin{array}{c}\text { Blade } \\
\text { number }\end{array}$ & Solidity & $\begin{array}{c}\text { Chord } \\
(\mathrm{m})\end{array}$ & $\begin{array}{l}\text { Pitch } \\
\text { (deg) }\end{array}$ & TSR & $\begin{array}{l}\text { Power } \\
\text { (watts) }\end{array}$ & $\begin{array}{l}\text { Diffuser } \\
\text { exit } \\
\text { radius(m) }\end{array}$ & $\begin{array}{c}\text { Diff. } \\
\text { exit } \\
\text { area to } \\
\text { nozzle } \\
\text { area } \\
\text { ratio }\end{array}$ \\
\hline 3 & 0.190 & 0.0675 & 25 & 1.45 & 4.18 & 0.5906 & 3.000 \\
\hline 6 & 0.197 & 0.035 & 26 & 1.40 & 4.08 & & \\
\hline 9 & 0.211 & 0.025 & 27 & 1.34 & 4.02 & & \\
\hline 12 & 0.225 & 0.02 & 28 & 1.29 & 3.97 & & \\
\hline 15 & 0.211 & 0.015 & 27 & 1.34 & 3.93 & & \\
\hline 18 & 0.211 & 0.0125 & 27 & 1.34 & 3.90 & & \\
\hline 21 & 0.246 & 0.0125 & 29 & 1.23 & 3.87 & & \\
\hline 24 & 0.225 & 0.01 & 28 & 1.29 & 3.85 & & \\
\hline
\end{tabular}

As expected, Table 7 shows that if the DNA is increased to 3 , the diffuser exit radius needed to produce $4 \mathrm{~W}$ is about $0.59 \mathrm{~m}$. This is a reasonably sized system for the underground mine application. Figure 26 illustrates the effects of increasing the diffuser exit area ratio on power output. 


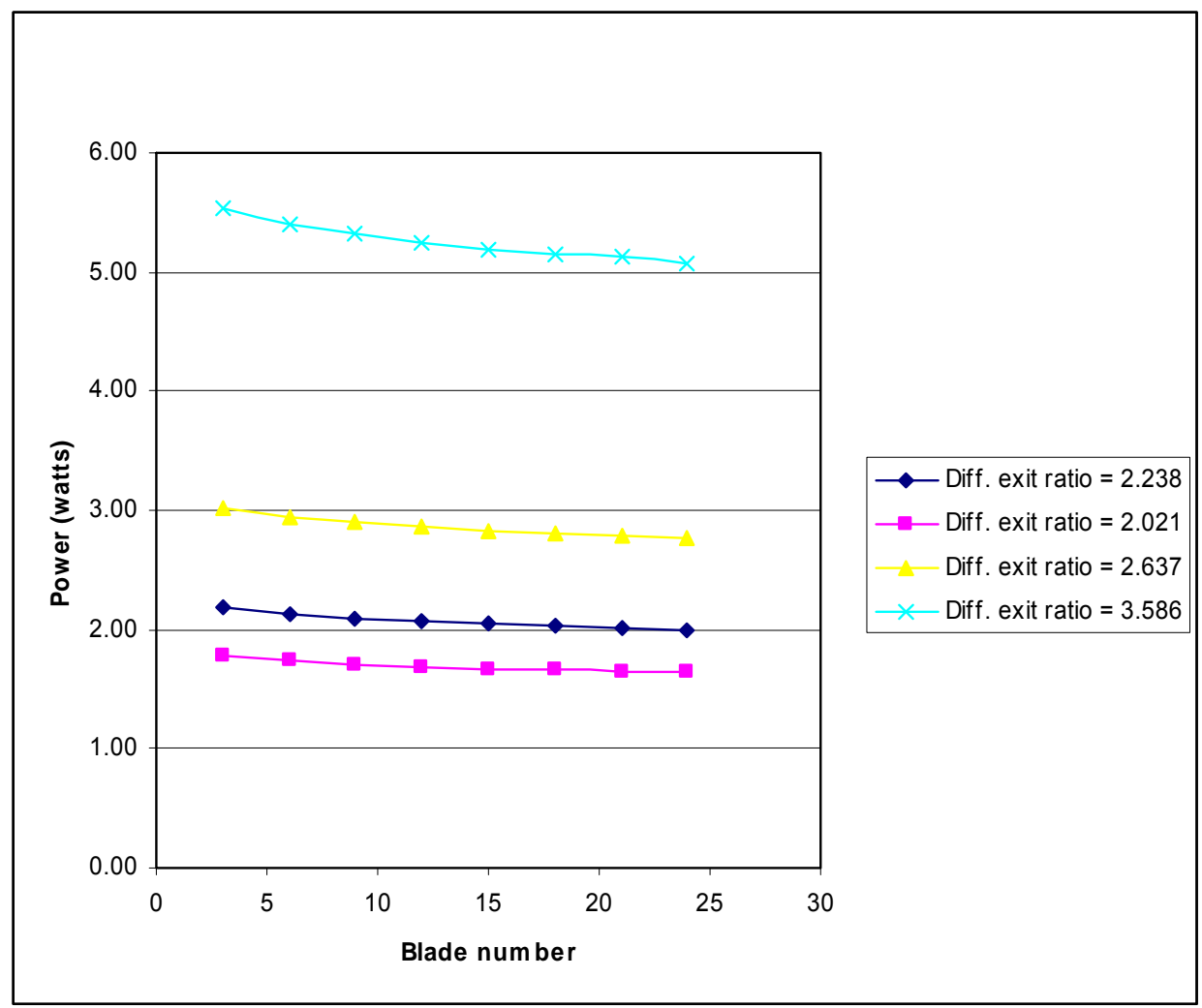

Figure 26 Varying DNA for a windspeed of $1.54 \mathrm{~m} / \mathrm{s}$ and a diffuser exit ratio of $0.57 \mathrm{~m}$.

Figure 26 also indicates that the power output is slightly higher for the lower blade number configurations.

It is obvious that the diffuser shroud presented in Table 7 will produce the required power in the upper half of the airspeed regime proposed for this application. It is also obvious that if the velocity drops below this range the rotor and diffuser exit size will have to increase. Table 8 shows parameters for rotors and a diffuser that meet power requirements at the lower end of the flow regime. 
Table 8 Optimal Rotors within a diffuser shroud (low end of velocity range)

\begin{tabular}{|c|c|c|c|c|c|c|c|}
\hline \multicolumn{10}{|c|}{$\begin{array}{c}\text { Blade } \\
\text { number }\end{array}$} & Solidity & $\begin{array}{c}\text { Chord } \\
(\mathrm{m})\end{array}$ & $\begin{array}{c}\text { Pitch } \\
(\mathrm{deg})\end{array}$ & TSR & $\begin{array}{c}\text { Power } \\
(\text { watts })\end{array}$ & $\begin{array}{c}\text { Diffuser } \\
\text { exit } \\
\text { radius }(\mathrm{m})\end{array}$ & $\begin{array}{c}\text { Diff. exit area } \\
\text { to nozzle } \\
\text { area ratio }\end{array}$ \\
\hline 3 & 0.170 & 0.16 & 23.5 & 1.55 & 4.15 & 1.5606 & 3.000 \\
\hline 6 & 0.196 & 0.0925 & 25.5 & 1.42 & 4.05 & & \\
\hline 9 & 0.199 & 0.0625 & 26 & 1.40 & 3.99 & & \\
\hline 12 & 0.212 & 0.05 & 27 & 1.34 & 3.95 & & \\
\hline 15 & 0.212 & 0.04 & 27 & 1.34 & 3.91 & & \\
\hline 18 & 0.207 & 0.0325 & 27 & 1.35 & 3.88 & & \\
\hline 21 & 0.223 & 0.03 & 28 & 1.29 & 3.86 & & \\
\hline 24 & 0.212 & 0.025 & 27.5 & 1.32 & 3.83 & & \\
\hline
\end{tabular}

A significant increase in rotor size and diffuser exit is needed in order to meet power requirements in the low end of the velocity range. However, the design size could possibly be feasible in large mine entries.

It is obvious after sifting through all the data that there is not one single "most efficient" design that should be used to solve this problem. There are several solutions that stick out above the rest. Based on the data presented, Table 9 displays a summary of the most efficient designs recommended for usage in the solution of this problem.

Table 9 Final optimum design parameters.

\begin{tabular}{|c|c|c|c|c|c|c|c|}
\hline & $\begin{array}{l}\text { Blade } \\
\text { Number }\end{array}$ & Solidity & $\begin{array}{c}\text { Pitch } \\
\text { (deg) }\end{array}$ & $\begin{array}{c}\text { Axial } \\
\text { Int. } \\
\text { Factor } \\
\text { (a) }\end{array}$ & TSR & Cp & $\begin{array}{l}\text { Diffuser } \\
\text { exit area } \\
\text { to nozzle } \\
\text { area }\end{array}$ \\
\hline $\begin{array}{c}\text { Constant } \\
\text { pitch }\end{array}$ & 6 & $\begin{array}{c}18-22 \\
\%\end{array}$ & $24-25$ & $\sim 0.331$ & $\sim 1.4$ & 0.42 & 2 to 3 \\
\hline $\begin{array}{c}\text { w/Pitch } \\
\text { Distributio } \\
\mathrm{n}\end{array}$ & 6 & $\begin{array}{c}18-22 \\
\%\end{array}$ & $34-13$ & $\sim 0.331$ & $\sim 1.7$ & 0.42 & 2 to 3 \\
\hline
\end{tabular}

By designing a shrouded rotor that meets (or comes close) these parameters, it is possible to achieve the desired power output to charge radio batteries in an underground mine. $\mathrm{A}$ picture of a rotor/diffuser system (that will look similar to the system explained here) can be found in Appendix B. Since no specific mine was designed for, a concrete rotor/diffuser 
size cannot be determined. However, the model developed in this study is readily capable of producing specific results for any of the applications as described.

\subsection{Comparison of Results to Other Experiments/Theory}

Duquette [22] finds optimal solidities of $20-25 \%$ at $C_{p}$ 's of around 0.44 using BEM convergence method on a 12 bladed rotor for windspeeds of $5 \mathrm{~m} / \mathrm{s}$. These values are comparable to the values found in the study at hand. For an unshrouded 12 bladed rotor, optimal solidities of around $30 \%$ are found, with $C_{p}$ values around 0.4 . For the shrouded case, the optimal solidity is in this $20-25 \%$ range. Differences accrue due to the different windspeeds in the two experiments and the slightly different methodologies (convergence vs. analytical) used in the calculations of rotor parameters.

Buerskens [14] finds an optimal tip speed ratio of about $1.8\left(C_{p}=0.4\right)$ for the 6 bladed CWD $2740(1.37 \mathrm{~m}$ in radius) rotor by using both experimental data and BEM. The plot from Buerskens's research can be found in Figure 7 of the present document. The findings match almost exactly the optimum found in Figure 23 and Table 3 for a six bladed rotor with a radius of $1.18 \mathrm{~m}$. These findings validate the methodologies used in developing the present research and are displayed in Table 10.

Table 10 Comparison of unshrouded BEM (theoretical and experimental) results from related studies.

\begin{tabular}{|c|c|c|c|c|c|c|c|}
\hline & $\begin{array}{l}\text { Blade } \\
\text { Number }\end{array}$ & Solidity & $\begin{array}{l}\text { Pitch } \\
\text { (deg) }\end{array}$ & $\begin{array}{c}\text { Rotor } \\
\text { radius } \\
(\mathrm{m})\end{array}$ & $\begin{array}{c}\text { Wind- } \\
\text { speed } \\
(\mathrm{m} / \mathrm{s})\end{array}$ & TSR & $\mathrm{Cp}$ \\
\hline $\begin{array}{l}\text { Buerskens [14] } \\
\text { (experimental) }\end{array}$ & 6 & $46 \%$ & $\begin{array}{c}28.4- \\
17.3\end{array}$ & 1.37 & $\sim 7$ & $2^{*}$ & 0.395 \\
\hline $\begin{array}{c}\text { Rijs \& } \\
\text { Smulders [8] }\end{array}$ & 6 & $46 \%$ & $\begin{array}{c}28.4- \\
17.3\end{array}$ & 1.37 & $\sim 7$ & $1.8^{*}$ & 0.41 \\
\hline Duquette [22] & 12 & $25 \%$ * & $11.5^{*}$ & 1 & 8 & $\begin{array}{c}2.75 \\
*\end{array}$ & 0.43 \\
\hline Duquette [22] & 3 & $15 \%$ * & 9 * & 1 & 8 & $3.9^{*}$ & 0.39 \\
\hline Current Study & 12 & $32 \%$ * & $18.5^{*}$ & 1.18 & 1.54 & $1.6^{*}$ & 0.42 \\
\hline Current Study & 6 & $25 \%$ * & 16 * & 1.18 & 1.54 & $1.8^{*}$ & 0.43 \\
\hline Current Study & 3 & $13 \%$ * & $10.5^{*}$ & 1.18 & 1.54 & $2.6^{*}$ & 0.41 \\
\hline Current Study & 6 & $25 \%$ * & $15.5^{*}$ & 1 & 8 & $1.9^{*}$ & 0.44 \\
\hline
\end{tabular}


The * in Table 10 denotes an optimal value found for the particular blade number configuration. The optimum solidity, TSR and $C_{p}$ are very similar between the compared studies for unshrouded turbines and the results from current study. Differences can be accounted to variations in the airfoil/blade cross-sections used for each study and the absence of tip loss corrections in the current study. 


\section{CONCLUSIONS}

A numerical study was conducted in order to determine the feasibility of, and if possible, the optimum design of a wind turbine system to charge radio batteries in underground mines. The study found that the concept is indeed feasible and determined the optimum parameters needed to design such a device. The device will provide communication power in emergency situations and can potentially save human lives.

The optimization model developed in the study suggests using a final rotor design containing 6 blades, with a solidity of approximately $20 \%$. The 6 blade rotor configuration performed efficiently in the middle of the windspeed range. A 3 blade setup is also productive, but the cut-in windspeed (speed that the rotor begins to produce power) of a higher bladed rotor will be lower $[5,16,25]$. This is more beneficial to the application. A diffuser shroud must surround the rotor for structural integrity and safety as well as to augment the power of the system. The shroud should consist of an annular wing that tapers outward (diffuses) at its exit. The diffuser exit area should be 2- 3 times larger than the area of the nozzle (where the rotor is located). The rotor blades can have constant pitch and chord, although a small increase in power will be noticed if the blades utilize ideal twist. The rotor should be designed to operate in tip speed ratios around 1.5. Under these conditions the rotor will see coefficients of power of approximately 0.4 . Although this was not a full scale design operation, the concept has been numerically verified and further work must be done toward realizing such an innovative notion. 


\section{FUTURE WORK}

The research presented in this document should be verified experimentally. Full scale models including the diffuser shroud should be built and tested. A wind tunnel capable of achieving low constant speeds without undulations is needed to successfully verify the theoretical methods involved. The prototype should be tested in a mine as well. Computational Fluid Dynamics (CFD) could also be used to verify the results of the study.

Several factors are neglected in this study that may affect its overall outcome. No load on the rotor has been considered. The required power to charge the batteries is actually $2 \mathrm{~W}$, it is assumed that $2 \mathrm{~W}$ will be lost to electrical equipment, friction, etc.. This is where the required power of $4 \mathrm{~W}$ comes from. An electric generator that provides a load should be factored into the design. Also, cut-in windspeed was not analyzed. This could be very significant to this project. It was simply assumed that the rotor was load free until it started to rotate and that once it had started, the load (from the generator) could be applied. Tip losses in the model were neglected because the shroud significantly reduces them, but for design of unshrouded models (for other applications), finite wing theory (or some other tip loss theory) should be applied to the numerical model. The optimization model should be tweaked into a user friendly, graphical user interface (GUI) capable of producing the desired outputs for an optimum design after just a few clicks of a mouse.

It is felt that data for the high blade number designs analyzed may be skewed. The rotor size dealt with in this study is fairly small compared to other multibladed designs. A rotor of this size with this many blades should have a very high blockage factor. The induced forces, turbulence and air disturbances associated with this type of configuration will most likely cause rapid deterioration of the performance of the particular setup. This 
speculation should be verified with wind tunnel testing and corrections should be made to the model.

The effects of the diffuser back pressure velocity ratio, $\gamma$, should be analyzed both theoretically and experimentally. If the pressure in the exit of the diffuser is lower than the ambient pressure or $(\gamma \geq 1)$, the power augmentation of the system will increase[17,20]. This will increase the efficiency of the system.

Only the curved thin plate was analyzed as the blade cross-section in this study. Testing has been performed on some airfoils at low Reynolds numbers[23,33,34]. These studies should be searched to find the most efficient airfoil profiles for this application. 


\section{REFERENCES}

[1] Eggleston, David M., and Forrest S. Stoddard. Wind Turbine Engineering Design. New York: Van Nostrand Reinhold Company, 1987.

[2] "Standards for Underground Coal Mining." MSHA Federal Register Document, Rules and Regulations. 10 June 1996. Mine Safety and Health Administration. 17 Jan 2008 <http://www.msha.gov/REGS/FEDREG/FINAL/1996FINL/5453(1).htm>.

[3] "MSHA - Code of Federal Regulations." Title 30 CFR 75.325. June 27 1997. Mine Safety and Health Administration. 20 Jan 2008 <http://www.msha.gov/30cfr/75.325.htm>.

[4] Wortman, Andrize J.. Introduction to Wind Turbine Engineering. Boston: Butterworth Publishers, 1983. pp. 1.

[5] Wolff, Ben. Wind Energy. Philadelphia: The Franklin Institute Press, 1978. pp. 19.

[6] "Aermotor and Fiasa Windmills." Dean Bennett Supply. 10 Oct. 2006. 20 Feb 2008 $<$ http://www.aermotorwindmills.com/windmills.htm>.

[7] Duquette, Matthew, Kenneth Visser, and "Numerical Implications of Solidity and Blade Number on Rotor Performance of Horizontal Axis Wind Turbines ." Journal of Solar Energy Engineering Vol. 123(2003): 423-432.

[8] Rijs, R.P.P, and P.T. Smulders. "Blade Element Theory for Performance Analysis of Slow Running Wind Turbines." Wind Engineering Vol. 14(1990): 62-79.

[9] Wilson, R.E., B.S. Lissaman, and S.N. Walker. "Aerodynamic Performance of Wind Turbines." Oregon State University(1976).

[10] Jones, C.N.. "Blade Element Performance in Horizontal-Axis Wind Turbine Rotors.." Wind Engineering Vol. 7(1983): 129-137.

[11] Curvers, T.. "A Graphical Method for Calculating Wind Rotor Characteristics." Report R 257-S (Wind Energy Group)(1976).

[12] Smulders, P.T., J.W. Cleijne, Cong Xianzi, and Wang Xibo(CARDC). "CWD 2000 Windpump Tested Full Scale in CARDC 12m x 16m windtunnel." EWEC. Glasgow, U.K. (1989).

[13] Cleijne, J.W., and W. Van Helden. "Benchmark Test of Power Curve Computations, Final Report on the CWD Contribution." Report R 833-D(1986):

[14] Beurskens, H.J.M., and A.J.F.K. Hageman. "Low Speed Water Pumping Windmills: Rotor Tests and Overall Performance." 3rd Int. Symp. on Wind En. Syst. Cranfield U.K. (Aug. 26-29, 1980).

[15] Lilley, G.M., and W.J. Rainbird. A Preliminary Report on the Design and Performance of Ducted Windmills. Report 102. Cranfiel U.K.: 1956.

[16] Hau, Erich. Wind Turbines - Fundamentals, Technologies, Application, Economics. 2nd edition. Berlin: Springer, 2006.

[17] Igra, Ozer. "Research and Development for Shrouded Wind Turbines." Energy Cons. Management Vol. 21(1981): 13-48.

[18] Gilbert , B.L., R.A. Oman, and K.M. Foreman. "Fluid Dynamics of Diffuser-Augmented Wind Turbines." Journal of Energy Vol. 2(1976): 368-374.

[19] Werle, M.J., and W.M. Presz, Jr.. "Ducted Wind/Water Turbines and Propellers Revisited." FLODESIGN, INC.

[20] Van Bussel, Gerard J.W.. "The Science of Making More Torque from Wind: Diffuser Experiments and Theory Revisited.." Journal of Physics: Conference Series 75(2007): 1-12.

[21] Glauert, H.. Aerodynamic Theory (W.F. Durand, Ed). Division L, Vol. IV. New York: Dover Publications, Inc, 1963.

[22] Duquette, Matthew. "The Effect of Solidity an Blade Number on the Aerodynamic Performance of Small Horizontal Axis Wind Turbines."Clarkson University. Masters Thesis. 2002. 
[23] Hageman, A.J.F.K. "Catalogue of Aerodynamic Characteristics of Airfoils in the Reynolds number Range 10^4-10^6." Report R 433-D(1980).

[24] Van Bussel, G.J.W.. "An Assessment of the Performance of Diffuser Augmented Wind Turbines." 3rd ASME/JSME Fluid Engineering Conference FEDSM99-7830, San Fransico(1999).

[25] Khan, M.A., and K.D. Visser. "On Adapting a Small PM Wind Generator for a Multiblade, High Solidity Wind Turbine." IEEE Transactions on Energy Conversion TEC-00332-2003(2003).

[26] Sanuki, M.. "Studies On Biplane Wind Vanes Ventilator Tubes And Cup Anenometers." Papers in Meterology and Geophysics (Japan) Vol. 1, No. 2-4(1950): 279-290.

[27] Iwasaki, M.. "The Experimental and Theoretical Investigation of Windmills." Rep. Res. Inst. App. Mech. (Japan) Vol. 2, No. 8(1953).

[28] Igra, O.. "Shrouds for Aerogenerators." AIAA Journal, presented at the AIAA 14th Aerospace Conference Vol. 76-181(1976): 1481-1483.

[29] Hansen, M.O.L., N.N. Sorenson, and R.G.J. Flay. "Effect of Placing a Diffuser around a Wind Turbine." Wind Engineering Vol. 3(2000): 207-213.

[30]Hampsey, Mark. "Multiobjective Evolutionary Optimisation of Small Wind Turbine Blades."University of Newcastle. Ph.D. Dissertation. 2002.

[31] Glauert, H.. The Elements of Aerofoil and Airscrew Theory. New York: The Macmillan Company, 1943.

[32]Spera, D.A. (ed.). Wind Turbine Technology. New York: American Society of Mechanical Engineers, 1995.

[33] Selig, M., B. McGranahan, and B. Broughton. "UIUC Low-Speed Airfoil Tests." 2001. 2 Apr 2008 $<$ http://amber.aae.uiuc.edu/ m-selig/uiuc_lsat.html>.

[34] Laitone, E.V.. "Aerodynamic Lift at Reynolds Numbers below 7x104." AIAA Journal 34(9)(1996): 1941-1943.

[35] "Information About Diffuser Windsystems." Concentrating Wind Systems - Sense or Nonsense. 20 May 1997. 15 Apr 2008 <http://www.ifb.uni-stuttgart.de/ doerner/diffuser.html>. 


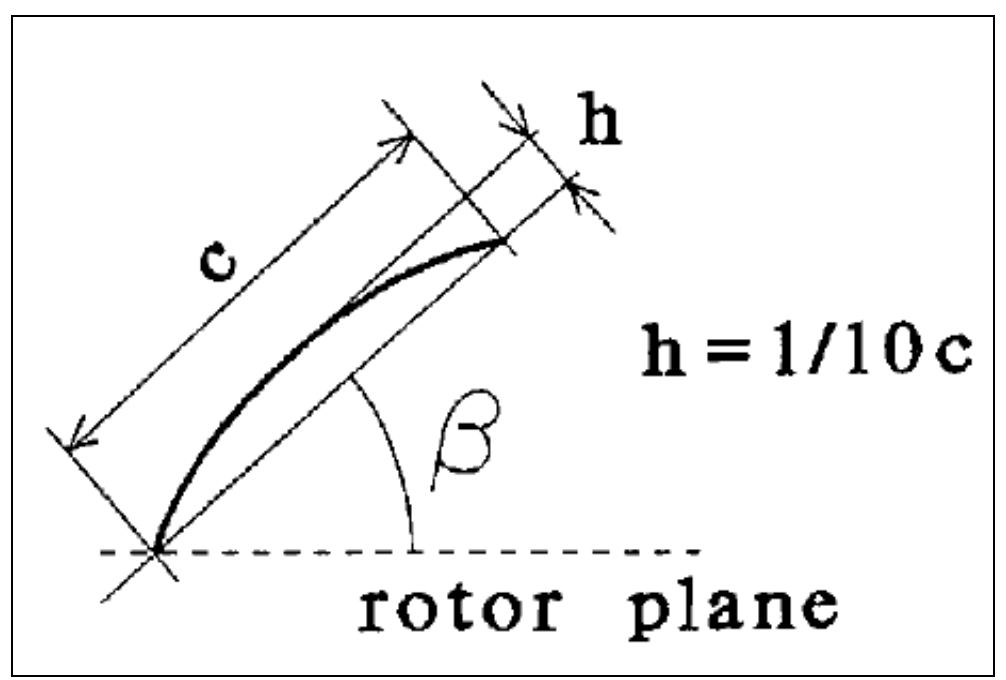

Figure 27 Curvature of blade used in calculations[8].

Table 11 Profile characteristics for curved plate at $\mathrm{Re}=$ 100000 [23].

\begin{tabular}{|c|c|c|}
\hline \multicolumn{3}{|c|}{$10 \%$ curv., no tube } \\
\hline$\alpha$ & $\mathrm{C}_{1}$ & $\mathrm{C}_{\mathrm{d}}$ \\
\hline-10.0 & -0.291 & 0.119 \\
\hline-8.0 & -0.309 & 0.107 \\
\hline-7.0 & -0.337 & 0.100 \\
\hline-6.0 & -0.365 & 0.093 \\
\hline & -0.393 & 0.085 \\
\hline & -0.200 & 0.073 \\
\hline 0.0 & 0.271 & 0.066 \\
\hline 2.0 & 0.652 & 0.069 \\
\hline 4.0 & 0.861 & 0.078 \\
\hline 6.0 & 1.315 & 0.057 \\
\hline 8.0 & 1.394 & 0.078 \\
\hline 10.0 & 1.448 & 0.101 \\
\hline 12.0 & 1.474 & 0.135 \\
\hline 13.0 & 1.452 & 0.182 \\
\hline 15.0 & 1281 & 0.283 \\
\hline 20.0 & 1.177 & 0.399 \\
\hline 25.0 & 1.260 & 0.550 \\
\hline 30.0 & 1.364 & 0.741 \\
\hline 45.0 & 1.313 & 1.268 \\
\hline 60.0 & 0.983 & 1.660 \\
\hline 75.0 & 0.496 & 1.822 \\
\hline 85.0 & 0.169 & 1.920 \\
\hline 90.0 & 0.000 & 1.927 \\
\hline
\end{tabular}




\section{APPENDIX B:ADDITIONAL FIGURES AND DATA}

The following figures display the relationship between blade number, chord length and rotor coefficient of power. Each graph shows the solution set for a different in-flow angle. The purpose of the display is to show how the solution optimums (ridge) change over the spectrum of in-flow angles. The index numbers read from the graph correspond to actual values of blade numbers and chord lengths. The corresponding indices are found in Table 12.

Table 12 Index and corresponding values

\begin{tabular}{|c|c|c|c|}
\hline Chord Index & Chord Length $(\mathrm{m})$ & Blade Index & Blade number \\
\hline 1 & 0.005 & 1 & 3 \\
\hline 2 & 0.0075 & 2 & 6 \\
\hline 3 & 0.01 & 3 & 9 \\
\hline 4 & 0.0125 & 4 & 12 \\
\hline 5 & 0.015 & 5 & 15 \\
\hline 6 & 0.0175 & 6 & 18 \\
\hline 7 & 0.02 & 7 & 21 \\
\hline 8 & 0.0225 & 8 & 24 \\
\hline 9 & 0.025 & & \\
\hline 10 & 0.0275 & & \\
\hline 11 & 0.03 & & \\
\hline 12 & 0.0325 & & \\
\hline 13 & 0.035 & & \\
\hline 14 & 0.0375 & & \\
\hline 15 & 0.04 & & \\
\hline 16 & 0.0425 & & \\
\hline 17 & 0.045 & & \\
\hline 18 & 0.0475 & & \\
\hline 19 & 0.05 & & \\
\hline 20 & 0.0525 & & \\
\hline 21 & 0.055 & & \\
\hline 22 & 0.0575 & & \\
\hline 23 & 0.06 & & \\
\hline 24 & 0.0625 & & \\
\hline 25 & 0.065 & & \\
\hline 26 & 0.0675 & & \\
\hline 27 & 0.07 & & \\
\hline 28 & 0.0725 & & \\
\hline 29 & 0.075 & & \\
\hline 30 & 0.0775 & & \\
\hline 31 & 0.08 & & \\
\hline 32 & 0.0825 & & \\
\hline 33 & 0.085 & & \\
\hline
\end{tabular}




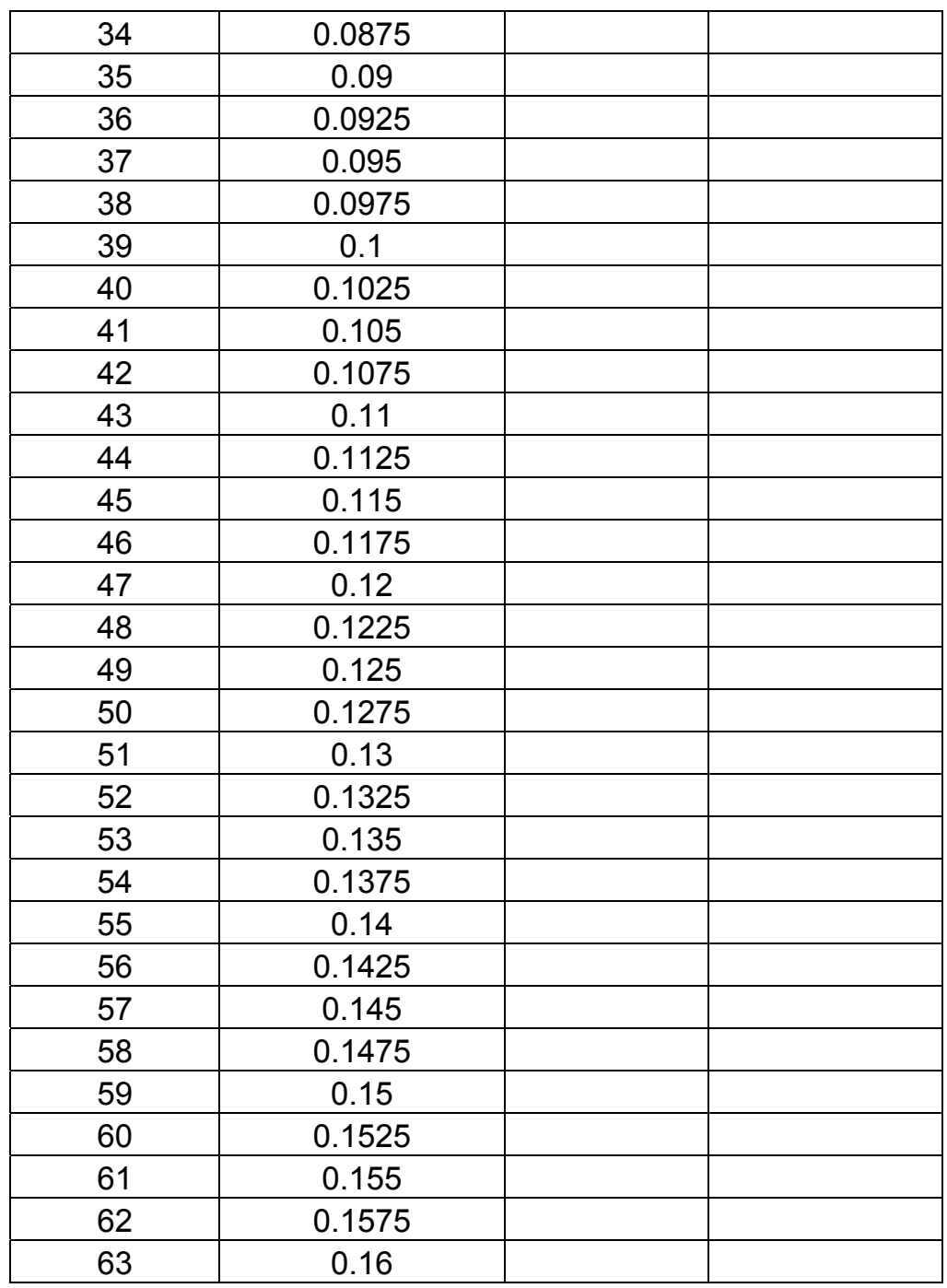




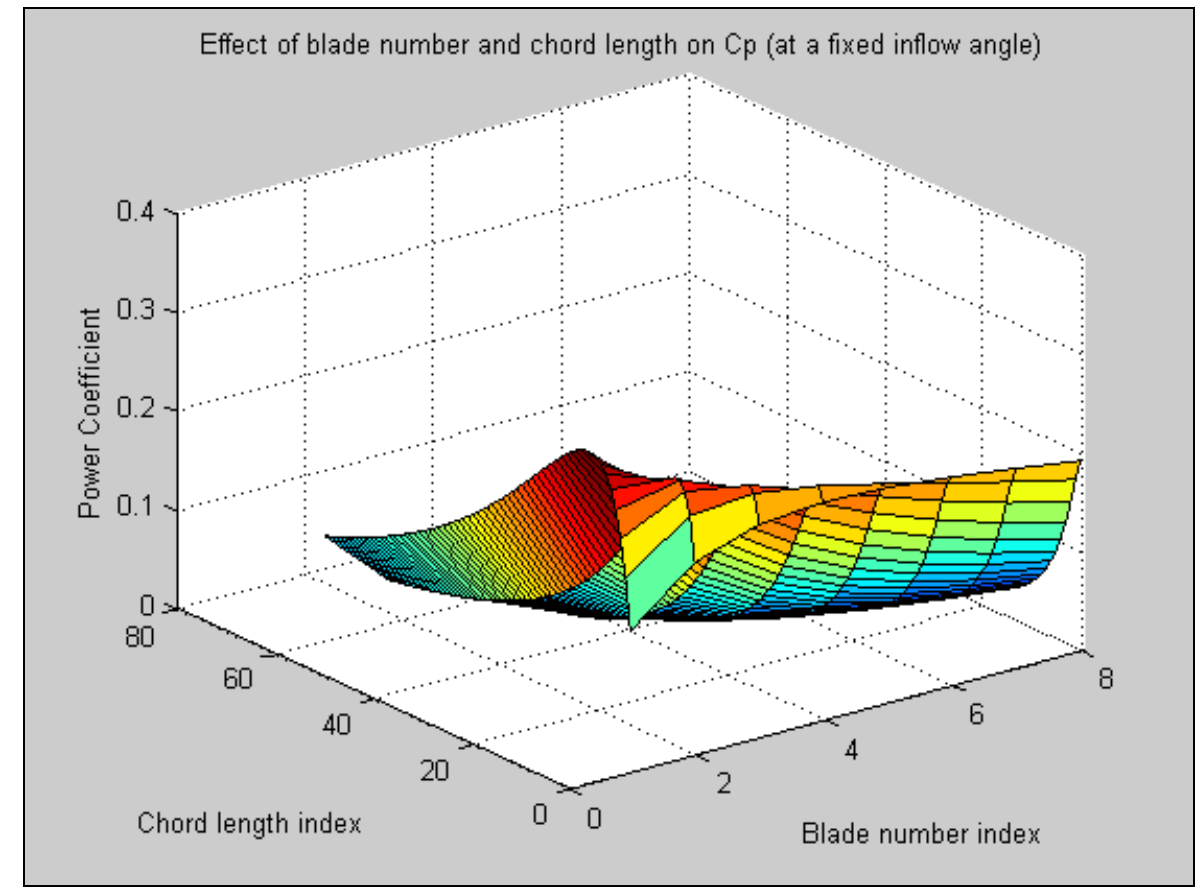

Figure 28 In-flow angle $=10$ degrees.

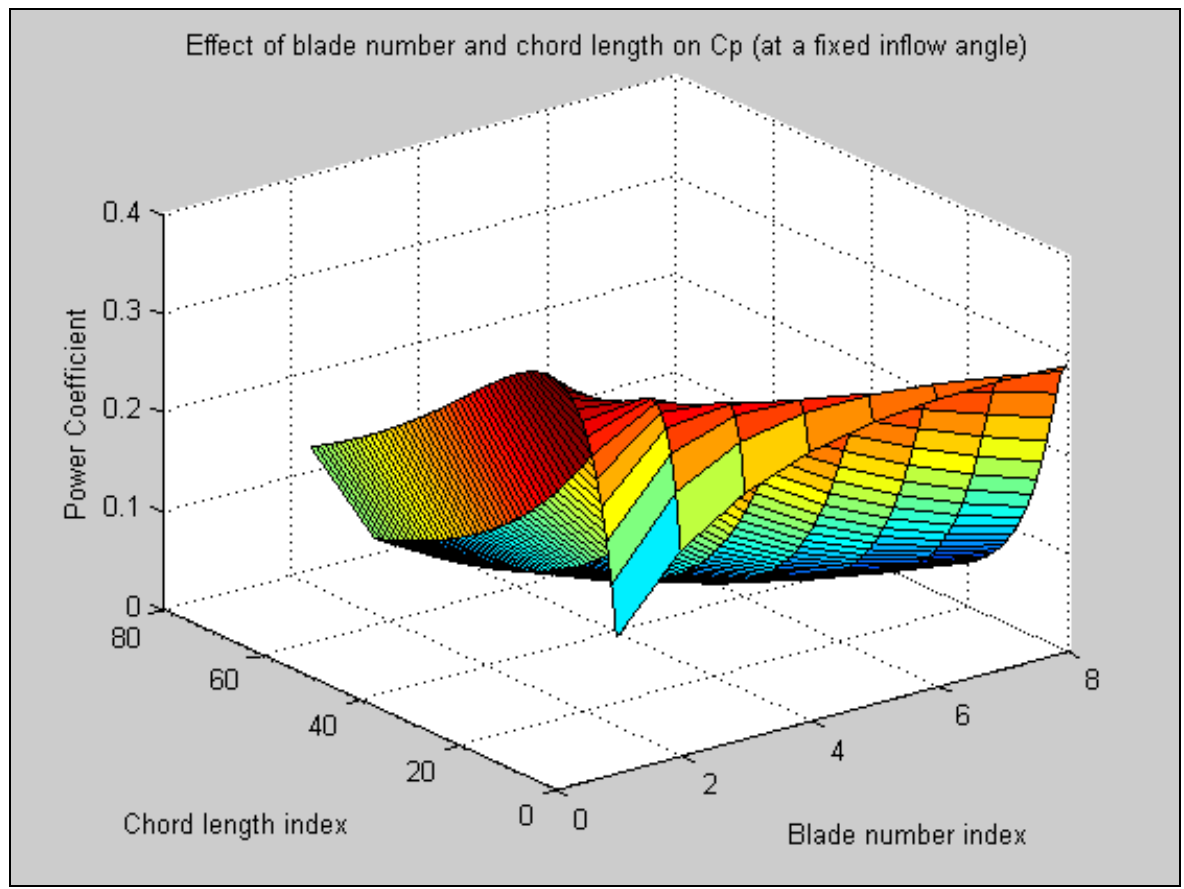

Figure 29 In-flow angle $=13$ degrees 


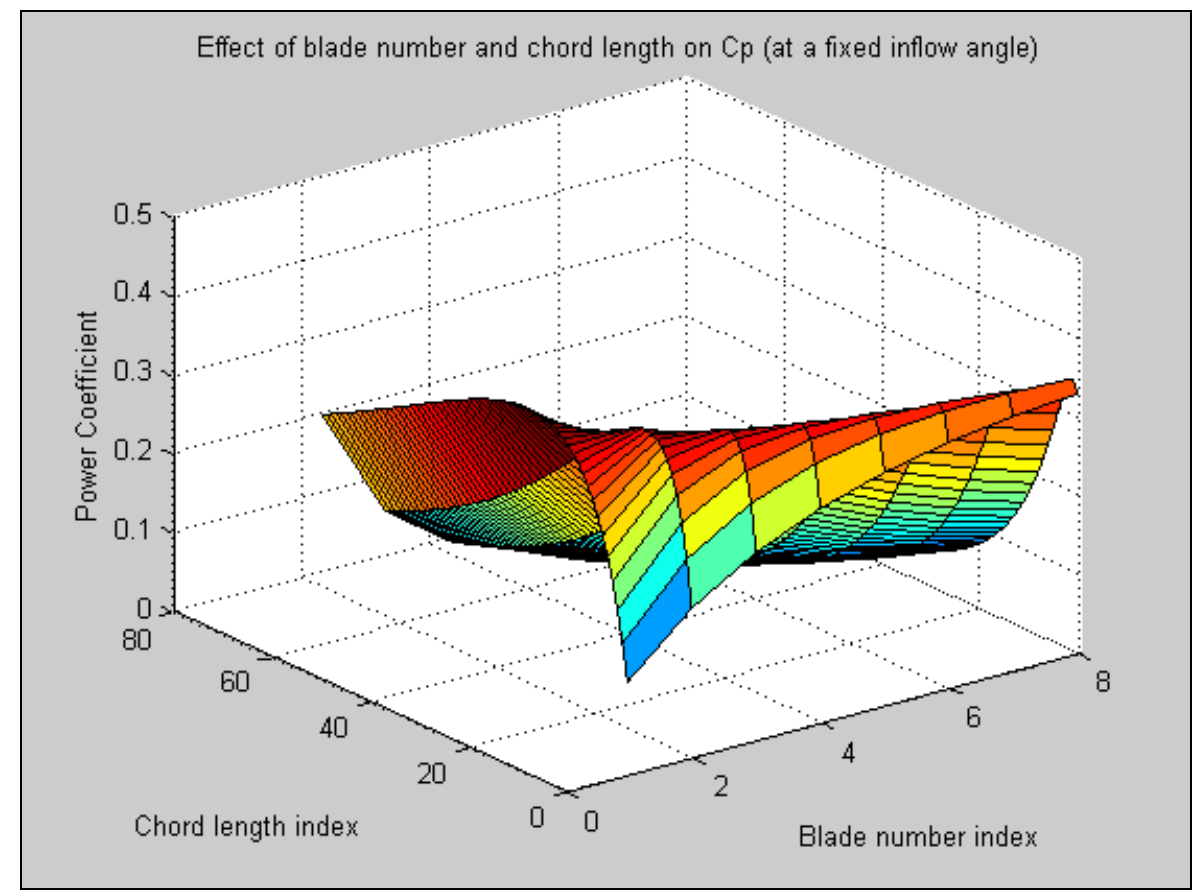

Figure 30 In-flow angle $=16$ degrees.

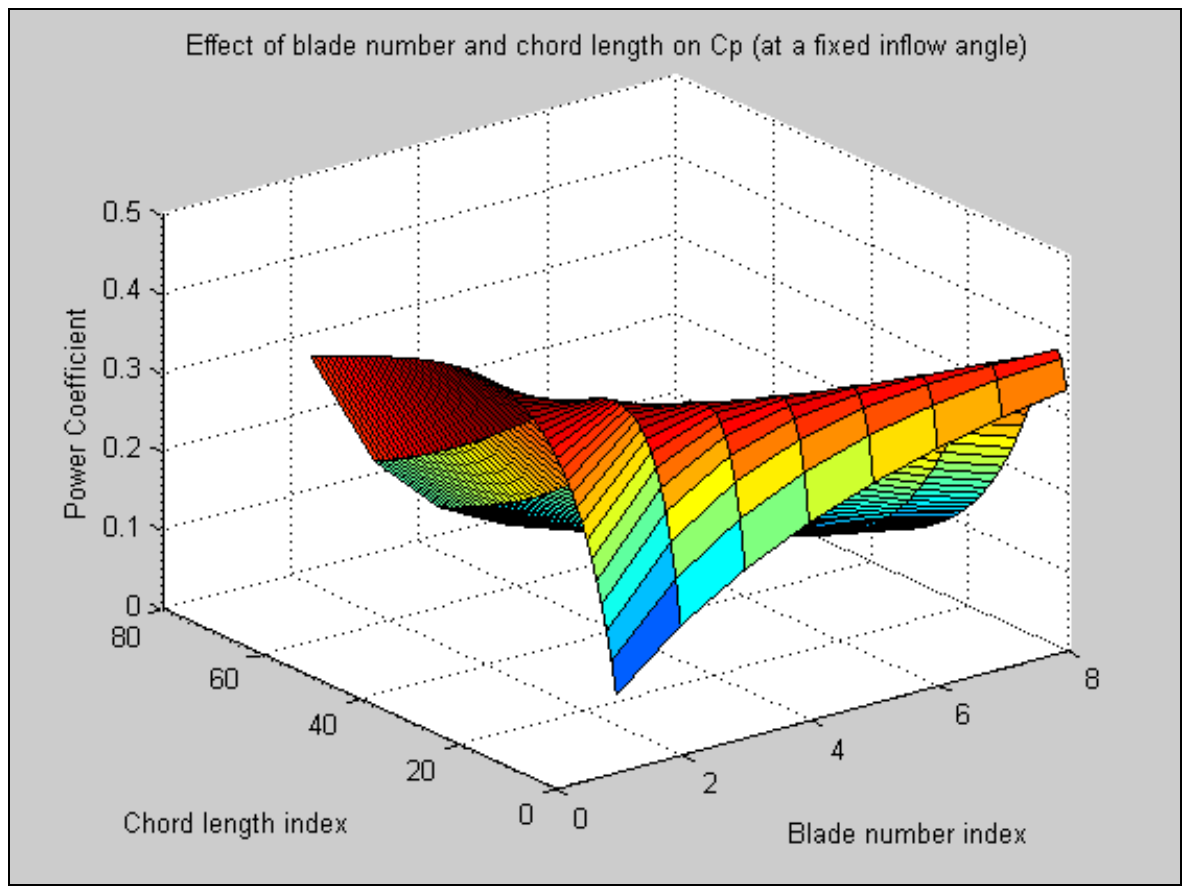

Figure 31 In-flow angle $=19$ degrees 


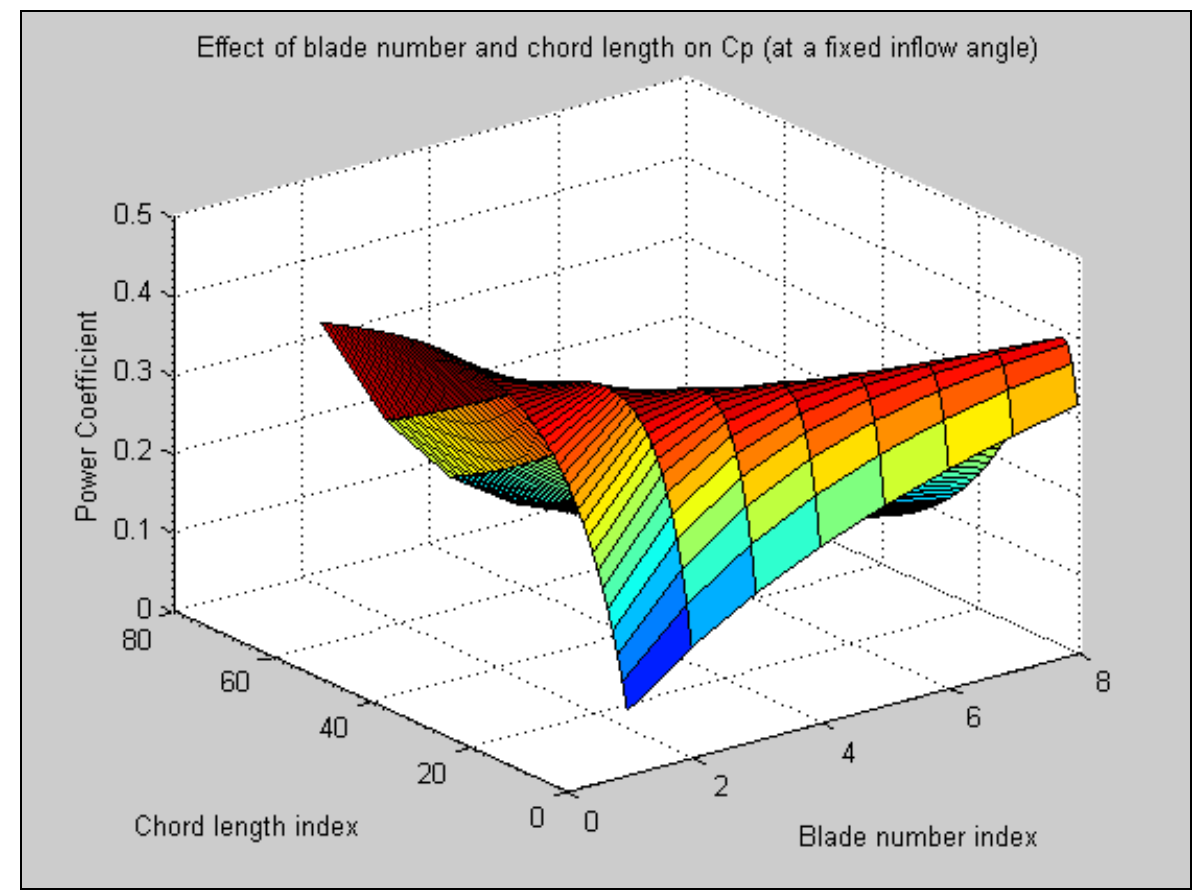

Figure 32 In-flow angle $=22$ degrees.

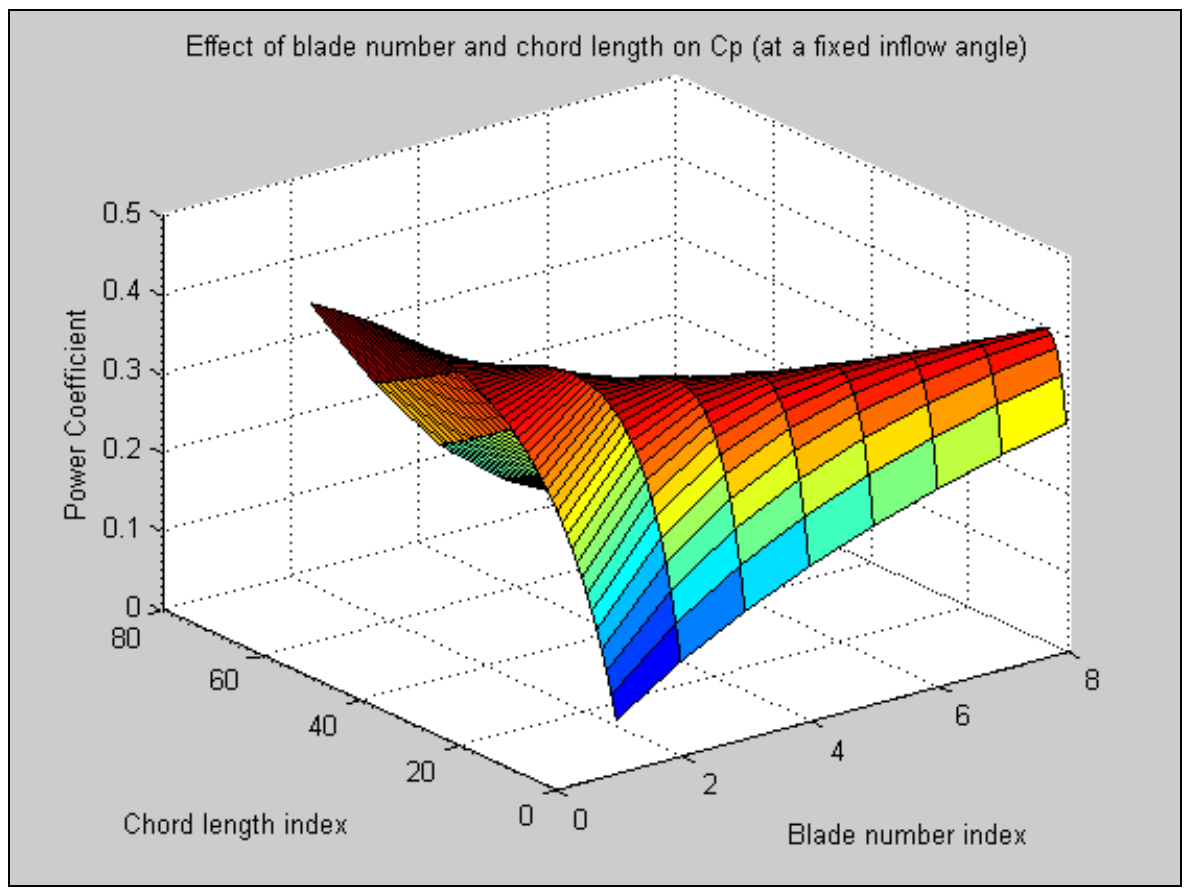

Figure 33 In-flow angle $=25$ degrees 


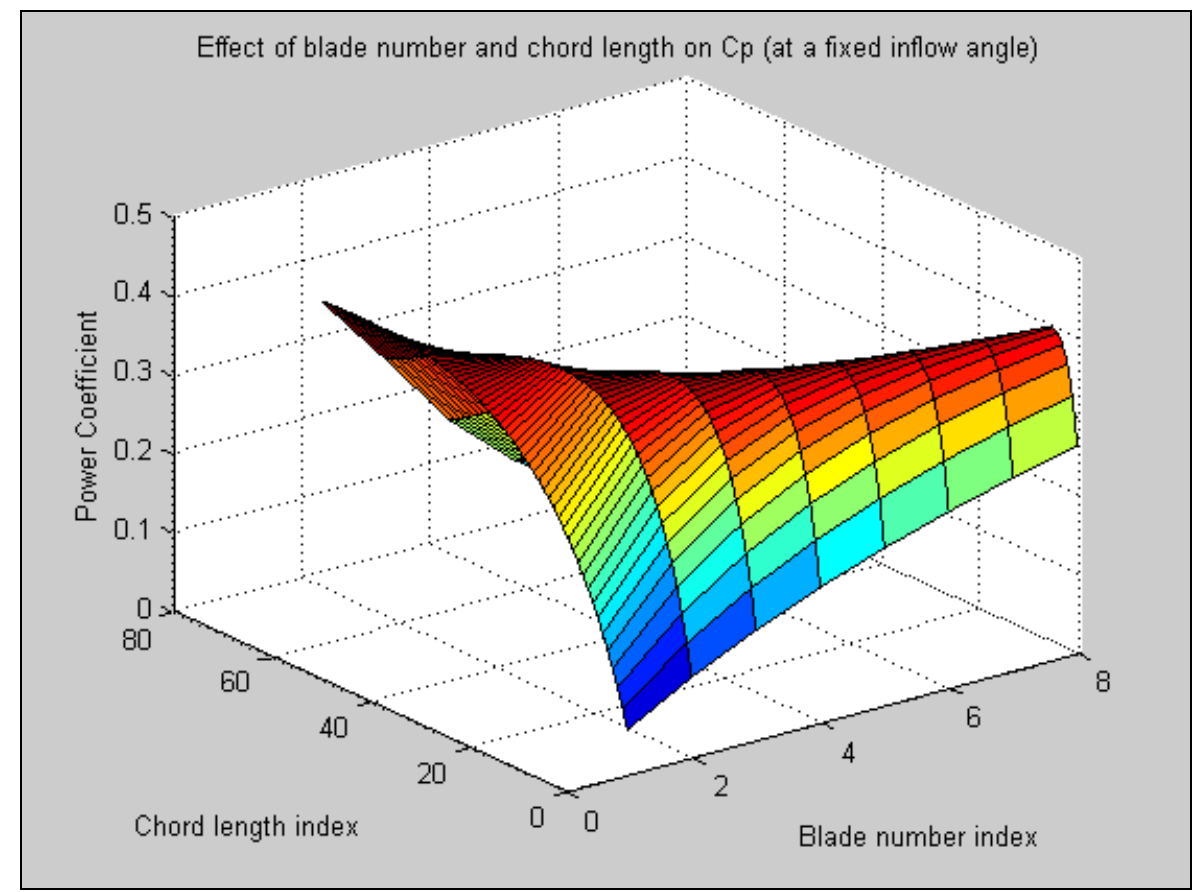

Figure 34 In-flow angle $=28$ degrees.

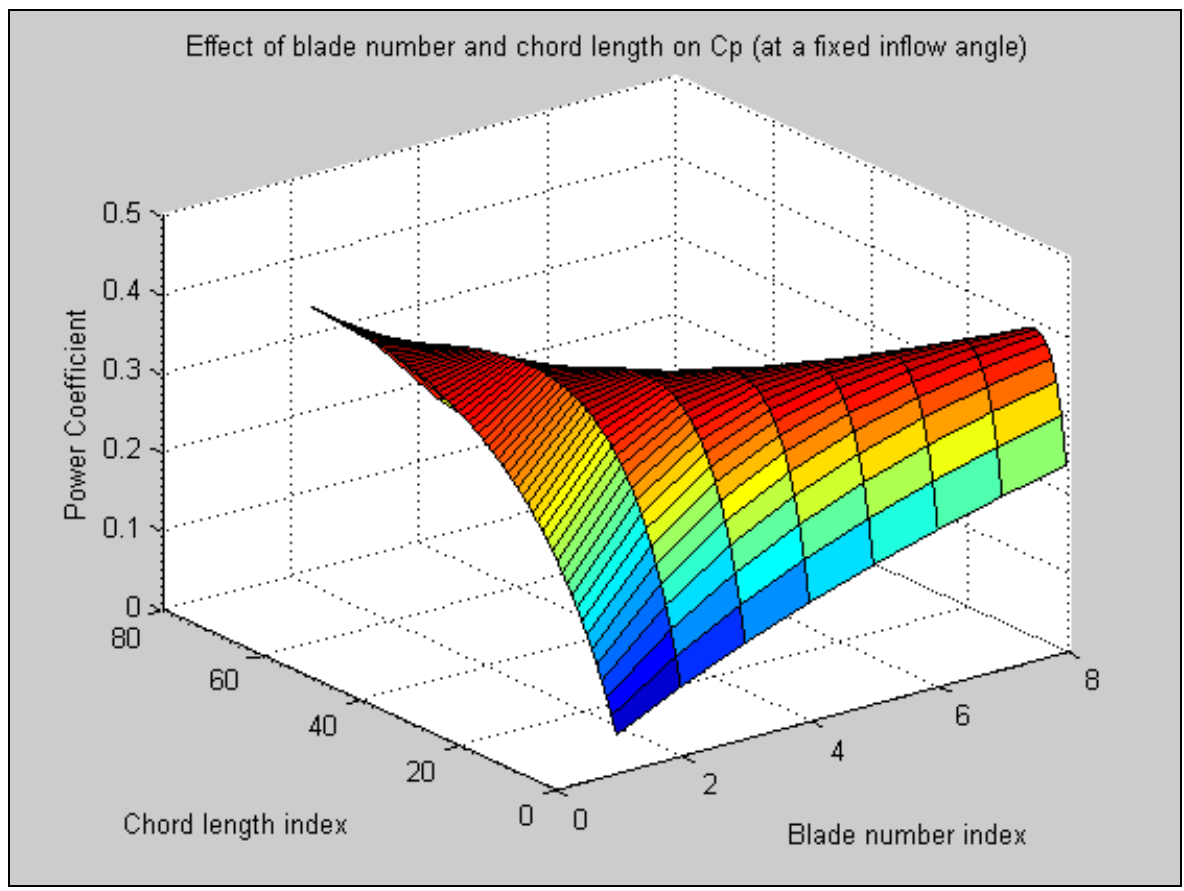

Figure 35 In-flow angle $=31$ degrees 


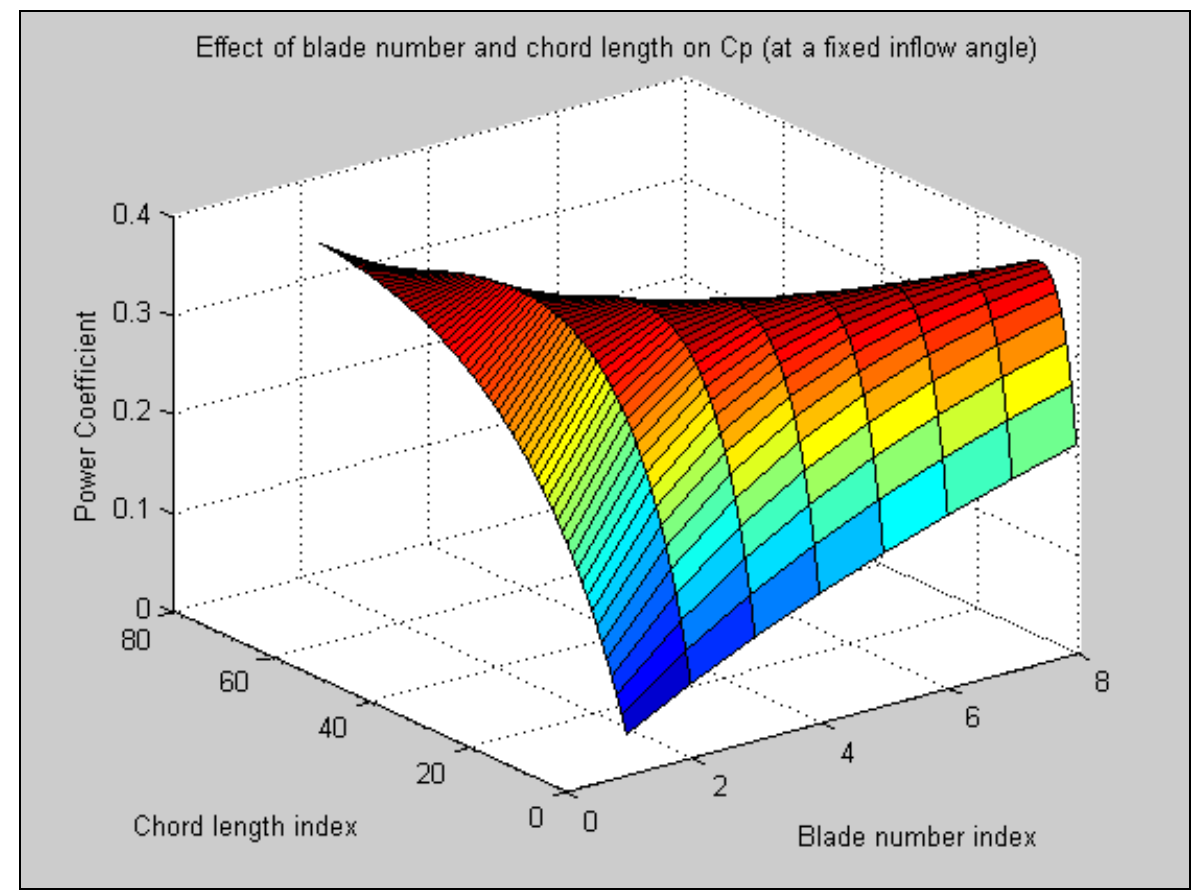

Figure 36 In-flow angle $=34$ degrees.

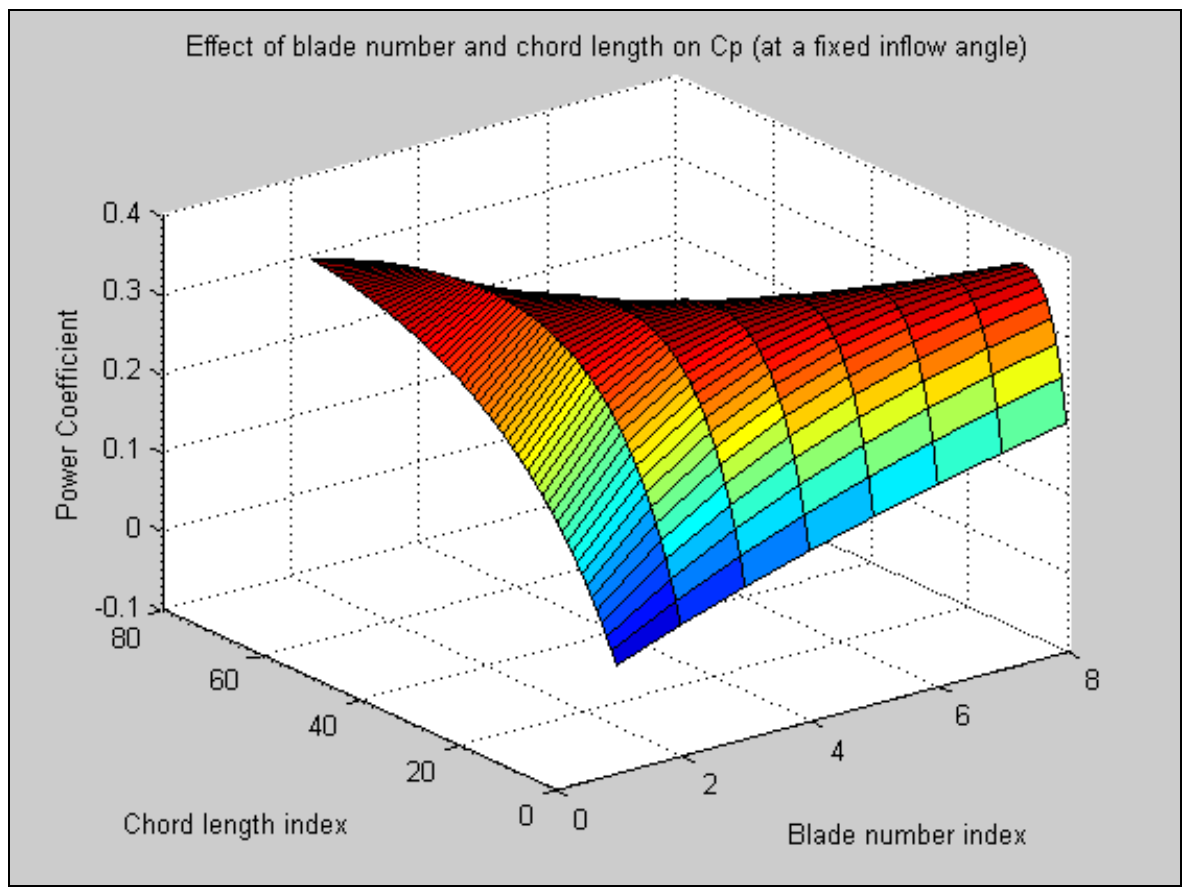

Figure 37 In-flow angle $=37$ degrees 


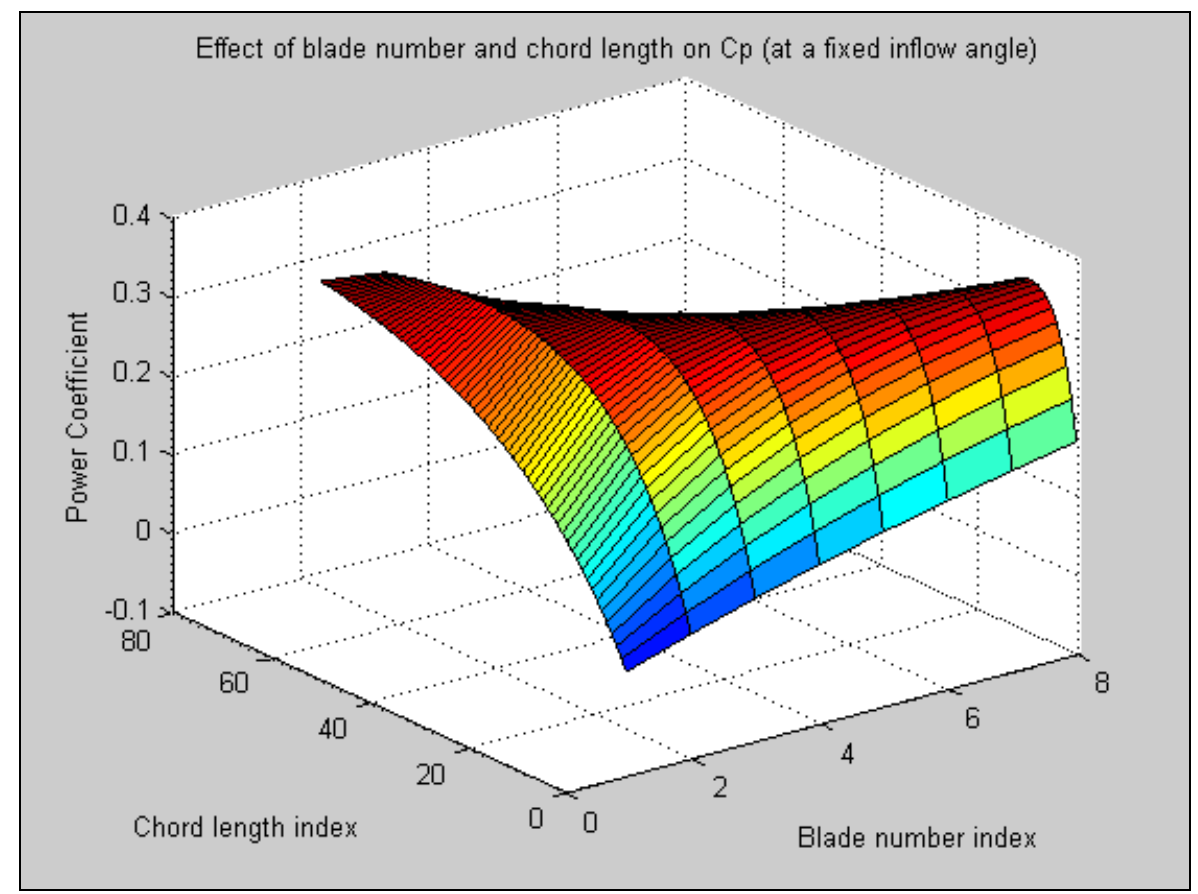

Figure 38 In-flow angle $=40$ degrees.

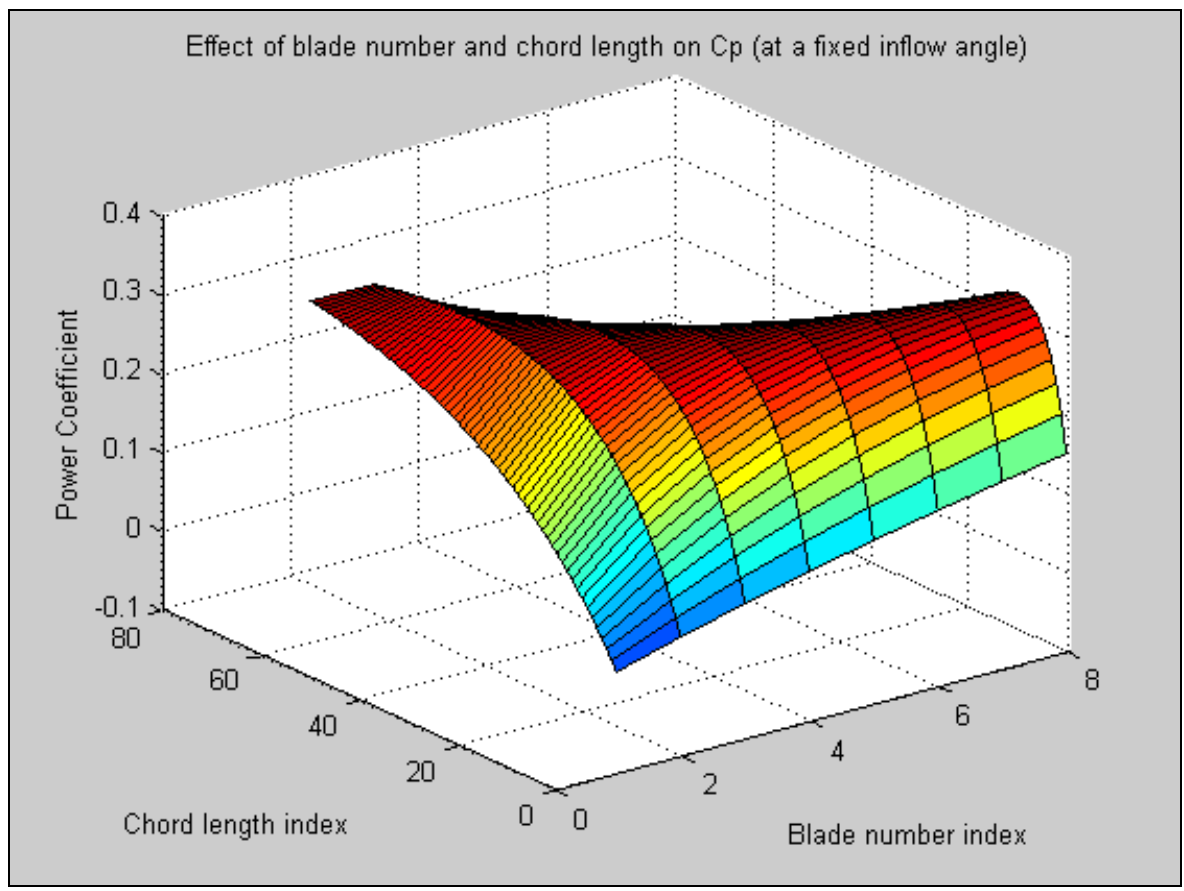

Figure 39 In-flow angle $=43$ degrees 


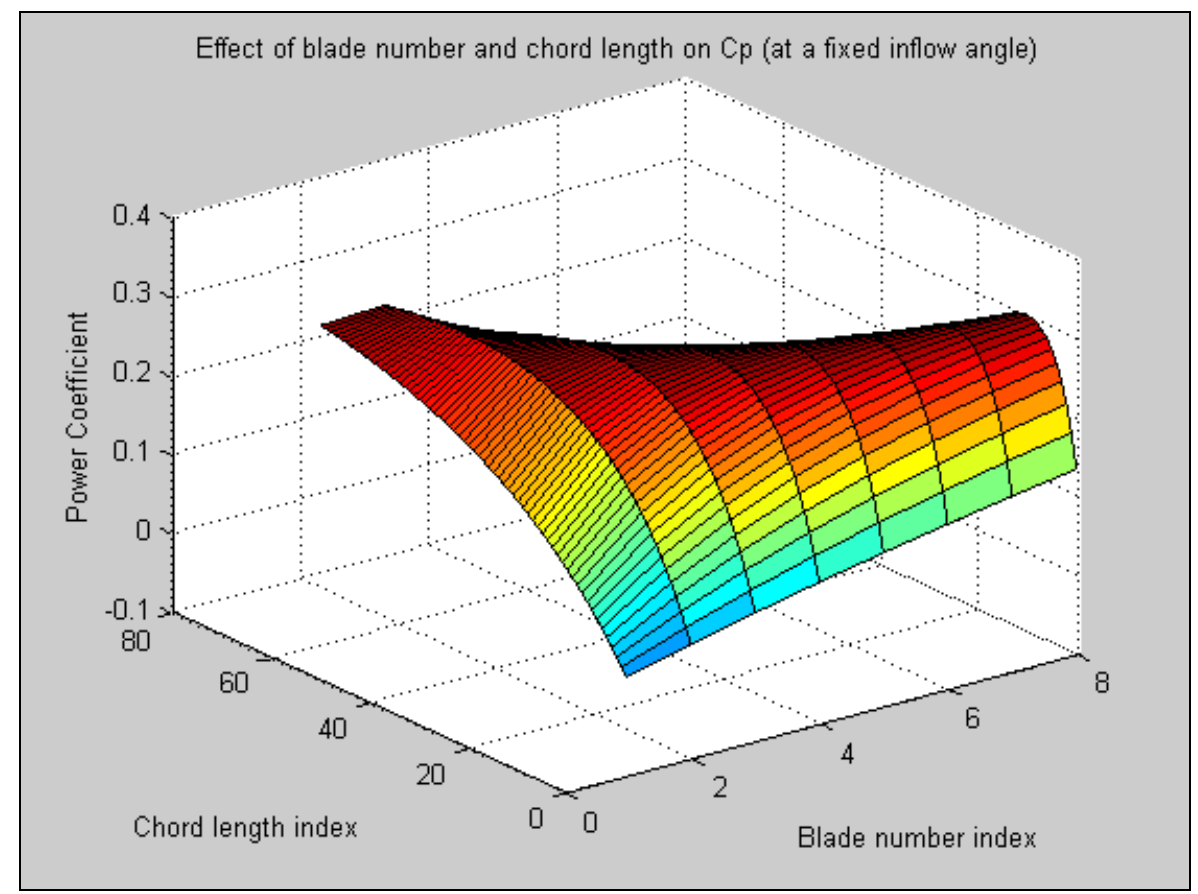

Figure 40 In-flow angle $=46$ degrees.

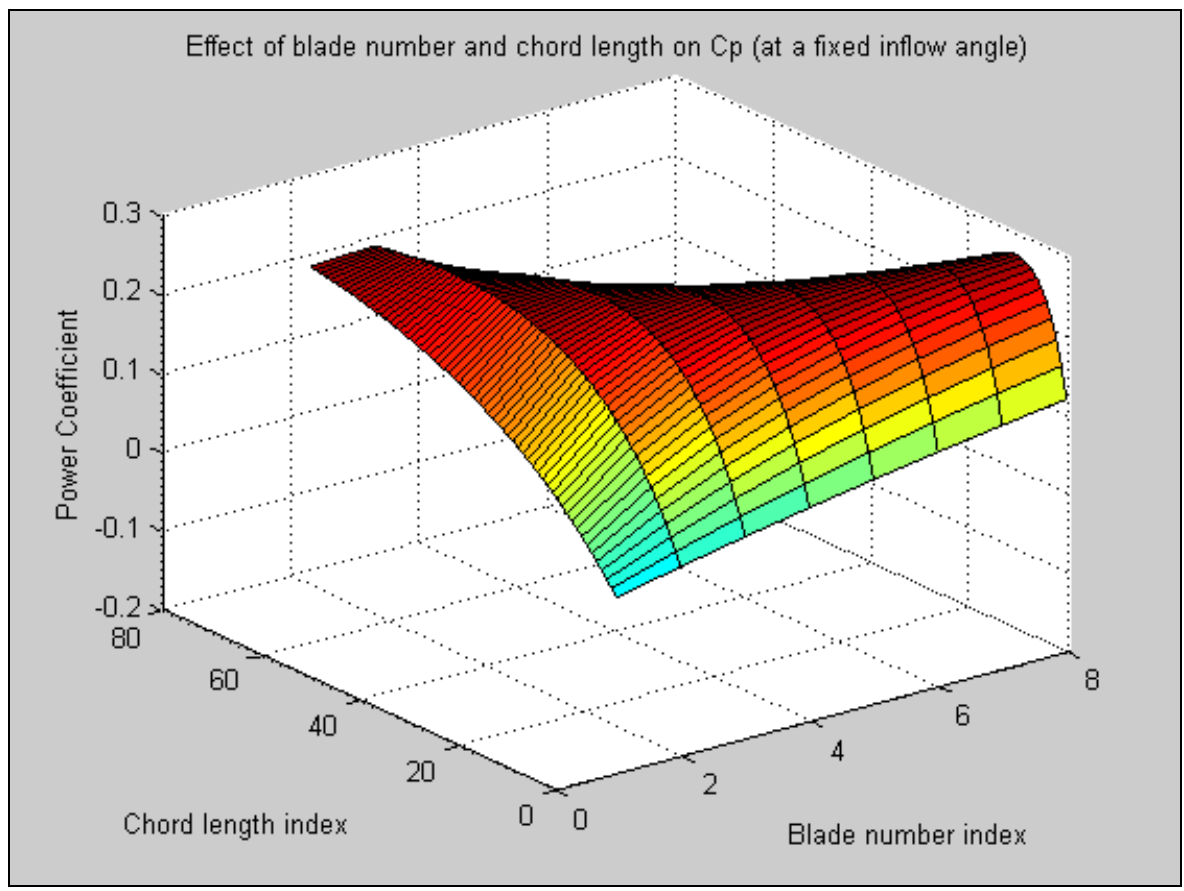

Figure 41 In-flow angle $=49$ degrees 


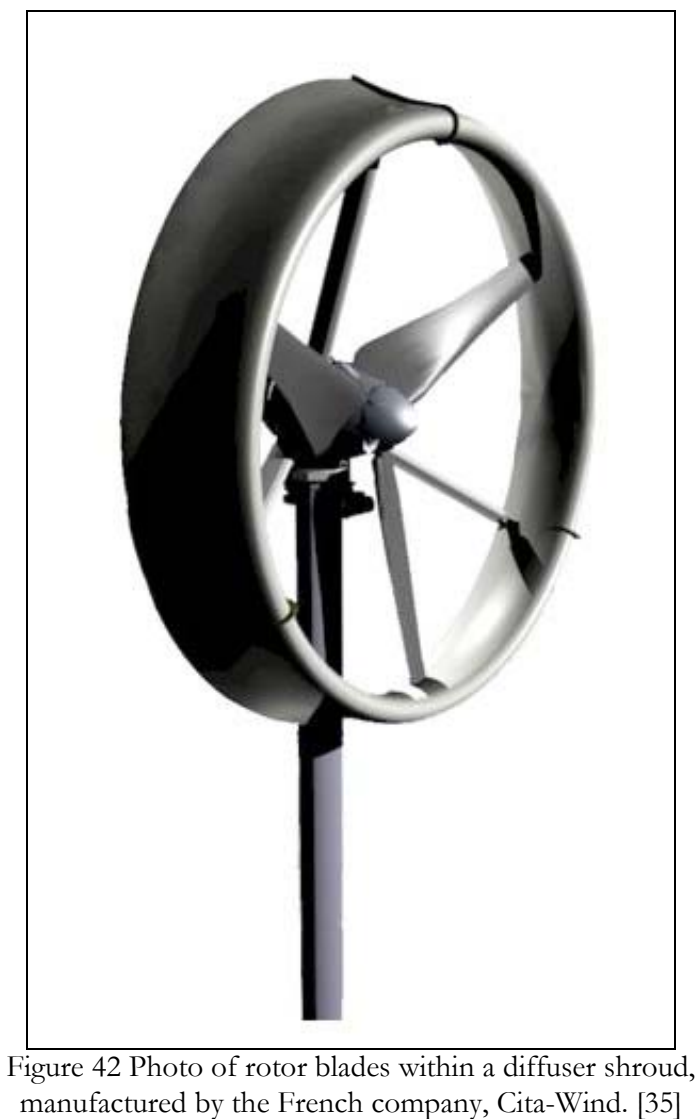

Figure 42 shows a diffuser shroud surrounding a 3-bladed rotor that would similar to the optimal design found in this study. 


\section{APPENDIX C:MODEL CODE}

\section{Shrouded model code;}

shroud_rotor_model.m (general program to calculate outputs from inputs - for shrouded rotor)

clc

clear

close all

\%analytical method from rijs and smulders

\%\%\%\%\%\%\%\%\%\%\%\%\%\%\%\%INPUTS\%\%\%\%\%\%\%\%\%\%\%\%\%\%\%\%

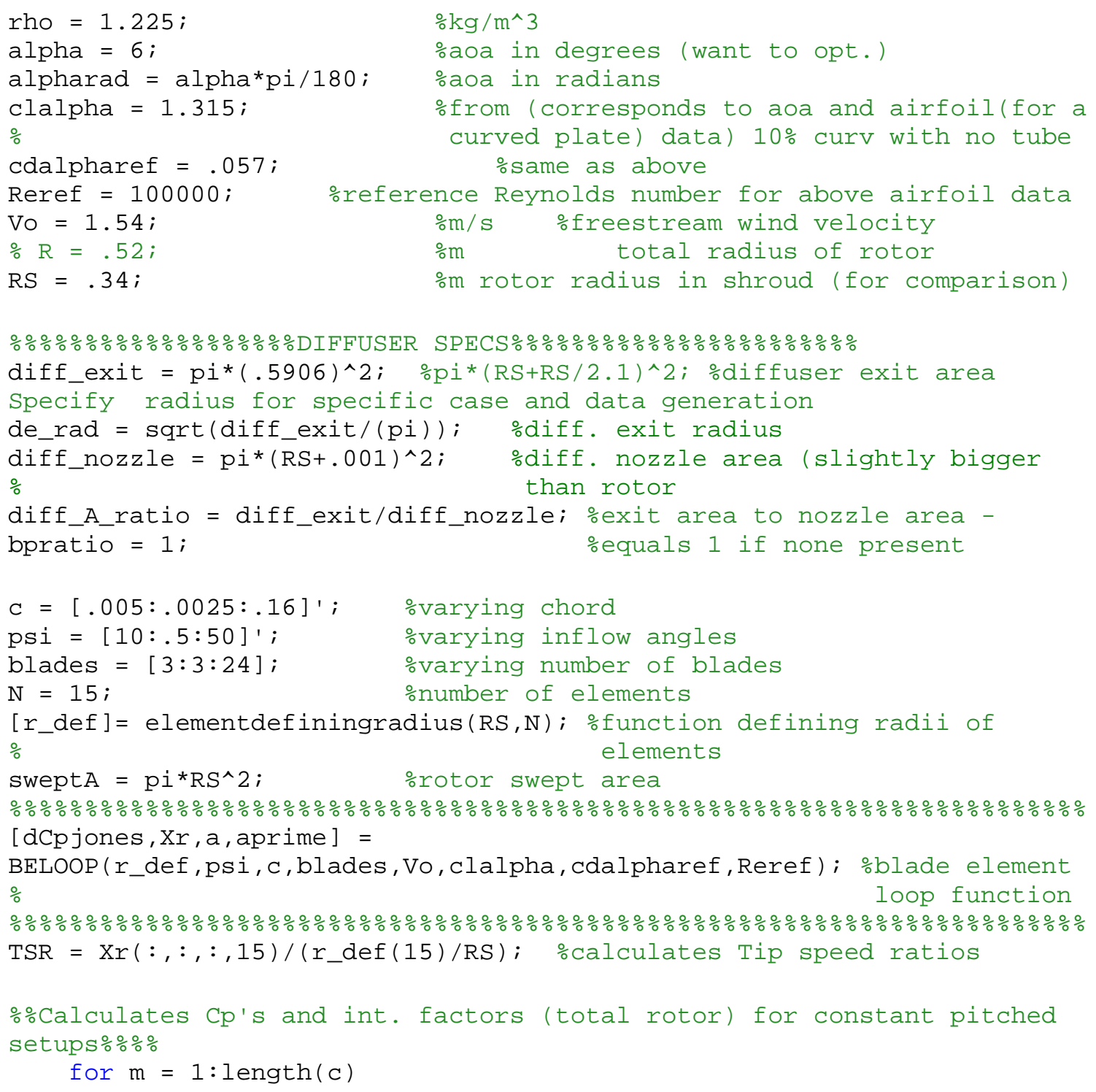




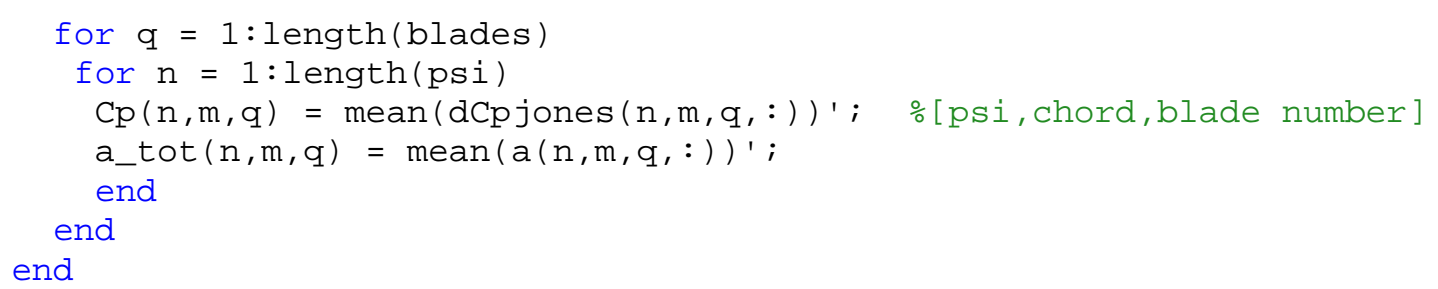

\section{Functions (used in above model):}

elementdefiningradius.m (defines radius at each blade element station)

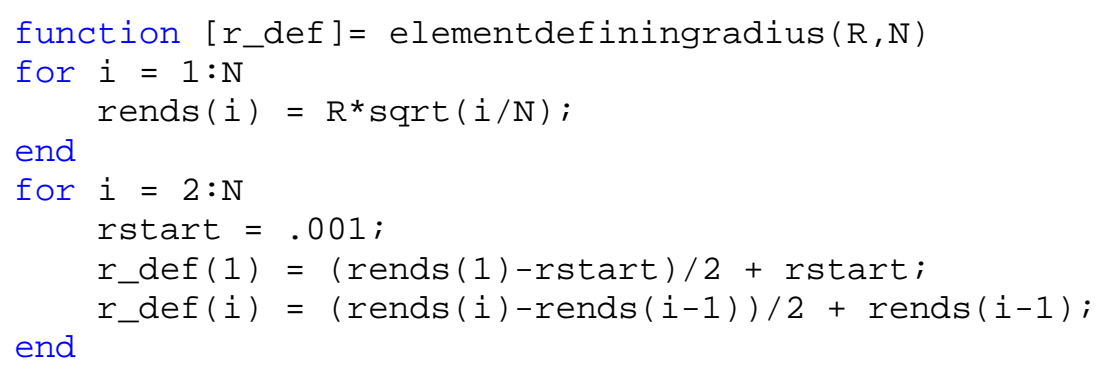

BELOOP.m (blade element loop calculations)

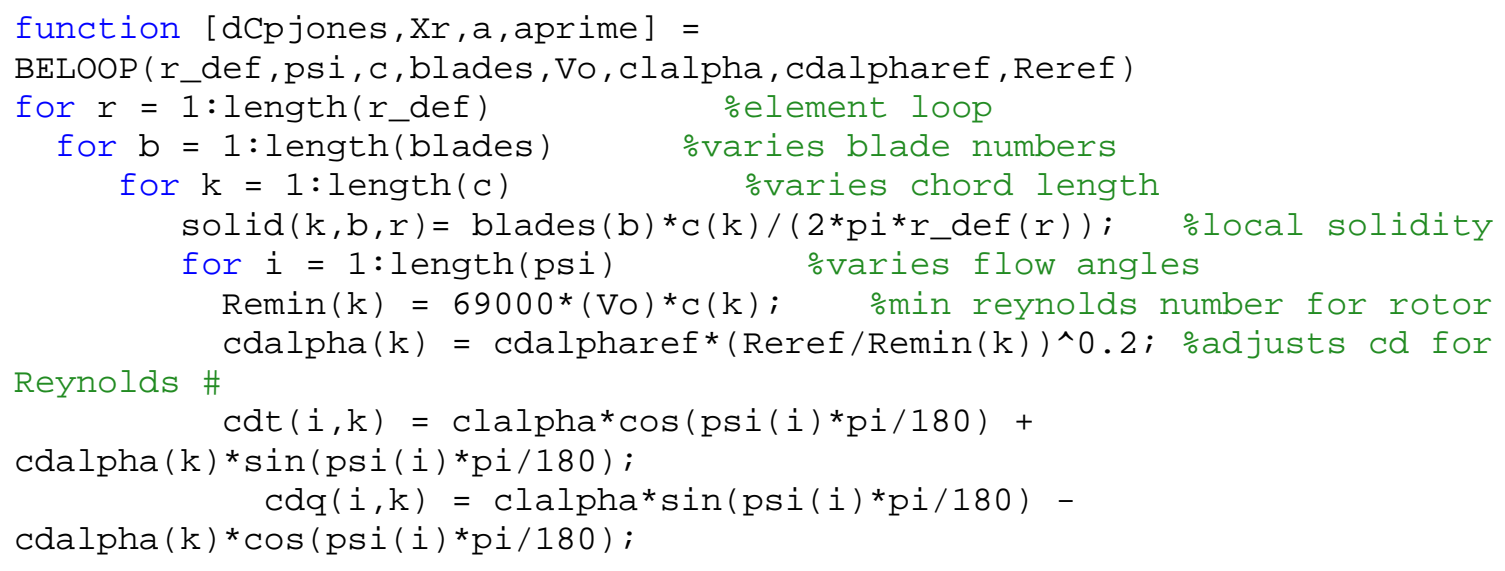




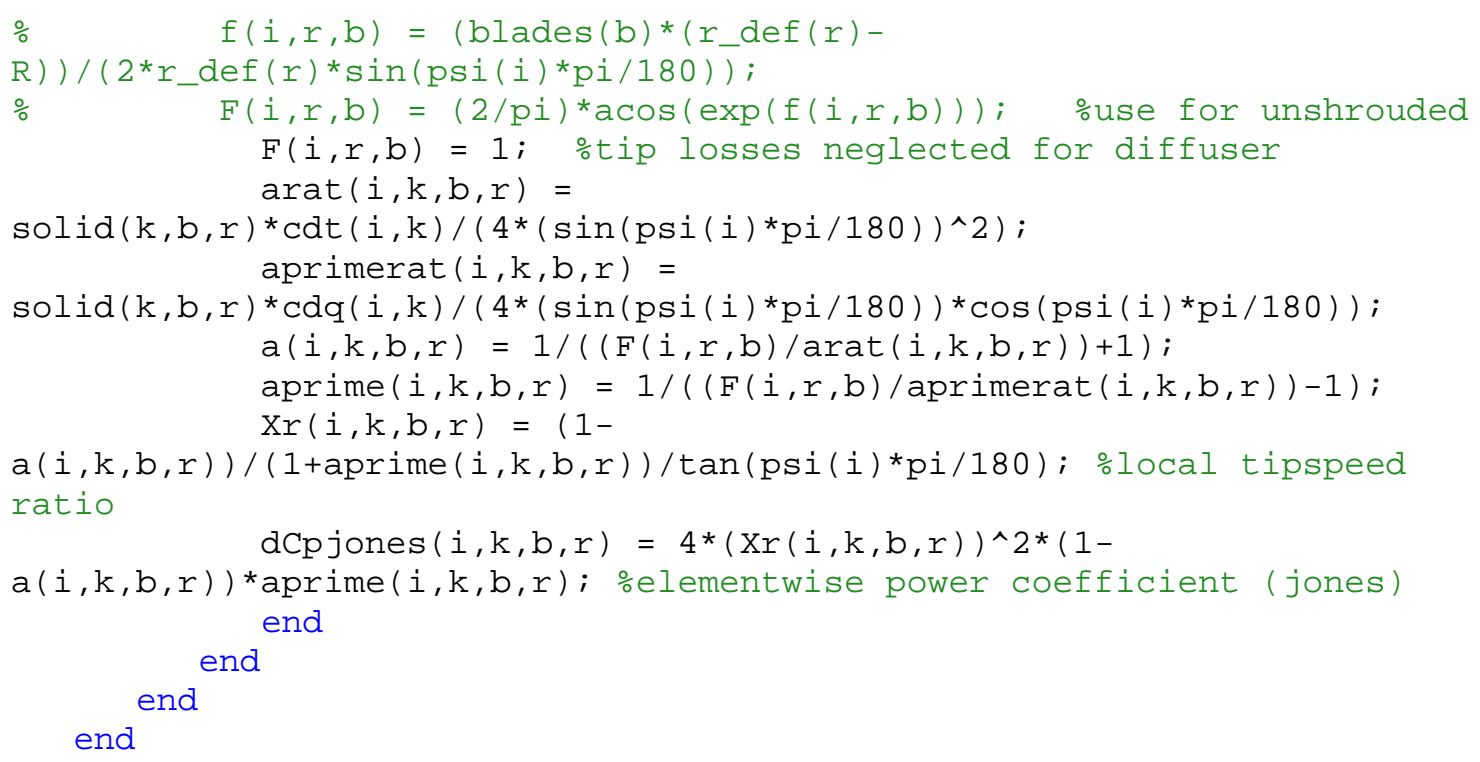




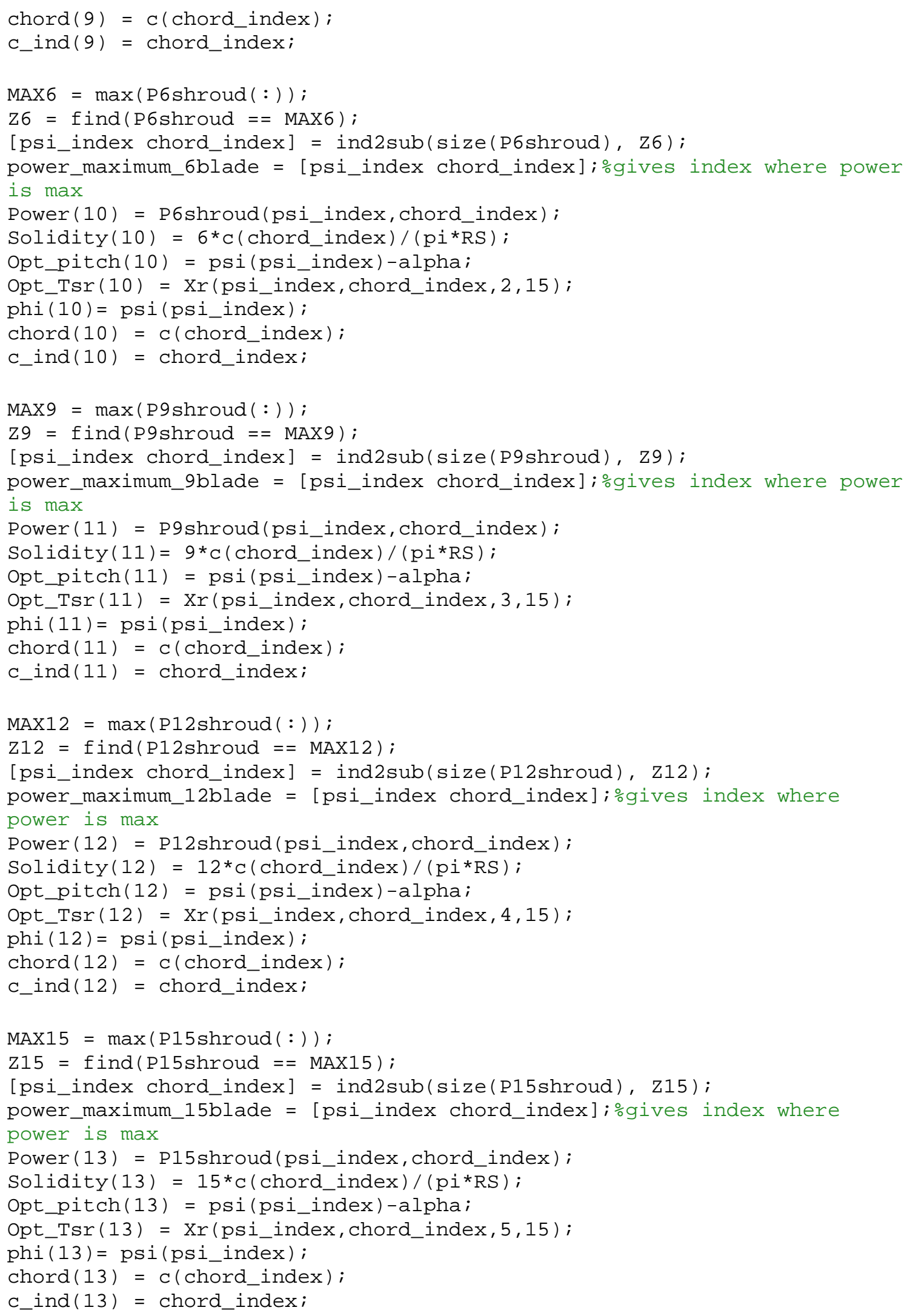




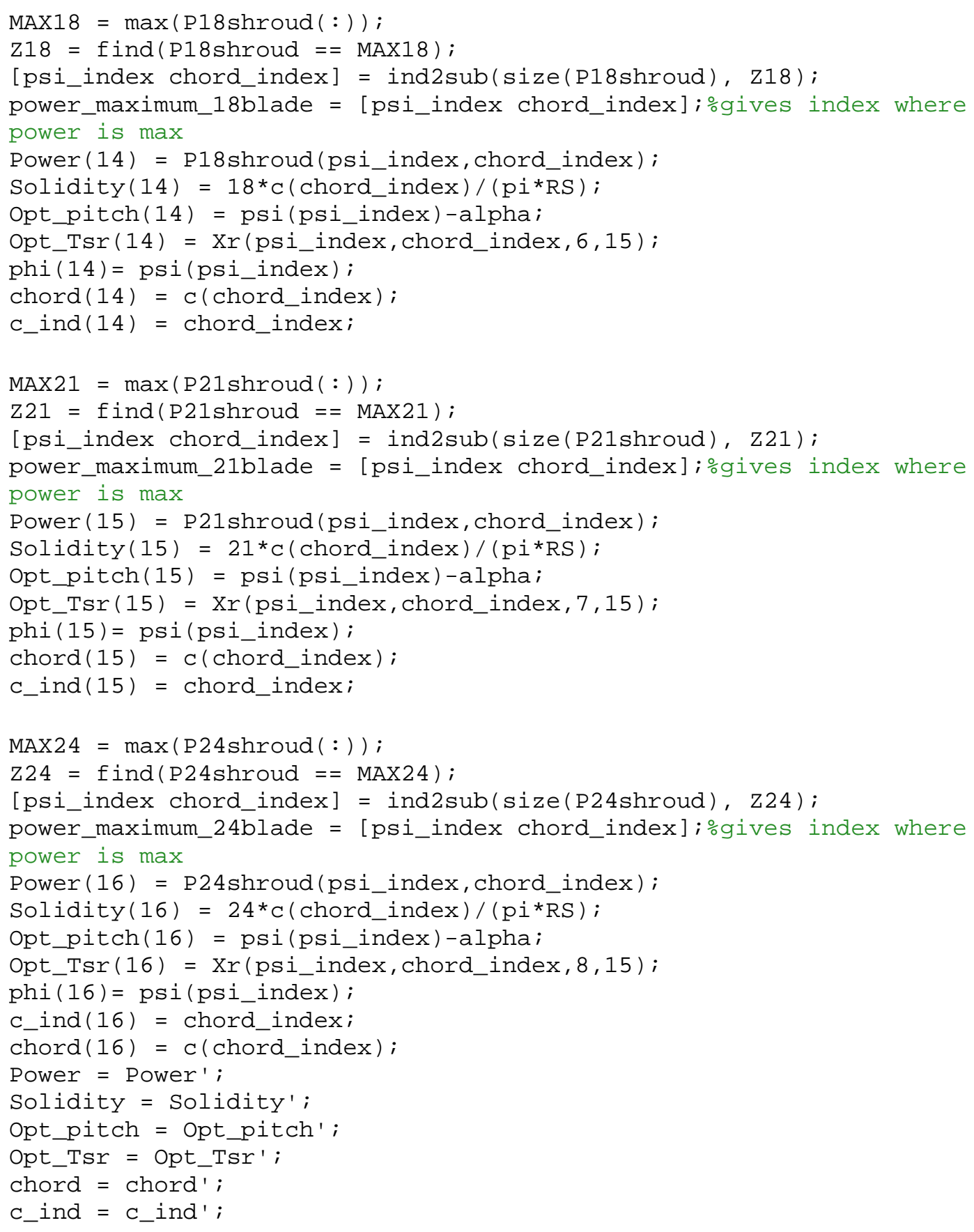




\section{Unshrouded model code;}

(does not include functions like the shrouded model)

rotor_analytical_fixed_r_and_v_model.m

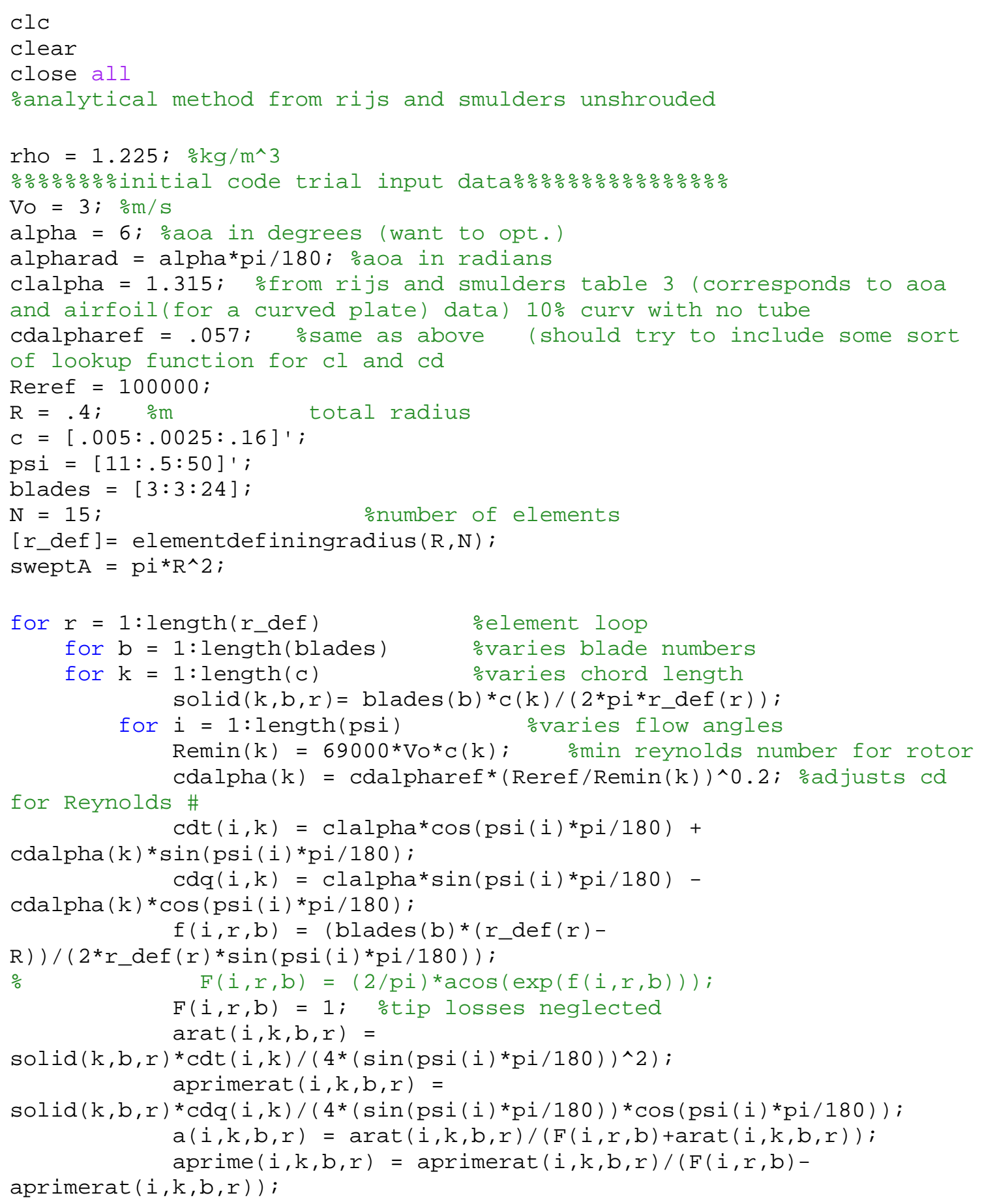




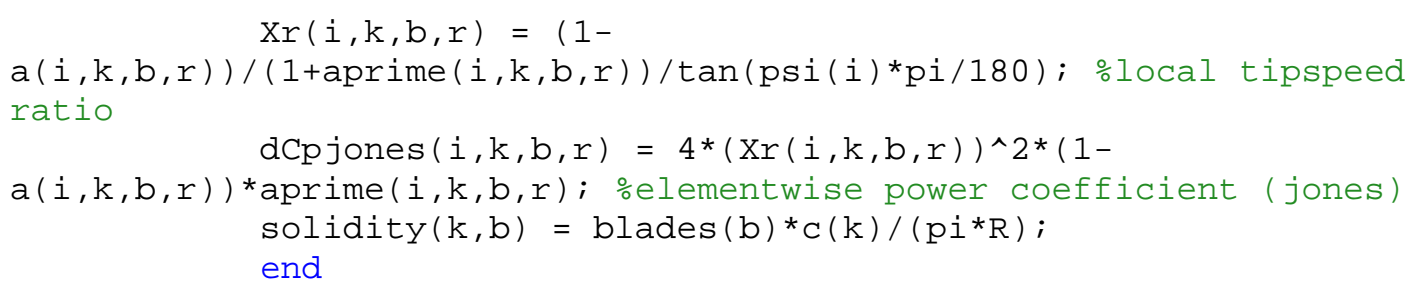




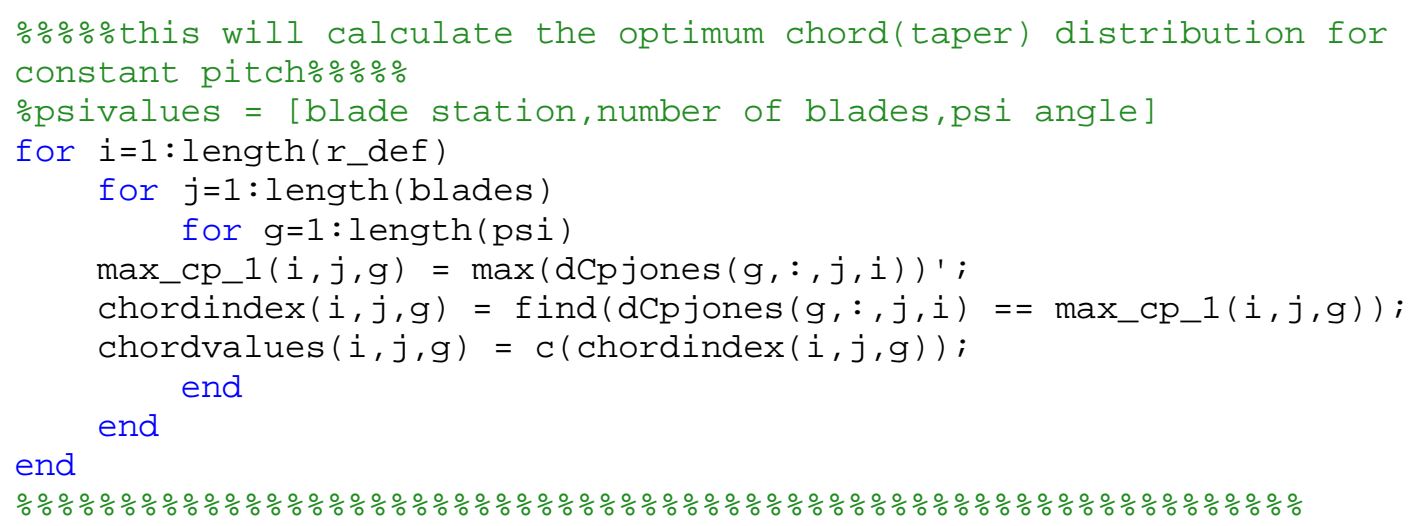




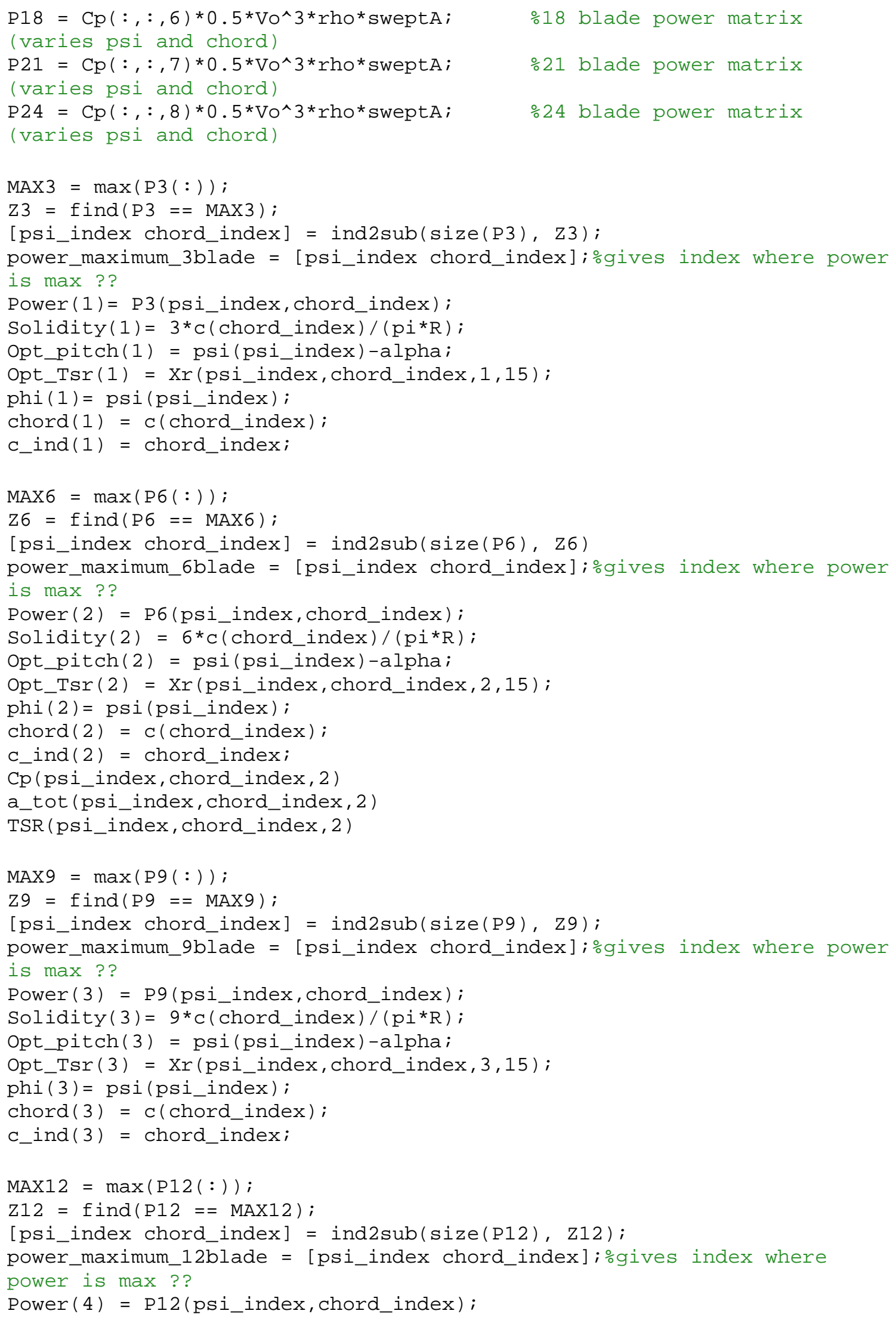




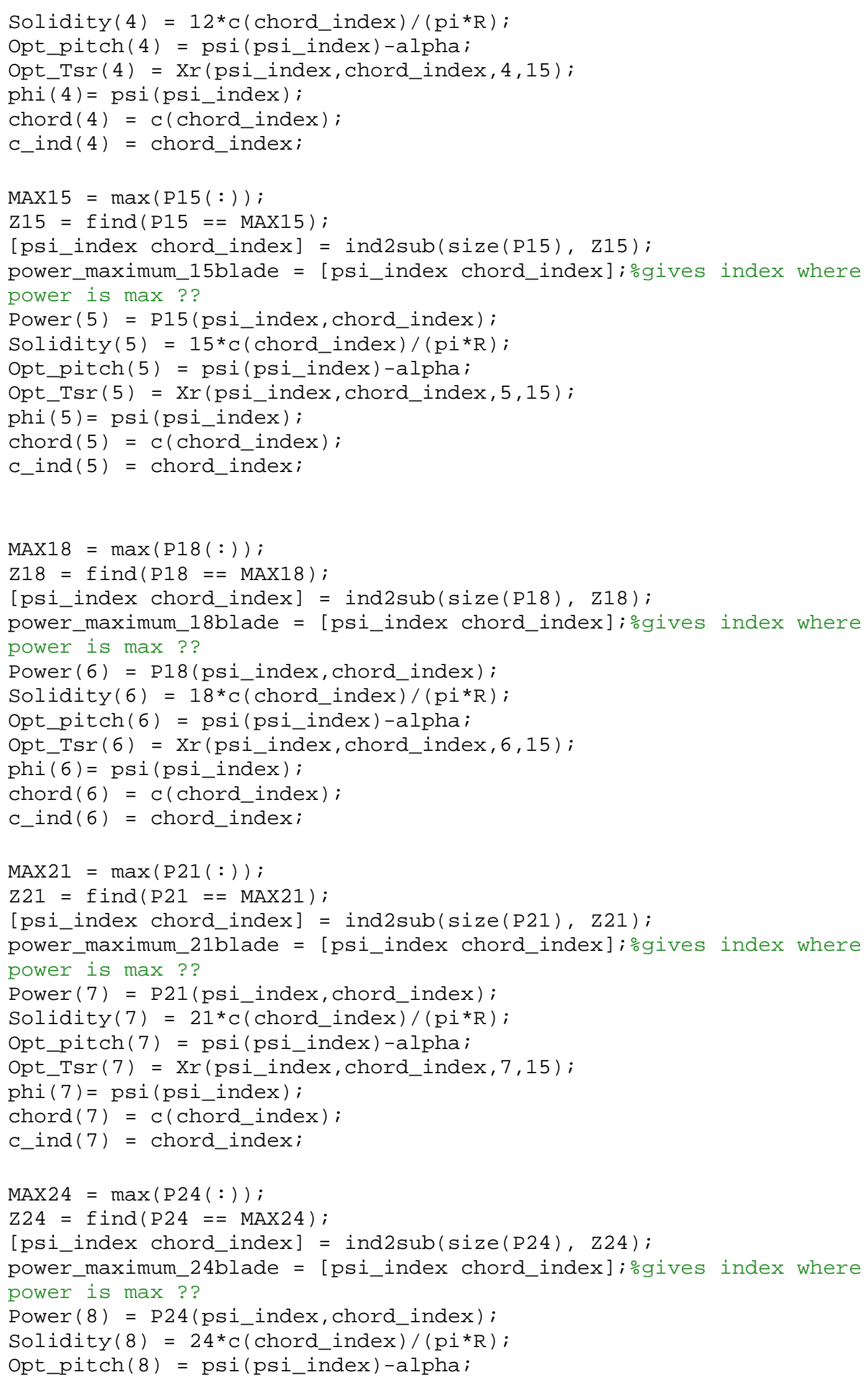


opt_Tsr $(8)=\operatorname{xr}\left(p s i \_\right.$index, chord_index, 8, 15) ;

phi $(8)=$ psi $\left(p s i \_i n d e x\right)$;

c_ind $(8)=$ chord_index;

chord $(8)=c($ chord_index $)$;

Power = Power';

Solidity = Solidity'

opt_pitch = Opt_pitch';

opt_Tsr $=$ Opt_Tsr';

chord $=$ chord $^{\prime}$;

c_ind = c_ind ' ; 


\section{Plots;}

The following codes were used within the above programs to generate plots to display results.

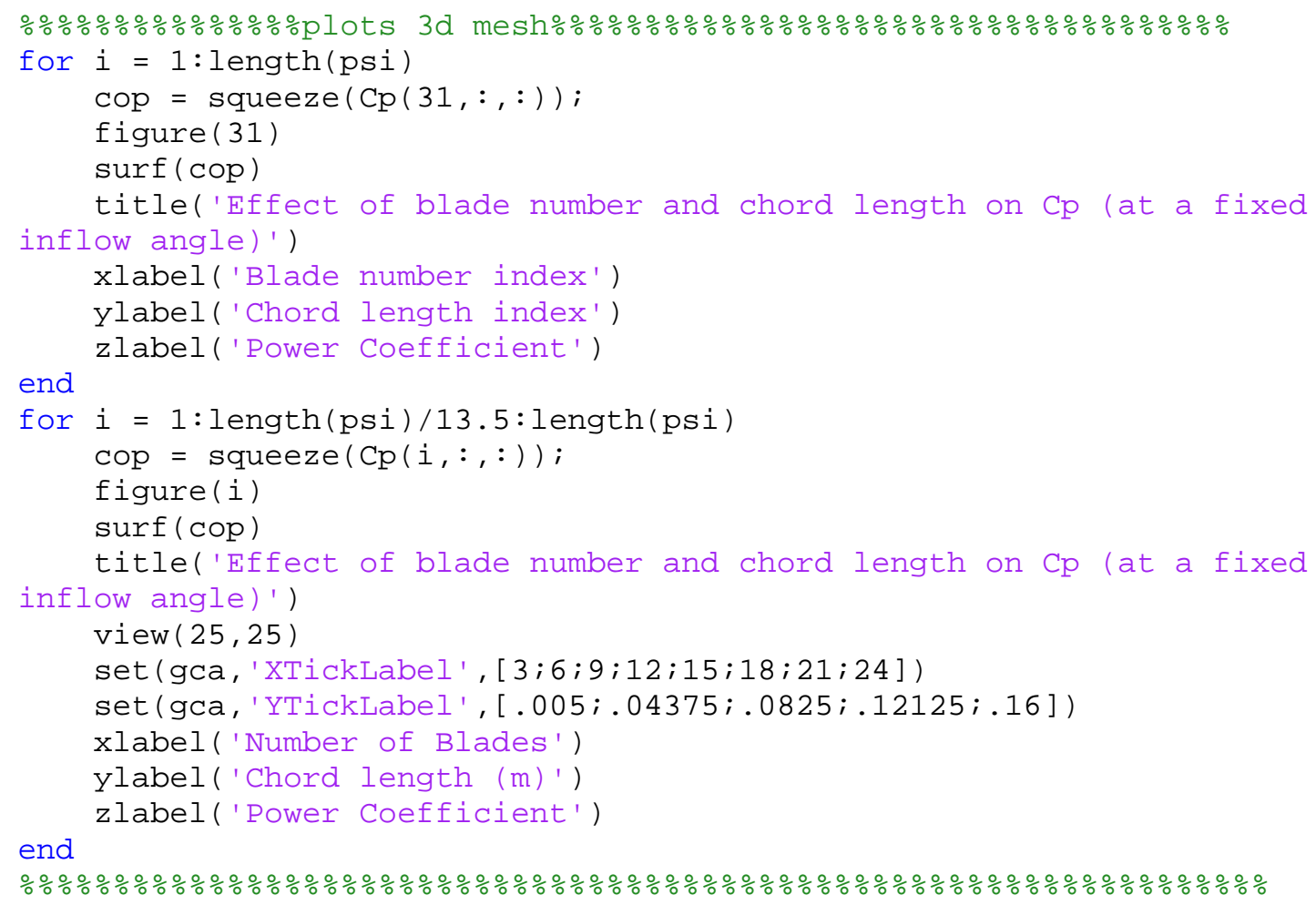

\%\%\%\% \%lots 2d curves for Cp vs. chord index for each blade number\%\% \%\%\%"ust specify inflow angle\%\%\%\%\%\%\%\%\%\%\%\%\%\%\%\%\%\%\%\%\%\%\%\%\%\%\%\%\%\%\% figure(899)

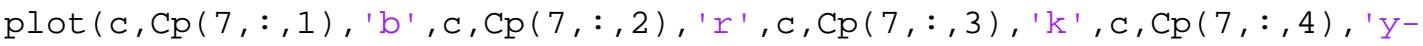


xlabel('Chord length $(\mathrm{m})$ ')

grid on

figure(901)

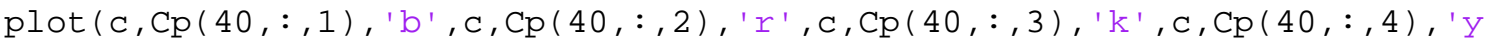

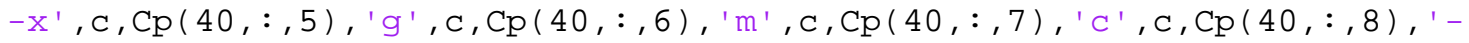
$0^{\prime}$ )

legend('3 Blades','6 Blades','9 Blades','12 Blades', '15 Blades', '18 Blades','21 Blades', '24 Blades');

$\%$ title('Cp (at a fixed inflow angle(32.5 deg.) and a fixed number of blades)' ')

ylabel('Power Coefficient')

xlabel('Chord length $(\mathrm{m})^{\prime}$ )

grid on

figure(902)

plot $\left(c, c p(73,:, 1)\right.$, ' b' ', c, cp (73, : , 2), ' $r^{\prime}, c, c p(73,:, 3)$, ' $k$ ' , c, cp $(73,:, 4)$, 'y $-x^{\prime}, c, C p(73,:, 5),{ }^{\prime} g$ ', $c, C p(73,:, 6),{ }^{\prime} m{ }^{\prime}, c, C p(73,:, 7),{ }^{\prime} c^{\prime}, c, C p(73,:, 8),{ }^{\prime}-$ o')

legend('3 Blades','6 Blades', '9 Blades','12 Blades', '15 Blades', '18 Blades', '21 Blades', '24 Blades');

$\%$ title('Cp (at a fixed inflow angle(36.5 deg.) and a fixed number of blades)' ')

ylabel('Power Coefficient')

xlabel('Chord length (m)')

grid on

figure(903)

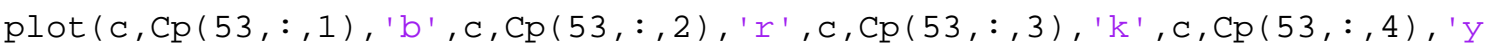

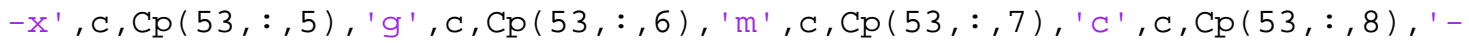
o')

legend('3 Blades', '6 Blades', '9 Blades','12 Blades', '15 Blades', '18 Blades',' 21 Blades', '24 Blades');

$\% \quad$ title('Cp (at a fixed inflow angle(40.5 deg.) and a fixed number of blades)' ')

ylabel('Power Coefficient')

xlabel('Chord length $(\mathrm{m})$ ')

grid on

\%\%\%\%\%\%\%\%\%\%\%\%\%\%\%\%\%\%\%\%\%\%\%\%\%\%\%\%\%\%\%\%\%\%\%\%\%\%\%\%\%\%\%\%\%\%\%\%\%\%\%\%\%\%\%\%\%\%\%

$\% \% \% \% \% \%$ plots the optimum twist for a selected case $\% \% \% \% \% \%$

$\%$ PSI $=45 ; \quad \%$ defined relative wind angle (degrees) just for

testing??

for $i=1:$ length (opt_cases)

pitch $=\operatorname{psivalues}(:$, blade_number_index(i), chord_max_index(i) ) alpha;

blade_station $=1: 1: \mathrm{N}$;

figure(i)

plot (blade_station, pitch)

$\% \quad$ title('optimal twist distribution')

xlabel('Blade Station Number')

ylabel('Pitch Angle (degrees)')

\%\%\%\%\%\%\%\%\%\%\%\%\%\%\%\%\%\%\%\%\%\%\%\%\%\%\%\%\%\%\%\%\%\%\%\%\%\%\%\%\%\%\%\%\%\%\%\%\%

end 


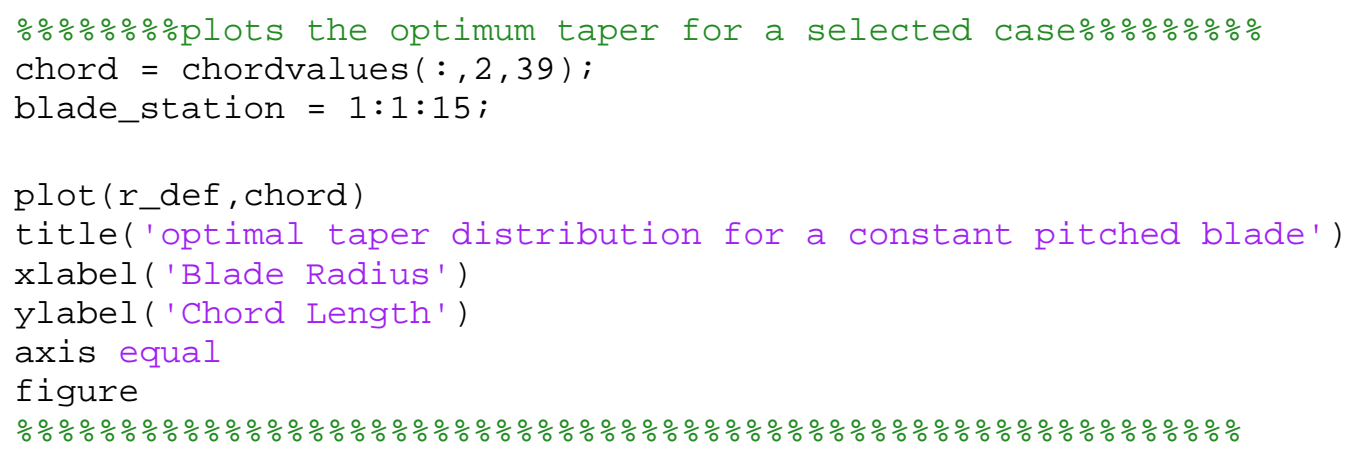




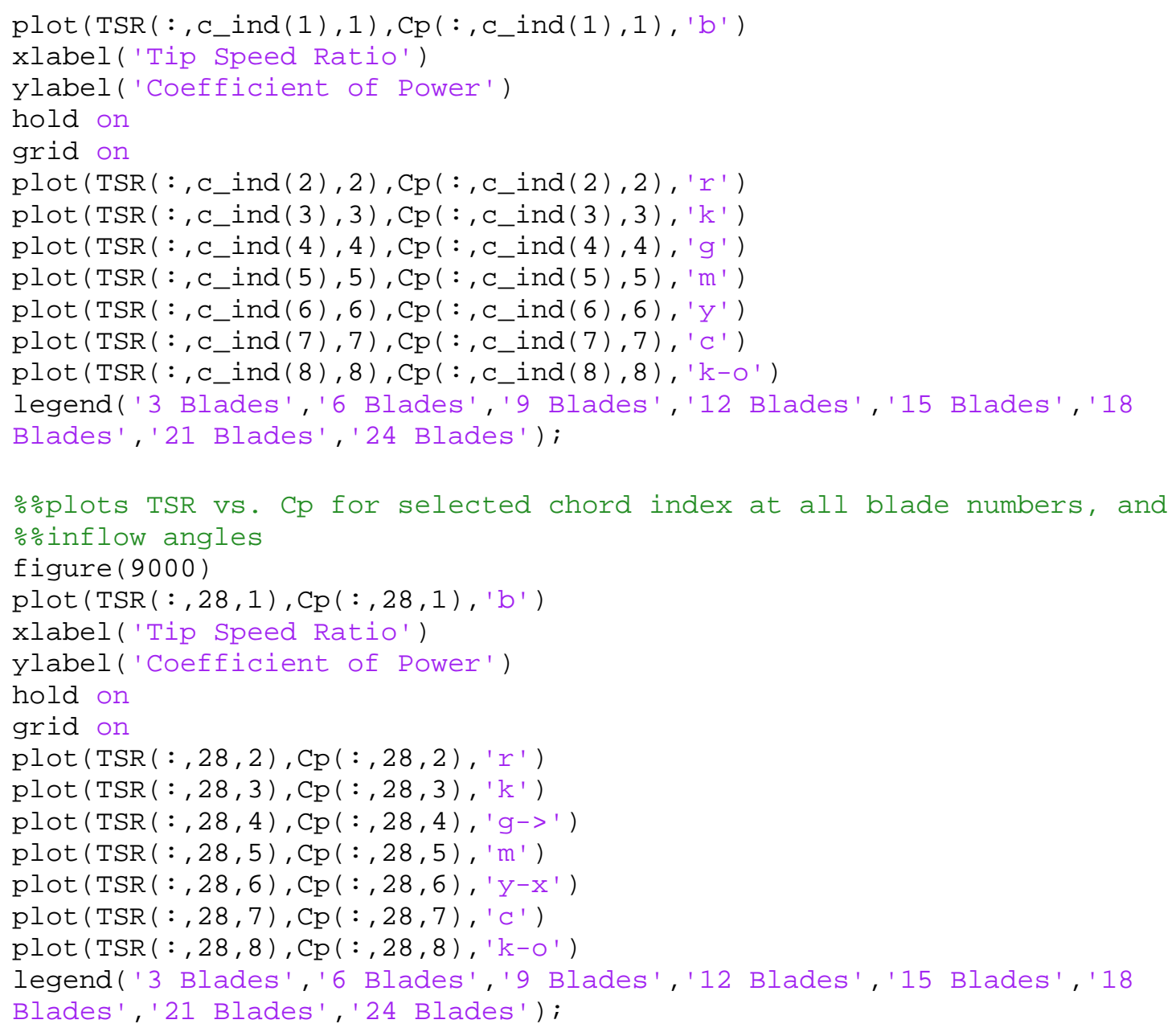

